\title{
Microvascular dysfunction, physical activity, and cardiometabolic diseases
}

Citation for published version (APA):

Li, W. (2020). Microvascular dysfunction, physical activity, and cardiometabolic diseases. [Doctoral Thesis, Maastricht University]. Maastricht University. https://doi.org/10.26481/dis.20201022wl

Document status and date:

Published: 01/01/2020

DOI:

10.26481/dis.20201022wl

Document Version:

Publisher's PDF, also known as Version of record

\section{Please check the document version of this publication:}

- A submitted manuscript is the version of the article upon submission and before peer-review. There can be important differences between the submitted version and the official published version of record.

People interested in the research are advised to contact the author for the final version of the publication, or visit the DOI to the publisher's website.

- The final author version and the galley proof are versions of the publication after peer review.

- The final published version features the final layout of the paper including the volume, issue and page numbers.

Link to publication

\footnotetext{
General rights rights.

- You may freely distribute the URL identifying the publication in the public portal. please follow below link for the End User Agreement:

www.umlib.nl/taverne-license

Take down policy

If you believe that this document breaches copyright please contact us at:

repository@maastrichtuniversity.nl

providing details and we will investigate your claim.
}

Copyright and moral rights for the publications made accessible in the public portal are retained by the authors and/or other copyright owners and it is a condition of accessing publications that users recognise and abide by the legal requirements associated with these

- Users may download and print one copy of any publication from the public portal for the purpose of private study or research.

- You may not further distribute the material or use it for any profit-making activity or commercial gain

If the publication is distributed under the terms of Article $25 \mathrm{fa}$ of the Dutch Copyright Act, indicated by the "Taverne" license above, 
Microvascular dysfunction, physical activity, and cardiometabolic diseases 
(c) Wenjie Li, Maastricht, 2020

No part of this book may be reproduced or transmitted in any form or by any means, without prior permission in writing by the author, or when appropriate, by the publishers of the publications.

Layout by: Wenjie Li

Cover designed by: Xiaowen Yin, Wenjie Li

Printed by: ProefschriftMaken 


\title{
Microvascular dysfunction, physical activity, and cardiometabolic diseases
}

\author{
DISSERTATION \\ to obtain the degree of Doctor at the Maastricht University, \\ on the authority of the Rector Magnificus, \\ Prof.dr. Rianne M. Letschert, \\ in accordance with the decision of the Board of Deans, \\ to be defended in public on \\ Thursday, October 22, 2020, at 14:00 hours \\ by
}

Wenjie Li 
Supervisor:

Prof.dr. C.D.A. Stehouwer

Co-supervisors:

Dr. A.J.H.M. Houben

Dr. M.T. Schram

Assessment Committee:

Prof.dr. M.C.G.J. Brouwers (Chair)

Prof.dr. H.J.G.M. Crijns

Dr. E.C. Eringa

Dr. R.G. IJzerman (Amsterdam UMC)

Prof.dr. M. Visser (Amsterdam UMC) 


\section{Contents}

Chapter 1 General introduction I 5

Chapter 2 Microvascular phenotyping in the Maastricht Study: design, and main findings, 2010-2018 | 21

Chapter 3 Type 2 diabetes and $\mathrm{HbA1C}$ are independently associated with wider retinal arterioles: The Maastricht Study I 47

Chapter 4 Microvascular dysfunction is associated with altered beta cell function: The Maastricht Study I 75

Chapter 5 Microvascular dysfunction is associated with higher cardiovascular risk: The Maastricht Study I 101

Chapter 6 Accelerometer-measured sedentary time and physical activity and incident cardiovascular disease: The Maastricht study | 131

Chapter 7 Summary and general discussion $\quad 155$

Valorisation addendum | 171

Acknowledgements I 179

Curriculum Vitae I 184

Scientific output | 185 



\section{Chapter 1}

General Introduction 
The cardiometabolic disease is a cluster of diseases and conditions, including cardiovascular and metabolic diseases such as coronary heart disease, stroke, type 2 diabetes, and non-alcoholic fatty liver disease. The high morbidity and mortality of cardiometabolic disease has made it become a major public health problem worldwide. Cardiovascular diseases contribute to almost one-third of all global deaths ${ }^{1}$. In addition, type 2 diabetes is a leading cause of blindness, kidney failure, and lower limb amputation, which deprives more than 400 million people of their healthy life expectancy ${ }^{2}$. Thanks to the efforts by researchers in the past decade, we can witness significant strides in identifying the risk factors and potential mechanisms as well as effective prevention and treatment ${ }^{2-5}$. However, much still needs to be done. More recently, accumulative evidences have suggested a potential role of microvascular (dys)function and physical (in)activity in cardiometabolic diseases. This dissertation will further focus on this topic. In the present chapter, we will mainly introduce the definition and assessment of microvascular (dys)function and physical (in)activity, as well as their potential role in cardiometabolic diseases based on previous findings.

\section{The microcirculation}

\section{Definition and function}

Based on anatomical criteria, the microcirculation consists of blood vessels with a diameter $<150 \mu \mathrm{m}$, including arterioles, capillaries, venules, and some specialized structures such as arteriovenous shunts ${ }^{6,7}$. Alternatively, all the vessels that have myogenic response to an increasing pressure, such as the smallest arteries, can be included. Small arteries and arterioles are characterized by abundant vascular smooth muscle cells encircling the endothelium, which is essential for the high resistance at the arteriole level. Capillaries are the smallest vessels and compose of a layer of endothelial cells surrounded by the basement membrane. With different structures (continuous, fenestrated, and discontinuous), the permeability of capillaries differs across the body and allows substance exchange between capillaries and tissue via diffusion, vesicles, intracellular clefts, and fenestration. Venules are capable of constriction despite the weaker muscular coat, and play a role in regulating hydrostatic pressure in capillaries. Attributed to the porous structure, fluid and macromolecular exchange can also occur at the venule level. The coordinated collaboration of different vessels and cells is the basis of microvascular function. 
The microcirculation plays a variety of roles in both physiological and pathophysiological states. A primary function of the microcirculation is delivering oxygen and nutrients to and removing the waste from the tissue ${ }^{8}$. By affecting flowmotion and hydrostatic pressure at the capillary level, the microcirculation optimizes the delivery according to local metabolic demand. Remarkably, it can maintain a relatively stable hydrostatic pressure and thus a constant substance exchange with tissue, regardless of large fluctuations in upstream blood pressure ${ }^{9}$. This ability to create a resistance to flow also enables the microcirculation to be a determinant of blood pressure. Constriction of arterioles, metarterioles, and precapillary sphincters keeps more blood in the artery and increases systemic blood pressure, whereas dilatation of these resistance vessels decreases peripheral resistance and systemic blood pressure. In addition to regulating substance exchange and blood pressure, the microcirculation also contributes to heat change between skin surface and thermal environment, protection of the brain environment by the blood-brain barrier, assistance in endocrine system communication, and immune response ${ }^{8-11}$.

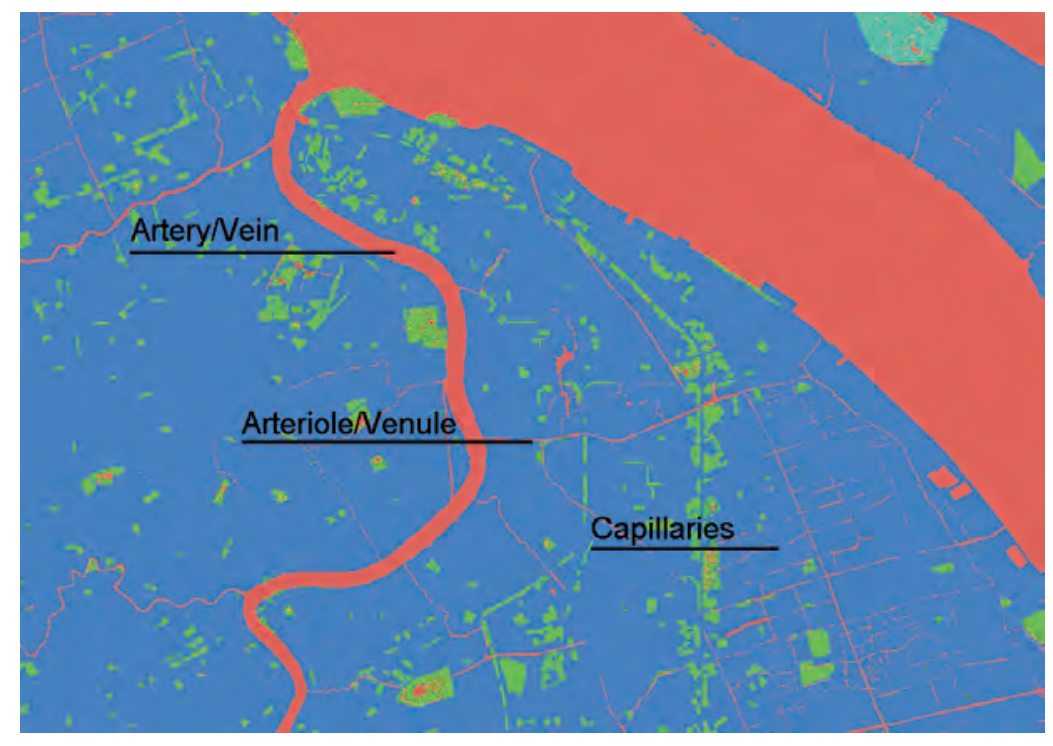

Figure 1.1 Water system on the earth as a metaphor for microcirculation. The microcirculation can be compared to the water system on the earth. It provides nutrition to the land, transmits information across regions, and forms a variety of terrains and cultures. The figure shows part of Shanghai area (map data are available on Amap.com). Blue: land; Red: water; Green: green belt; Light blue: scenic area 


\section{Microvascular measurements}

Since M. Malpighi and A. van Leeuwenhoek first observed the blood flow through capillaries under the microscope hundreds of years ago, quantitative techniques have been developed to measure microvascular parameters ${ }^{7}$. For example, videomicroscopy can dynamically visualize the microcirculation; laser Doppler flowmetry can quantify blood flow in the microcirculation; magnetic resonance imaging (MRI) can identify cerebral small vessel diseases. Besides measurements in the resting state, we can measure stimulus-induced responses to determine (maximal or submaximal) microvascular reactivity, such as local heating for the skin and flicker light for the retina ${ }^{12,13}$. What's more, technical advances have allowed a transition of some measurements from manual/semi-automated to fully automated image analysis, which enables application in population-based studies. Recent studies are gradually applying these techniques to observe the structure and function of the microcirculation in (patho)physiological status. The use of these techniques may provide further insight into the status of the microcirculation in the pathogenesis of various diseases, and show the similarity and heterogeneity across territories. However, the different protocols of some novel techniques may cause inconsistent results across studies, and are yet to be standardized. Therefore, the description of measurement protocols is necessary.

\section{Microvascular dysfunction is a systemic phenomenon}

\section{Microvascular dysfunction and type 2 diabetes}

Microvascular complications of type 2 diabetes typically include retinopathy, nephropathy, and neuropathy. Beckman et al. advanced the notion that microvascular dysfunction may be a widespread phenomenon rather than only affecting one part of the body ${ }^{14}$. Indeed, we and others have found that type 2 diabetes and hyperglycemia are associated with microvascular dysfunction in different territories in the body, including wider retinal arterioles ${ }^{15-21}$, impaired flicker light-induced retinal arteriolar dilation ${ }^{22}$, impaired heat-induced skin hyperemic response ${ }^{22}$, and cerebral small vessel disease ${ }^{23}$. The mechanism by which hyperglycemia impairs microvascular function is not well elucidated. It may involve mitochondrial overproduction of reactive oxygen species ${ }^{24,25}$, the formation of advanced glycation end products (AGEs) ${ }^{26}$, increased polyol pathway and hexosamine pathway ${ }^{24,26,27}$, and activation of protein kinase $\mathrm{C}$ isoforms ${ }^{24}$. Notably, microvascular dysfunction can occur before the diagnosis of type 2 
diabetes and even prediabetes ${ }^{22,23,28-30}$, suggesting hyperglycemia is not a necessary cause of microvascular dysfunction. A broad array of cardiometabolic risk factors such as age ${ }^{31}$, male sex ${ }^{31}$, obesity ${ }^{32}$, hypertension ${ }^{33}$, physical inactivity ${ }^{34,35}$, and current smoking ${ }^{31}$ may also be independent determinants of microvascular dysfunction.

Conversely, microvascular dysfunction may also contribute to type 2 diabetes. An extensive number of studies have shown that microvascular dysfunction, as measured by different techniques, is associated with a higher risk of type 2 diabetes ${ }^{28-30}$. This association may be explained by impaired insulin-mediated glucose disposal and, possibly, insulin secretion ${ }^{36}$. Insulin can induce endothelial-dependent vasodilation and functional capillary recruitment, thus promoting muscle glucose uptake in human and animals ${ }^{36-41}$. In rats, inhibition of nitric oxide synthase, which completely blocked the effect of insulin on both blood flow and capillary recruitment, can blunt insulin-mediate glucose uptake by approximately $40 \%$ ${ }^{41}$. More recently, evidences suggest that insulin with physiological concentration has a more significant impact on capillary recruitment than on blood flow ${ }^{40}$. In addition, microvascular dysfunction around pancreatic islets may contribute to a decreased insulin secretion with or without beta cell dysfunction, though there is no established causal link in humans yet ${ }^{42,43}$.

Taken together, the relationship between microvascular dysfunction and type 2 diabetes may be bidirectional, which forms a vicious circle and promotes the development of type 2 diabetes. Until now, glucose-lowering treatment can reduce the risk of microvascular complications in diabetes and prediabetes ${ }^{44-47}$, whereas there is lacking evidence to show preventive or treatment effect of the medication that improves microvascular function on diabetes $^{48}$.

Islet microvascular dysfunction: a potential target to modulate beta cell function

The pancreatic islet is characterized by a rich vascularization ${ }^{49}$. Intraislet endothelial cells are thin, highly fenestrated, and closely interacted with beta cells, allowing for rapid detection of glucose levels and dissemination of secreted insulin ${ }^{49}$. Pericytes, which cover the endothelial cells, play a role in maintaining structural stability and controlling vascular permeability and blood flow ${ }^{50,51}$. The bidirectional communication between beta cells and microvascular cells is essential for beta cell survival, proliferation, and insulin secretion ${ }^{49,50}$.

Mouse experiments have provided shreds of evidence showing that microvascular dysfunction may lead to impaired insulin secretion. Islet microvascular endothelial cells play a critical role in islet development and beta cell proliferation by producing vasoactive/angiogenic 
substances and growth factors ${ }^{42,52,53}$. In the adult pancreas, on the one hand, microvascular dysfunction such as hypovascularization and endothelial dysfunction can reduce blood flow, resulting in insufficient delivery of oxygen and nutrients as well as decreased insulin secretagogues entry into the beta cells and insulin' s entry into the circulation ${ }^{43,54}$. On the other, hypervascularization may promote islet inflammation and beta cell death in the long term ${ }^{54}$.

It remains dubious whether the present findings, mainly on rodent islets, apply to human islets. Although humans have a similar range of islet sizes as rodents ${ }^{55}$, the cellular arrangement and microvascular morphology differ between human and rodent islets. Unlike rodent islets that classically comprise a beta cell core $(60-80 \%$ of cells in islets) surrounded by a non-beta-cell mantle, human islets are proposed to have a trilaminar structure in which beta cells $(50-75 \%)$ directly contact with non-beta cells on both sides ${ }^{56-58}$. The human islets also have less dense and tortuous with thicker basement membrane than rodent islets ${ }^{59-61}$. The islets from a mouse model for obese type 2 diabetes are characterized by capillary loss ${ }^{62}$, whereas the islets from humans with type 2 diabetes exhibit increased capillary density and fragmented capillaries ${ }^{59}$. These findings suggest that there may be a different relationship between islet microcirculation and endocrine cells in humans versus rodents. Therefore, the association of microvascular dysfunction of beta cell function needs to be further evaluated in humans.

\section{Microvascular dysfunction and cardiovascular risk}

Micro- and macrovascular diseases often coexist in patients with long-term pathological states. One explanation can be shared risk factors and mechanisms ${ }^{63}$. We and others have found that multiple cardiovascular risk factors are associated with microvascular dysfunction and disease, including older age, male sex, smoking, hyperglycemia, hypertension, inflammation, and dyslipidemia ${ }^{31,63}$. The risk factors impair micro- and macro-vasculatures via various mechanisms. Aging, for example, exacerbates oxidative stress and leads to exhaustion of vascular progenitor cells ${ }^{64}$; adult men have less distensible arteries than women, and female sex hormones protect against vascular damage ${ }^{65,66}$. These cardiovascular risk factors and corresponding pathological pathways impair vasculatures across the body and are frequently present in combination, thereby magnifying the potential for vascular damage ${ }^{63}$.

The other explanation is that micro- and macrovascular dysfunction may be interconnected. Microvascular diseases such as retinopathy and nephropathy are independently associated with incident cardiovascular disease ${ }^{63,67}$. Although the underlying mechanism remains unclear, microvascular dysfunction may play a potential role in the development of cardiovascular 
disease. As a determinant of peripheral vascular resistance, it may increase blood pressure and impair the endothelial cells of arteries. As a channel of delivering oxygen and nutrients, it can also result in tissue ischemia and hemorrhage. Besides, inflammatory mediators generated in the microvasculature may further activate an inflammatory response in lesion-prone microand macrovasculatures, which initiates the development of an atherosclerotic plaque ${ }^{68}$. These mediators build a link of micro- and macrovascular status between non-culprit and culprit territories ${ }^{69-72}$. As macrovascular lesions may also affect microvascular function ${ }^{63}$, the interrelated micro- and macro-vascular dysfunction, along with presence of risk factors, may constitute a vicious circle of tissue damage.

\section{Physical activity and cardiovascular disease}

\section{Physical activity, inactivity, and sedentary behavior}

With increasing evidence indicating influences of physical activity and sedentary behavior on health outcomes, many countries and organizations have published relevant guidelines. Both the World Health Organization (WHO) and the United States guidelines for physical activity suggest a combination of moderate to vigorous-intensity aerobic physical activity and musclestrengthening activities ${ }^{73,74}$. The guidelines also suggest reducing sitting time. According to the definitions by $\mathrm{WHO}{ }^{73,75}$, moderate-intensity physical activity consumes approximately 3-6 metabolic equivalents (MET, the ratio of a person's working metabolic rate relative to their resting metabolic rate), and vigorous-intensity consumes more than 6 METs. Physical inactivity is defined as an absence or sufficient level of physical activity required to meet the current physical activity recommendations (less than 150 minutes of moderate-intensity activity per week for adults). Sedentary behavior is defined as any waking behavior characterized by an energy expenditure less than $1.5 \mathrm{METs}$, generally referring to sitting, reclining, and lying posture.

For decades, assessment of physical activity has been totally based on questionnaires. Despite the advantages of convenience and time-saving, use of questionnaires has certain limits of validity due to recall and social desirability bias ${ }^{76}$. Recently, the development of objective monitors has enabled off-laboratory assessment of physical activity and more precise and extended data, such as volume and pattern of activity over multiple days ${ }^{77}$. By use of such devices, previous study found that moderate to vigorous-intensity physical activity and sedentary behavior is mainly accumulated in sporadic bouts (i.e., bouts of $<10 \mathrm{~min}$ ) in youth ${ }^{77}$. 
These portions may be less memorable and therefore underestimated by self-reported questionnaires. Additionally, levels of light-intensity physical activity can hardly be assessed via questionnaires. The ignored portions of physical activity and sedentary behavior may also raise health benefits or risks.

Association of physical activity and sedentary behavior with cardiovascular risk

Based on self-reported physical activity and sedentary behavior, an extensive amount of evidence has supported an inverse relationship between physical activity and cardiovascular risk $^{78}$. Notably, physical activity may have a dose-response effect on the risk of cardiovascular disease. Compared with individuals having low amounts of physical activity, those with moderate and high amounts had $20 \%$ and $40 \%$ reduced cardiovascular risk, respectively ${ }^{78}$. Nevertheless, higher levels of physical activity are not able to offset the increased risk of cardiovascular disease associated with being overweight or obese, whereas high levels of physical fitness can ${ }^{78,79}$. This finding suggests that physical activity may not certainly lead to physical fitness. It may also reflect less precise assessment of physical activity by self-reported questionnaires than assessment of physical fitness. Therefore, further studies of physical activity measured by objective monitors are needed for public health recommendations.

Sedentary behavior may be a risk factor for cardiovascular disease, independently of physical activity. It is possible that an individual having high levels of physical activity sits more of the rest of the day, and therefore has a lower energy expenditure. Indeed, among physically active individuals, those spending more time sitting have an increased risk of all-cause and cardiovascular mortality compared with those sitting less ${ }^{80}$. However, it may be unhealthy behavior such as snacking while watching TV, but not the sedentary behavior per se, that accounts for the adverse associations. Besides the volume of sedentary behavior, the pattern also matters. Epidemiological evidence suggests that prolonged sedentary bouts are associated with worse cardiometabolic risk factors and higher risks of cardiovascular disease 81,82 . What's more, experimental trials have found that interrupting bouts of sedentary behavior with light-intensity activity can significantly benefit the cardiometabolic health, which was independent of total sedentary time ${ }^{79}$.

\section{Objectives and outline of this dissertation}

Taken together, both microvascular dysfunction and physical (in)activity may prove important for cardiometabolic disease. Microvascular dysfunction may be present long before the 
diagnosis of type 2 diabetes and associated with altered beta cell function. In addition, both microvascular dysfunction and physical inactivity may contribute to the development of cardiovascular disease. Testing these hypotheses reduces the knowledge gap in the etiology of cardiometabolic diseases, which is essential for prevention and treatment. However, current knowledge is limited by either technique for microvascular and physical activity assessments in humans or insufficient adjustment for confounding. Therefore, the general objectives of this dissertation were to investigate the associations of microvascular dysfunction and physical activity with cardiometabolic health, in a population-based cohort study (The Maastricht Study), with a broad array of potential confounders taken into account. Figure 1.2 demonstrates a schematic overview of the studies included in this dissertation.

In Chapter 2, we described detailed protocols of a variety of non-invasive microvascular measurements in skin, retina, brain, and sublingual tissue as well as plasma and urine biomarker assessments, which have been implemented in The Maastricht Study. We additionally provided a summary of the main findings and perspectives of microvascular phenotyping, with an update up to 2018.

In Chapter 3, we investigated the associations of oral glucose tolerance test-based glucose metabolism status (normal glucose metabolism, prediabetes, type 2 diabetes) and measures of blood glucose with retinal microvascular diameters. In addition, we explored whether retinal arteriolar and venular diameters were mutually related.

In Chapter 4, we explored whether islet microvascular dysfunction, using measures of generalized microvascular function, was associated with fasting insulin secretion and glucosestimulated insulin secretion.

In Chapter 5, we performed a systematic evaluation of the association of microvascular dysfunction with incident cardiovascular disease. We also explored whether the association differs regarding cardiovascular disease in different vascular beds (coronary, cerebral, and peripheral).

In Chapter 6, we investigated the association between the volume and the pattern of physical activity and sedentary behavior with incident cardiovascular disease. 


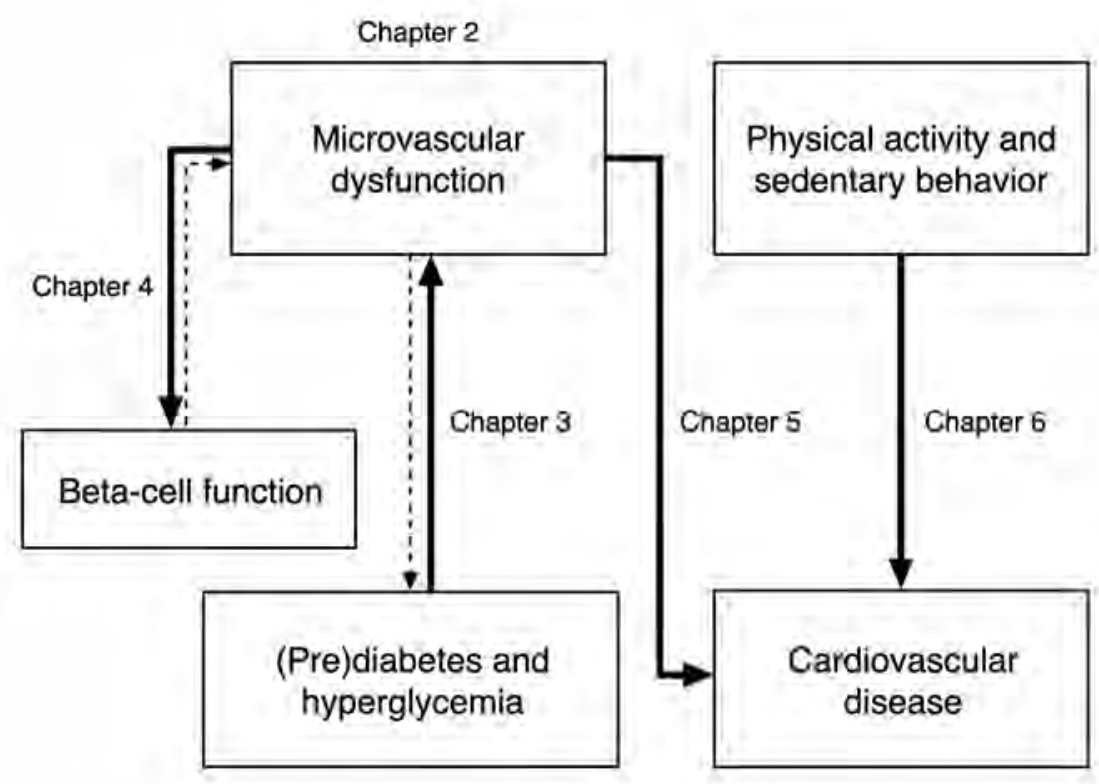

Figure 1.2 Schematic overview of the studies included in this dissertation. Solid arrows indicate associations that we hypothesized and investigated in the present dissertation. Dashed lines represent potential reverse associations. 


\section{References}

1. World Health Organization. Cardiovascular diseases (CVDs).(2017) Available at: http://www. who. int/newsroom/fact-sheets/detail/cardiovascular-diseases-(cvds). Accessed: 20th August 2020.

2. International Diabetes Federation. IDF Diabetes Atlas Ninth Edition 2019.

3. World Health Organization. Global status report on noncommunicable diseases 2014 (No. WHO/NMH/NVI/15.1). World Health Organization. 2014.

4. Leening MJG, Siregar S, Vaartjes I, Bots ML, Versteegh MIM, van Geuns RJ, et al. Heart disease in the Netherlands: a quantitative update. Neth Heart J. 2014;22(1):3-10.

5. Weiwei C, Runlin G, Lisheng L, Manlu Z, Wen W, Yongjun W, et al. Outline of the report on cardiovascular diseases in China, 2014. Eur Heart J Suppl. 2016;18(suppl_F):F2-F11.

6. Houben A, Martens RJH, Stehouwer CDA. Assessing Microvascular Function in Humans from a Chronic Disease Perspective. J Am Soc Nephrol. 2017;28(12):3461-3472.

7. Barker JH, Anderson GL, Menger MD, editors. Clinically applied microcirculation research. Routledge; 2019.

8. Aird WC. Phenotypic heterogeneity of the endothelium: I. Structure, function, and mechanisms. Circ Res. 2007;100(2):158-173.

9. Guyton AC, Hall JE. Overview of the circulation; biophysics of pressure flow, and resistance. Textbook of medical physiology, 12th edn. Saunders, Elsevier; 2011:157-66.

10. De Boer MP, Meijer RI, Wijnstok NJ, Jonk AM, Houben AJ, Stehouwer CD, et al. Microvascular dysfunction: a potential mechanism in the pathogenesis of obesity-associated insulin resistance and hypertension. Microcirculation. 2012;19(1):5-18.

11. Houben AJ, Eringa EC, Jonk AM, Serne EH, Smulders YM, Stehouwer CD. Perivascular Fat and the Microcirculation: Relevance to Insulin Resistance, Diabetes, and Cardiovascular Disease. Curr Cardiovasc Risk Rep. 2012;6(1):80-90.

12. Agarwal SC, Allen J, Murray A, Purcell IF. Comparative reproducibility of dermal microvascular blood flow changes in response to acetylcholine iontophoresis, hyperthermia and reactive hyperaemia. Physiol Meas. 2010;31(1):1-11.

13. Nagel E, Vilser W. Flicker observation light induces diameter response in retinal arterioles: a clinical methodological study. Br J Ophthalmol. 2004;88(1):54-56.

14. Beckman JA, Duncan MS, Damrauer SM, Wells QS, Barnett JV, Wasserman DH, Bedimo RJ, Butt AA Marconi VC, Sico JJ, Tindle HA. Microvascular Disease, Peripheral Artery Disease, and Amputation. Circulation. 2019;140(6):449-458.

15. Nguyen TT, Wang JJ, Sharrett AR, Islam FA, Klein R, Klein B, et al. Relationship of retinal vascular caliber with diabetes and retinopathy: the multi-ethnic study of atherosclerosis (MESA). Diabetes Care 2008;31(3):544-549.

16. Jeganathan VS, Sabanayagam C, Tai ES, Lee J, Lamoureux E, Sun C, et al. Retinal vascular caliber and diabetes in a multiethnic Asian population. Microcirculation 2009;16(6):534-543.

17. Tikellis G, Wang JJ, Tapp R, Simpson R, Mitchell P, Zimmet PZ, et al. The relationship of retinal vascular calibre to diabetes and retinopathy: the Australian Diabetes, Obesity and Lifestyle (AusDiab) study. Diabetologia 2007;50(11):2263-2271.

18. Cheung CY, Lamoureux E, Ikram MK, Sasongko MB, Ding J, Zheng Y, et al. Retinal vascular geometry in Asian persons with diabetes and retinopathy. J Diabetes Sci Technol 2012;6(3):595-605.

19. Islam FM, Nguyen TT, Wang JJ, Tai ES, Shankar A, Saw SM, et al. Quantitative retinal vascular calibre changes in diabetes and retinopathy: the Singapore Malay eye study. Eye (Lond) 2009;23(8):1719-1724.

20. Tsai AS, Wong TY, Lavanya R, Zhang R, Hamzah H, Tai ES, Cheung CY. Differential association of retinal arteriolar and venular caliber with diabetes and retinopathy. Diabetes Res Clin Pract 2011;94(2):291-298.

21. Kifley A, Wang JJ, Cugati S, Wong TY, Mitchell P. Retinal vascular caliber, diabetes, and retinopathy. Am J Ophthalmo 2007;143(6):1024-1026.

22. Sörensen BM, Houben AJ, Berendschot TT, Schouten JS, Kroon AA, van der Kallen CJ, et al. Prediabetes and type 2 diabetes are associated with generalized microvascular dysfunction: the Maastricht Study. Circulation. 2016;134(18):1339-1352. 
23. van Agtmaal MJ, Houben AJ, de Wit V, Henry RM, Schaper NC, Dagnelie PC, et al. Prediabetes is associated with structural brain abnormalities: the Maastricht Study. Diabetes Care. 2018;41(12):2535-2543.

24. Giacco F, Brownlee M. Oxidative stress and diabetic complications. Circ Res. 2010;107(9):1058-1070.

25. Brownlee M. The pathobiology of diabetic complications: a unifying mechanism. diabetes. 2005;54(6):16151625.

26. Chilelli NC, Burlina S, Lapolla A. AGEs, rather than hyperglycemia, are responsible for microvascular complications in diabetes: a "glycoxidation-centric" point of view. Nutr Metab Cardiovasc Dis. 2013;23(10):913-919.

27. Yan LJ. Redox imbalance stress in diabetes mellitus: Role of the polyol pathway. Animal Model Exp Med. 2018;1(1):7-13.

28. Muris DM, Houben AJ, Schram MT, Stehouwer CD. Microvascular dysfunction is associated with a higher incidence of type 2 diabetes mellitus: a systematic review and meta-analysis. Arterioscler Thromb Vasc Biol. 2012;32(12):3082-3094.

29. Qiu S, Cai X, Liu J, Yang B, Zügel M, Steinacker JM, Sun Z, Schumann U. Association between circulating cell adhesion molecules and risk of type 2 diabetes: A meta-analysis. Atherosclerosis. 2019;287:147-154.

30. Sabanayagam C, Lye WK, Klein R, Klein BE, Cotch MF, Wang JJ, et al. Retinal microvascular calibre and risk of diabetes mellitus: a systematic review and participant-level meta-analysis. Diabetologia. 2015;58:2476-2485.

31. Sörensen BM, Houben AJ, Berendschot TT, Schouten JS, Kroon AA, van der Kallen CJ, Henry RM, et al. Cardiovascular risk factors as determinants of retinal and skin microvascular function: The Maastricht Study. PloS one. 2017;12(10):e0187324.

32. Jonk AM, Houben AJ, Schaper NC, de Leeuw PW, Serné EH, Smulders YM, Stehouwer CD. Obesity is associated with impaired endothelial function in the postprandial state. Microvasc Res. 2011;82(3):423-429.

33. Serné EH, Gans RO, Ter Maaten JC, Tangelder GJ, Donker AJ, Stehouwer CD. Impaired skin capillary recruitment in essential hypertension is caused by both functional and structural capillary rarefaction. Hypertension. 2001;38(2):238-242.

34. Tikellis G, Anuradha S, Klein R, Wong TY. Association between physical activity and retinal microvascular signs: the Atherosclerosis Risk in Communities (ARIC) Study. Microcirculation. 2010;17(5):381-393.

35. Anuradha S, Dunstan DW, Healy GN, Shaw JE, Zimmet PZ, Wong TY, Owen N. Physical activity, television viewing time, and retinal vascular caliber. Med Sci Sports Exerc. 2011;43(2):280-286.

36. Stehouwer CD. Microvascular dysfunction and hyperglycemia: a vicious cycle with widespread consequences. Diabetes. 2018;67(9):1729-1741.

37. Muris DM, Houben AJ, Schram MT, Stehouwer CD. Microvascular dysfunction: an emerging pathway in the pathogenesis of obesity-related insulin resistance. Rev Endocr Metab Disord. 2013;14(1):29-38.

38. Jonk AM, Houben AJ, De Jongh RT, Serné EH, Schaper NC, Stehouwer CD. Microvascular dysfunction in obesity: a potential mechanism in the pathogenesis of obesity-associated insulin resistance and hypertension. Physiology. 2007;22(4):252-260.

39. Vincent MA, Barrett EJ, Lindner JR, Clark MG, Rattigan S. Inhibiting NOS blocks microvascular recruitment and blunts muscle glucose uptake in response to insulin. Am J Physiol Endocrinol Metab. 2003;285(1):E123129.

40. Clark MG, Wallis MG, Barrett EJ, Vincent MA, Richards SM, Clerk LH, Rattigan S. Blood flow and muscle metabolism: a focus on insulin action. Am J Physiol Endocrinol Metab. 2003;284(2):E241-258.

41. Jongh RT, Clark AD, IJzerman RG, Serné EH, Vries G, Stehouwer CD. Physiological hyperinsulinaemia increases intramuscular microvascular reactive hyperaemia and vasomotion in healthy volunteers. Diabetologia. 2004;6(47):978-986.

42. Hogan MF, Hull RL. The islet endothelial cell: a novel contributor to beta cell secretory dysfunction in diabetes. Diabetologia. 2017;60(6):952-959.

43. Hashimoto S, Kubota N, Sato H, Sasaki M, Takamoto I, Kubota T, et al. Insulin receptor substrate-2 (Irs2) in endothelial cells plays a crucial role in insulin secretion. Diabetes. 2015;64:876-886.

44. UK Prospective Diabetes Study (UKPDS) Group. Intensive blood-glucose control with sulphonylureas or insulin compared with conventional treatment and risk of complications in patients with type 2 diabetes (UKPDS 33). The lancet. 1998;352(9131):837-853. 
45. ADVANCE Collaborative Group. Intensive blood glucose control and vascular outcomes in patients with type 2 diabetes. N Engl J Med. 2008;358(24):2560-2572.

46. Sjöström L, Peltonen M, Jacobson P, Ahlin S, Andersson-Assarsson J, Anveden Å, et al. Association of bariatric surgery with long-term remission of type 2 diabetes and with microvascular and macrovascular complications. Jama. 2014;311(22):2297-2304.

47. Carlsson LM, Sjöholm K, Karlsson C, Jacobson P, Andersson-Assarsson JC, Svensson PA, et al. Long-term incidence of microvascular disease after bariatric surgery or usual care in patients with obesity, stratified by baseline glycaemic status: a post-hoc analysis of participants from the Swedish Obese Subjects study. Lancet Diabetes Endocrinol. 2017;5(4):271-279.

48. Jonk AM, Houben AJ, Schaper NC, de Leeuw PW, Serné EH, Smulders YM, Stehouwer CD. Acute angiotensin II receptor blockade improves insulin-induced microvascular function in hypertensive individuals. Microvasc Res. 2011;82(1):77-83.

49. Peiris H, Bonder CS, Coates PT, Keating DJ, Jessup CF. The $\beta$-cell/EC axis: how do islet cells talk to each other?. Diabetes. 2014;63(1):3-11.

50. Alexandre-Heymann L, Larger É. The pericyte of the pancreatic islet regulates capillary diameter and loca blood flow. Med Sci (Paris). 2018;34(8-9):649.

51. Richards OC, Raines SM, Attie AD. The role of blood vessels, endothelial cells, and vascular pericytes in insulin secretion and peripheral insulin action.Endocr Rev. 2010;31(3):343-363.

52. Johansson M, Mattsson G, Andersson A, Jansson $L$ and Carlsson PO. Islet endothelial cells and pancreatic beta-cell proliferation: studies in vitro and during pregnancy in adult rats. Endocrinology. 2006;147:2315-2324.

53. Konstantinova I and Lammert E. Microvascular development: learning from pancreatic islets. Bioessays. 2004;26:1069-1075.

54. Staels W, Heremans Y, Heimberg H, De Leu N. VEGF-A and blood vessels: a beta cell perspective. Diabetologia. 2019:1-8.

55. Dolenšek J, Rupnik MS, Stožer A. Structural similarities and differences between the human and the mouse pancreas. Islets. 2015;7(1):e1024405.

56. Cabrera O, Berman DM, Kenyon NS, Ricordi C, Berggren PO, Caicedo A. The unique cytoarchitecture of human pancreatic islets has implications for islet cell function. Proc Natl Acad Sci USA. 2006;103(7):23342339.

57. Bosco D, Armanet M, Morel P, Niclauss N, Sgroi A, Muller YD, Giovannoni L, Parnaud G, Berney T. Unique arrangement of $\alpha$-and $\beta$-cells in human islets of Langerhans. Diabetes. 2010;59(5):1202-1210.

58. Noguchi GM, Huising MO. Integrating the inputs that shape pancreatic islet hormone release. Nat Metab. 2019;1(12):1189-1201.

59. Brissova M, Shostak A, Fligner CL, Revetta FL, Washington MK, Powers AC, Hull RL. Human islets have fewer blood vessels than mouse islets and the density of islet vascular structures is increased in type 2 diabetes. J Histochem Cytochem. 2015;63(8):637-645

60. Otonkoski T, Banerjee M, Korsgren O, Thornell LE, Virtanen I. Unique basement membrane structure of human pancreatic islets: implications for $\beta$-cell growth and differentiation. Diabetes Obes Metab. 2008;10:119-127.

61. Virtanen I, Banerjee M, Palgi J, Korsgren O, Lukinius A, Thornell LE, et al. Blood vessels of human islets of Langerhans are surrounded by a double basement membrane. Diabetologia. 2008;51(7):1181-1191.

62. Li X, Zhang L, Meshinchi S, Dias-Leme C, Raffin D, Johnson JD, Treutelaar MK, Burant CF. Islet microvasculature in islet hyperplasia and failure in a model of type 2 diabetes. Diabetes. 2006;55(11):29652973.

63. Krentz AJ, Clough G, Byrne CD. Interactions between microvascular and macrovascular disease in diabetes: pathophysiology and therapeutic implications. Diabetes Obes Metab. 2007;9(6):781-891.

64. Ungvari Z, Tarantini S, Donato AJ, Galvan V, Csiszar A. Mechanisms of vascular aging. Circ Res. 2018; 123(7), 849-867.

65. Ahimastos AA, Formosa M, Dart AM, Kingwell BA. Gender differences in large artery stiffness pre-and post puberty. J Clin Endocrinol Metab. 2003; 88(11), 5375-5380.

66. Albrektsen G, Heuch I, Løchen M L, Thelle DS, Wilsgaard T, Njølstad I, Bønaa KH. Lifelong gender gap in risk of incident myocardial infarction: the Troms $\varnothing$ Study. JAMA Intern Med. 2016;176(11), 1673-1679. 
67. Brownrigg JR, Hughes, CO, Burleigh D, Karthikesalingam A, Patterson BO, Holt PJ, et al. Microvascular disease and risk of cardiovascular events among individuals with type 2 diabetes: a population-level cohort study. Lancet Diabetes Endocrinol. 2016;4(7), 588-597.

68. Stokes KY,Granger DN. The microcirculation: a motor for the systemic inflammatory response and large vessel disease induced by hypercholesterolaemia?. J Physiol. 2005; 562(3), 647-653.

69. Radhakrishnan A, Pickup LC, Price AM, Law JP, Edwards NC, Steeds RP, et al. Coronary microvascular dysfunction: a key step in the development of uraemic cardiomyopathy?. Heart. 2019;105(17):1302-1309.

70. Cho EB, Shin HY, Park SE, Chun P, Jang HR, Yang JJ, et al. Albuminuria, cerebrovascular disease and cortical atrophy: among cognitively normal elderly individuals. Sci Rep. 2016;6(1):1-8.

71. Martens RJ, Henry RM, Houben AJ, van der Kallen CJ, Kroon AA, Schalkwijk CG, et al. Capillary rarefaction associates with albuminuria: the Maastricht Study. J Am Soc Nephrol. 2016;27(12):3748-3757.

72. McGeechan K, Liew G, Macaskill P, Irwig L, Klein R, Klein BE, et al. Meta-analysis: retinal vessel caliber and risk for coronary heart disease. Ann Intern Med. 2009;151(6):404-13.

73. World Health Organization. Global action plan on physical activity 2018-2030: more active people for a healthier world. World Health Organization 2019.

74. Piercy KL, Troiano RP, Ballard RM, Carlson SA, Fulton JE, Galuska DA, et al. The physical activity guidelines for Americans. Jama 2018; 320(19):2020-2028.

75. World Health Organization. What is moderate-intensity and vigorous-intensity physical activity. Global Strategy on Diet, Physical Activity and Health 2014.

76. Bull FC, Maslin TS, Armstrong T. Global physical activity questionnaire (GPAQ): nine country reliability and validity study. Journal of Physical Activity and healthJ Phys Act Health. 2009; 6(6):790-804.

77. Esliger DW, Tremblay MS. Physical activity and inactivity profiling: the next generation. Appl Physiol Nutr Metab. 2007;32(S2E):S195-S207.

78. Shiroma EJ, Lee IM. Physical activity and cardiovascular health: Lessons learned from epidemiological studies across age, Gender, and race/ethnicity. Circulation. 2010;122:743-752.

79. Fogelholm M. Physical activity, fitness and fatness: relations to mortality, morbidity and disease risk factors. A systematic review. Obesity reviews 2010; 11(3): 202-221.

80. Katzmarzyk PT, Church TS, Craig CL, Bouchard C. Sitting time and mortality from all causes, cardiovascular disease, and cancer. Med Sci Sports Exerc. 2009; 41(5): 998-1005.

81. Diaz KM, Goldsmith J, Greenlee H, Strizich G, Qi Q, Mossavar-Rahmani Y, et al. Prolonged, uninterrupted sedentary behavior and glycemic biomarkers among US hispanic/latino adults: the HCHS/SOL (Hispanic Community Health Study/Study of Latinos). Circulation. 2017;136(15):1362-1373.

82. Bellettiere J, LaMonte MJ, Evenson KR, Rillamas-Sun E, Kerr J, Lee IM, et al. Sedentary behavior and cardiovascular disease in older women: the OPACH Study. Circulation. 2019; 139(8):1036-1046.

83. Chastin SF, Egerton T, Leask C, Stamatakis E. Meta-analysis of the relationship between breaks in sedentary behavior and cardiometabolic health. Obesity. 2015;23(9):1800-1810. 


\section{Chapter 2}

Microvascular Phenotyping in The Maastricht Study:

Design, and Main findings, 2010-2018

Wenjie Li, Miranda T Schram, Ben M Sörensen, Marnix JM van Agtmaal, Tos TJM Berendschot, Carroll AB Webers, Jacobus FA Jansen, Walter H Backes, Ed HBM Gronenschild, Casper G Schalkwijk, Coen DA Stehouwer, Alfons JHM Houben 


\section{Abstract}

Microvascular dysfunction (MVD) is a common pathophysiological change in various diseases, such as type 2 diabetes mellitus (T2DM), heart failure, dementia and depression. Recent technical advances enable the measurement and quantification of microvascular changes non-invasively in humans. In this paper, we describe the protocols of the microvascular measurements applied in The Maastricht Study, an ongoing prospective population-based cohort study, which includes a variety of non-invasive measurements in skin, retina, brain, and sublingual tissue as well as plasma and urine biomarker assessments. Following this, we summarize our main findings involving these microvascular measurements up to 2018. Finally, we provide a brief perspective of future microvascular investigations, within the framework of The Maastricht Study 


\section{Introduction}

Microvascular dysfunction (MVD) is involved in the development and progression of various diseases, such as type 2 diabetes mellitus (T2DM), heart failure, dementia, and depression ${ }^{1-8}$. The microcirculation performs essential functions in both physiological and pathophysiological states, including delivery of oxygen and nutrients, removal of waste, heat exchange with the environment, assistance in endocrine system communication, blood pressure regulation, and immune response ${ }^{9-12}$. Investigation of microvascular function can thus expand our knowledge of the pathophysiology of different diseases.

Nowadays, state-of-the-art technologies enable assessment of both structural and functional aspects of the human microcirculation in different regions ${ }^{13-21}$. Introducing these measurements in a population-based setting permits the study of microvascular changes that occur in various diseases, as well as their similarities and differences across various territories. Additionally, the description of measurement protocols is necessary in order to identify whether differences in results across studies are based on differences in methodology.

The general design of The Maastricht Study, a population-based cohort study, has been described previously ${ }^{22}$. In the present paper, we describe a wide range of microvascular measurements that have been implemented gradually in The Maastricht Study and provide a summary of the main findings and perspectives on microvascular phenotyping, with an update through the end of 2018.

\section{Methods}

A detailed description of the study population and design of The Maastricht Study can be found in the Supplemental Material and a previous paper ${ }^{22}$. The Maastricht Study is an ongoing observational, prospective, population-based cohort study. All residents of the southern part of the Netherlands aged $40-75$ years are eligible for participation. Baseline data assessment took place from November 2010 to January 2020. Table 2.1 gives an overview of all microvascular measurements and corresponding variables used to assess microvascular (dys)function that have been implemented in The Maastricht Study. Microvascular measurements applied from the onset of the study include skin capillary density and recruitment, skin flowmotion, and biomarkers of endothelial function obtained from plasma and urine samples. Measurements of heat-induced skin hyperemic response, retinal static and 
dynamic measurements, and magnetic resonance imaging (MRI) measurements were introduced after approximately 8, 11, and 13 months, respectively. Lastly, measurement of endothelial glycocalyx thickness was introduced 22 months after initiation of the study. Data collection in The Maastricht Study and validation of the microvascular measurements are described in the Supplemental Material.

\section{$\underline{\text { Retinal microvascular reactivity }}$}

The retinal microvascular dilation response to flicker light, which is related to nutritive demands of activated retinal neurons and is nitric-oxide-dependent ${ }^{16,23}$, is measured in a dimly lit room using the Dynamic Vessel Analyzer (Imedos Systems $\mathrm{GmbH}$, Jena, Germany). Mydriasis is induced with 2 drops of tropicamide ( $0.5 \%)$ and 1 drop of phenylephrine (2.5\%) 15 minutes prior to the Dynamic Vessel Analyzer measurements. For safety reasons, participants with an intraocular pressure exceeding $30 \mathrm{~mm} \mathrm{Hg}$ are excluded from retinal measurements. Per participant, we randomly measure the left or right eye. During the measurement, the participant is instructed to focus on the tip of a fixed needle inside the retinal camera (FF450; Carl Zeiss AG, Jena, Germany) while the fundus of the eye is examined under green measuring light (530-600 nm; illumination of fundus approximately 6,500 lux). Straight arteriolar and venular segments of approximately $1.5 \mathrm{~mm}$ in length located $0.5-2.0$ disc diameters from the margin of the optic disc in the temporal section are examined (Figure 2.1A, left panel, zone “b” ).

After the specific vessel profile is recognized, its diameter is automatically and continuously measured for 150 seconds. A baseline recording of 50 seconds is followed by a 40-second flicker light exposure period (flicker frequency $12.5 \mathrm{~Hz}{ }^{24}$, bright:dark contrast ratio $25: 1$ ) and a subsequent 60 -second recovery period (Figure 2.1A, right panel). We use a 40-second flicker light stimulation based on the findings of Nagel et al. ${ }^{25}$ and Kotliar et al. ${ }^{26}$, who observed that healthy individuals exhibited maximum dilation immediately after the 20-second flicker stimulation, whereas the time to maximal arteriolar dilation of obese individuals was prolonged. We have chosen to perform a single cycle of 40 -second flicker light stimulation because of time restraints for the large amount of measurements in The Maastricht Study. Notably, despite a difference in flicker duration, the average arteriolar/venular percent-dilation responses we observe are comparable to those in studies using 3 cycles of short flicker light stimulation. The Dynamic Vessel Analyzer automatically corrects for alterations in luminance caused by, for example, slight eye movements. During blinks and small eye movements, the registration stops, and it restarts once the vessel segments are automatically reidentified ${ }^{16}$. 
The integrated Dynamic Vessel Analyzer software (version 4.51; Imedos Systems) automatically calculates baseline diameter and percentage dilation. Baseline diameter is calculated as the average diameter size of the 20 - to 50 -second recording and is expressed in measurement units, where 1 measurement unit is equal to $1 \mu \mathrm{m}$ of the Gullstrand eye ${ }^{27}$. Percentage dilation over baseline is based on the average dilation achieved at the time points 10 seconds and 40 seconds during the flicker stimulation period. Two regression lines are drawn (at intervals of $0-<10$ seconds and 10-40 seconds during flicker stimulation), and results are averaged to assess average percentage of dilation. The purpose of taking the average dilation is to account for interindividual variation in the curve shape during dilation.

\section{Retinal microvascular diameters and morphology}

State-of-the-art technology enables quantification and analysis of various features of retinal microvasculature (semi)automatically (e.g., vascular diameters, tortuosity, fractal dimension, and bifurcation features (Figure 2.1A, left panel). In The Maastricht Study, fundus photography of both eyes is performed 15 minutes after the pupils have been dilated with tropicamide $0.5 \%$ and phenylephrine $2.5 \%$. All fundus photographs are made with a focus, shot, and tracker fundus camera (model AFC-230; Nidek Co. Ltd., Aichi, Japan) in 45 degrees of at least 3 fields: 1 field centered on the optic disc, 1 field centered on the macula, and 1 temporal field positioned 1 disc diameter from the center of the macula.

Static retinal vessel analysis is performed with the RHINO software developed by the RetinaCheck Project group at the Eindhoven University of Technology (Eindhoven, the Netherlands) ${ }^{17,18}$. Retinal vessel diameters are measured 0.5-1.0 disc diameter away from the optic disc margin and 1.0-1.5 disc diameter away from the fovea (macula) center (zone "a” ), while retinal vascular tortuosity, retinal fractal dimension, and bifurcation-based features are studied within 1.0-2.5 disc diameters (zone “ $\mathrm{b}$ ") and 1.0-3.0 disc diameters (zone “c”) from the optic disc center or fovea (macula) center, respectively (Figure 2.1 A, left panel). The scale factor is based on the optic disc diameter, which is assumed to be $1,800 \mu \mathrm{m}^{28}$.

Retinal vessel diameters are presented as central retinal arteriolar equivalent and central retinal venular equivalent. Central retinal arteriolar equivalent and central retinal venular equivalent represent the equivalent single-vessel parent diameters for the 6 largest arterioles 
A)

B)

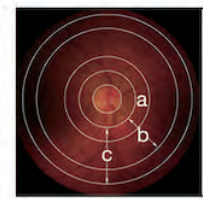

C)
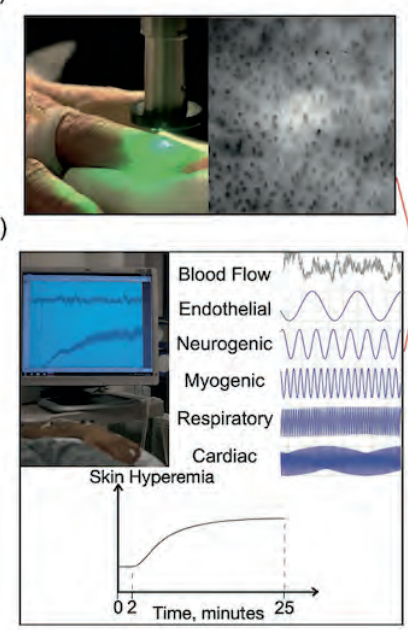

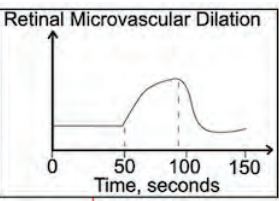

Retina

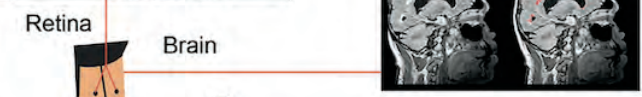

E)

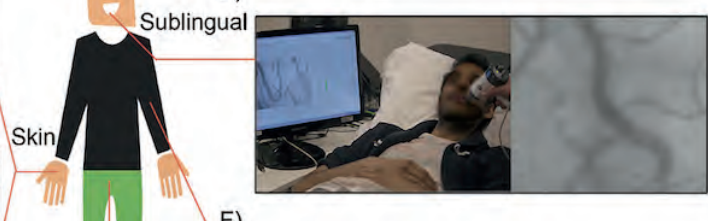

F)

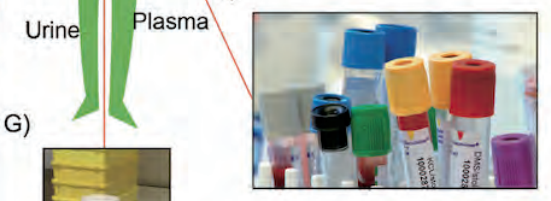

Figure 2.1 Noninvasive microvascular measurements in The Maastricht Study, Maastricht, the Netherlands, 2010 - 2018. A) Retinal microvascular diameters and morphology and retinal microvascular reactivity. Left: a typical example of an optic disc-centered image showing the retinal microvasculature. Zones a, b, and $\mathrm{c}$ are defined as the regions $1.0-1.5,1.0-2.5$, and $1.0-3.0$ disc diameters away from the optic disc center or fovea (macula) center, respectively. Right: schematic registration of a 40-second flicker light-induced retinal arteriolar dilation response using the Dynamic Vessel Analyzer (Imedos Systems GmbH, Jena, Germany). B) Skin capillary density and recruitment. Left: skin capillaries are visualized in the dorsal skin of the distal phalanges of the third and fourth fingers of the right hand by means of a digital video microscope. Right: a typical example of skin capillaries. C) Skin microvascular flowmotion (SMF) and skin heating response. Upper left panel: SMF measurement is performed by use of a laser Doppler system equipped with 2 probes at the dorsal side of both the left wrist and the left ankle. Upper right panel: frequency spectrum of SMF between $0.01 \mathrm{~Hz}$ and $1.60 \mathrm{~Hz}$, divided into 5 SMF components based on the cutpoints of Stefanovska et al. ${ }^{15}$ : endothelial, $0.01-0.02 \mathrm{~Hz}$; neurogenic, 0.02-0.06 Hz; myogenic, 0.06-0.15 Hz; respiratory, 0.15-0.40 Hz; and cardiac, $0.40-1.60 \mathrm{~Hz}$. Lower panel: schematic registration of a 23-minute heat-induced skin hyperemic response using laser Doppler flowmetry. D) Magnetic resonance imaging markers of cerebral small-vessel disease. Upper left panel: T1-weighted scan. Upper right panel: T1-weighted image with segmented volumes overlaid. Lower left panel: T2-weighted fluid-attenuated inversion recovery (FLAIR) scan. Lower right panel: T2-weighted FLAIR image with white matter hyperintensities marked in red. E) Endothelial glycocalyx thickness. Left: sublingual microcirculation is visualized by means of a sidestream dark field camera. Right: a typical example of sublingual microcirculation displayed by videomicroscopy. F) Plasma biomarkers. Venous plasma samples are taken to measure biomarkers of endothelial function. G) Urine biomarkers. Urinary albumin concentration is measured by means of two 24-hour urine collections. Albuminuria is defined as albumin excretion $\geqslant 30 \mathrm{mg} / 24$ hours. 
and largest venules in the region of interest, respectively. The calculations are based on the improved Knudtson-Hubbard formula ${ }^{29}$.

Retinal microvascular morphology includes retinal microvascular tortuosity, fractal dimension, and bifurcation-based features. We measure retinal arteriolar and venular tortuosity using both conventional and exponential methods ${ }^{30}$. We calculate fractal dimension on the basis of the box-counting method ${ }^{31}$. Calculation of microvascular bifurcation-based features, including branching angles, bifurcation index, asymmetry ratio, area ratio, and junction exponent, has been described elsewhere ${ }^{32}$.

\section{Skin capillary density and recruitment}

Skin microcirculation is considered a representative vascular bed with which to examine generalized systemic MVD ${ }^{33}$. In The Maastricht Study, skin capillaries are visualized in the dorsal skin of the distal phalanges of the third and fourth fingers of the right hand using a digital video microscope (CapiScope; KK Technology, Honiton, United Kingdom) with a system magnification of $\times 100{ }^{13}$. Participants are studied in the supine position with the investigated hand placed at heart level. The finger is fixed on a finger holder, and a miniature cuff (digit cuff; D. E. Hokanson, Inc., Bellevue, Washington) is applied to the base of the investigated finger (Figure 2.1B, left panel). Capillaries are visualized $4.5 \mathrm{~mm}$ proximal to the terminal row of capillaries in the middle of the nailfold, where capillaries run perpendicularly to the skin (Figure $2.1 \mathrm{~B}$, right panel). The investigator selects a region of interest of $1 \mathrm{~mm}^{2}$ of skin area.

Capillary density (mean of 2 fields) is measured under 3 conditions. First, baseline capillary density, defined as the number of continuously erythrocyte-perfused capillaries per $1 \mathrm{~mm}^{2}$ of skin, is measured. Capillaries are counted for 15 seconds at baseline. Second, capillary recruitment during postocclusive peak reactive hyperemia is assessed after arterial occlusion. Arterial occlusion is applied using a miniature cuff at the base of the investigated finger inflated to suprasystolic pressure $(260 \mathrm{mmHg})$ for 4 minutes. Immediately following release of the cuff, all (continuously and intermittently) perfused capillaries are counted for 15 seconds. Third, venous congestion is applied, with the cuff inflated to $60 \mathrm{mmHg}$ for 2 minutes, and all (continuously and intermittently) perfused capillaries are counted for 15 seconds in the second minute. The number of perfused capillaries is counted in the recorded digital raw data using a custom-built semi-automatic image analysis application (CapiAna) constructed by 2 of the authors (E.H.B.M.G. and A.J.H.M.H.) ${ }^{13}$. For analysis, we use absolute numbers of capillaries recorded at baseline, after arterial occlusion, and during venous congestion. In addition, we calculate percentage of capillary recruitment following arterial occlusion ([(capillary density 
during hyperemia-baseline capillary density)/baseline capillary density] $\times 100$ ) and percentage of capillary density during venous congestion ([(capillary density during venous congestion-baseline capillary density)/baseline capillary density] $\times 100$ ).

\section{Skin flowmotion}

Flowmotion is the fluctuation of microvascular perfusion as a result of spontaneous oscillations in arteriolar diameter (i.e., vasomotion). Skin microvascular flowmotion (SMF) can be monitored by laser Doppler flowmetry. This technique is based on a fiber-optic probe emitting laser light (wavelength $780 \mathrm{~nm}$ ) to the target tissue and collecting the back-scattered light, which undergoes a shift in frequency proportional to the velocity of moving erythrocytes. The measuring depth is $0.5-1.0 \mathrm{~mm}$, and the signal is predominantly derived from arterioles and venules ${ }^{16}$. We perform SMF measurements using a laser Doppler system (PeriFlux 5000; Perimed $A B$, Järfälla, Sweden) equipped with 2 probes, one at the dorsal side of the left wrist and the other at the dorsal side of the left ankle (Figure 2.1C, upper left panel). Since flowmotion has predominantly been observed in participants with a skin temperature above $29.3^{\circ} \mathrm{C}{ }^{34}$, the laser Doppler probes are maintained at $30^{\circ} \mathrm{C}$. The laser Doppler flowmetry output is recorded for 25 minutes with a sample rate of $32 \mathrm{~Hz}$, which gives semi-quantitative assessment of skin blood flow expressed in arbitrary perfusion units ${ }^{35}$.

A fast-Fourier transform algorithm is performed by means of a custom-built automatic software application created in MATLAB (MathWorks, Inc., Natick, Massachusetts) to distinguish the contributions of different frequency domains to the signal. The frequency spectrum between $0.01 \mathrm{~Hz}$ and $1.60 \mathrm{~Hz}$ is divided into 5 SMF components (using the cutpoints

of Stefanovska et al. ${ }^{15}$ ): endothelial, 0.01-0.02 Hz; neurogenic, 0.02-0.06 Hz; myogenic, 0.06-0.15 Hz; respiratory, 0.15-0.40 Hz; and cardiac, 0.40-1.60 Hz (Figure 2.1C, upper right panel). The results are presented as power spectrum density, which describes the density of power in a stationary, random process per unit of frequency and can be expressed as (perfusion units) $^{2}$ per Hz. Total energy is obtained by the sum of the power density values of the total frequency spectrum. To correct for spatial and temporal variations in the laser Doppler flowmetry signal, the relative contributions of the components are calculated by dividing the power of each component by the power of the total SMF $(0.01-1.60 \mathrm{~Hz})^{36}$.

\section{Skin heating response}

Local heat induces skin hyperemia and increases the skin blood flow. This heat-induced skin response is mainly dependent on nitric oxide and endothelium-derived hyperpolarizing factors 
37. To quantify this response, skin blood flow is measured by means of a laser Doppler system (PeriFlux 5000) as described above (Figure 2.1C, upper left panel). Two thermostatic probes are attached to the wrist and ankle to induce local heating. Skin blood flow is first recorded unheated for 2 minutes to serve as a baseline measure. Next, the temperature of the probe is rapidly and locally increased to $44^{\circ} \mathrm{C}$ and is then kept constant for the next 23 minutes (Figure 2.1C, lower panel). The heat-induced skin hyperemic response is expressed as the percentage increase in average perfusion units during the 23-minute heating phase over the average baseline perfusion units.

\section{MRI markers of cerebral small-vessel disease}

Brain MVD is reflected by MRI features of cerebral small-vessel disease, including white matter hyperintensities (WMHs), lacunar infarcts, and cerebral microbleeds. In The Maastricht Study, MRI is performed on a 3T MRI scanner (Siemens Magnetom Prisma-Fit Syngo MR D13D; Siemens AG, Erlangen, Germany) using a 64-element head coil for parallel imaging (Figure 2.1D). The MRI protocol consists of a 3-dimensional T1-weighted sequence (repetition time [TR]/echo time [TE]/inversion time [TI] 2,300 ms/2.98 ms/900 ms, 1.00-mm cubic voxel, 176 continuous slices, matrix size of $240 \times 250$, and reconstructed matrix size of $512 \times 512$ ), a T2-weighted fluid-attenuated inversion recovery (TR/TE/TI 5,000 ms/394 ms/1,800 ms, $0.98 \times$ $0.98 \times 1.26-\mathrm{mm}$ acquisition voxel, $0.49 \times 0.49 \times 1.00-\mathrm{mm}$ reconstructed voxel, 176 continuous slices, acquisition matrix size of $250 \times 250$, and reconstructed matrix size of $512 \times 512$ ), and a gradient recalled echo pulse sequence with susceptibility-weighted imaging. The protocols for MRI acquisition and analysis are in line with current imaging standards (STandards for ReportIng Vascular changes on nEuroimaging [STRIVE], version 2) ${ }^{19}$.

T1-weighted images and T2-weighted fluid-attenuated inversion recovery images are used to identify WMHs by use of an International Organization for Standardization (ISO)-13485 2012-certified automated method (which includes visual inspection) ${ }^{38}$. Numbers of all WMHs identified are summed for assessment of total WMH burden in milliliters. Periventricular WMHs are automatically defined as WMHs less than $3 \mathrm{~mm}$ from the cerebrospinal fluid and deep cortical WMHs as WMHs 3 or more mm from the cerebrospinal fluid ${ }^{39}$. This method has a small chance of misclassifying juxtacortical WMHs, which are relatively uncommon ${ }^{40}$, as periventricular WMHs. The location and number of lacunar infarcts are manually rated on T2 and fluid-attenuated inversion recovery images and defined as focal lesions of $\geqslant 3 \mathrm{~mm}$ and $<15 \mathrm{~mm}$ in size with a similar signal intensity as cerebrospinal fluid on all sequences and a hyperintense rim $^{19}$. The location and number of cerebral microbleeds are manually rated on 
3-dimensional $\mathrm{T} 2 *$ gradient recalled echo-weighted imaging with susceptibility-weighted imaging by means of the Microbleed Anatomical Rating Scale ${ }^{41}$ and defined as focal lesions of $\geqslant 2 \mathrm{~mm}$ and $\leqslant 10 \mathrm{~mm}$ in size with a hypointense signal on T2* gradient recalled echo- and susceptibility-weighted images ${ }^{19}$. Three neuroradiologists perform the rating of lacunar infarcts and cerebral microbleeds.

\section{Endothelial glycocalyx thickness}

The glycocalyx is a gel layer on the luminal side of endothelial cells which prevents blood cells from penetrating or adhering to the vessel wall. Impaired glycocalyx function would allow more red blood cells (RBCs) to penetrate deeper towards the endothelial surface, which may influence endothelial function ${ }^{42}$. We use the Glycocheck system (Microvascular Health Solutions, Inc., Salt Lake City, Utah) to measure glycocalyx thickness in the sublingual microcirculation (Figure 2.1E). After calibration, the lens is placed against the lingual frenum near the tongue base with limited pressure. The sidestream dark field camera uses green light-emitting diodes $(540 \mathrm{~nm})$ to detect the hemoglobin of passing RBCs. All measurable vessels are identified, recorded, and analyzed automatically. Vessels with RBC columns larger than $30 \mu \mathrm{m}$ in diameter or high tortuosity are excluded.

The results of analyses are presented as the perfused boundary region $(\mu \mathrm{m})$, which is calculated as the distance between the outer boundaries of the erythrocytes and the center lumen of the vessel ((perfused diameter-median RBC column width)/2) ${ }^{20}$. It reflects the dynamic lateral position of RBCs. Then the calculated perfused boundary region values, classified according to their corresponding RBC column widths between $5 \mu \mathrm{m}$ and $25 \mu \mathrm{m}$, are averaged to provide a single perfused boundary region value for each participant.

\section{Plasma and urine biomarkers}

Since microvascular endothelium covers approximately $98 \%$ of the total vascular surface area and synthetic capacity ${ }^{21}$, plasma or serum biomarkers of endothelial function, such as soluble vascular cell adhesion molecule-1, soluble intercellular adhesion molecule-1, soluble E-selectin, and von Willebrand factor, can be regarded as reflecting mainly microvascular endothelial function. Among these, soluble vascular cell adhesion molecule-1, soluble intercellular adhesion molecule-1, and soluble E-selectin are measured in ethylenediaminetetraacetic acid plasma samples with commercially available 4-plex sandwich immunoassay kits (Meso Scale Discovery, Rockville, Maryland) as described previously ${ }^{43}$. Von Willebrand factor is quantified in citrate plasma using an enzyme-linked immunosorbent assay (Dako Denmark A/S, Glostrup, 
Denmark). Concentrations of von Willebrand factor are expressed as a percentage of von Willebrand factor detected in pooled citrated plasma of healthy volunteers (Figure 2.1F).

Albuminuria can be regarded as a marker of generalized endothelial dysfunction ${ }^{3}$. To assess urinary albumin excretion, participants are requested to collect two 24-hour urine samples (Figure 2.1G). Urinary albumin concentration is measured with a standard immunoturbidimetric assay by means of an automatic analyzer (Beckman Synchron LX20; Beckman Coulter, Inc., Brea, California) and multiplied by collection volume to obtain 24-hour urinary albumin excretion. A urinary albumin concentration below the detection limit of the assay (2mg/L) is set at $1.5 \mathrm{mg} / \mathrm{L}$ before multiplying by collection volume. Only urine collections with a collection time between 20 hours and 28 hours are considered valid. If needed, urinary albumin excretion is extrapolated to a 24 -hour excretion. Microalbuminuria is defined as a 24-hour albumin excretion of $30-300 \mathrm{mg} / 24$ hours, and macroalbuminuria is defined as a 24-hour albumin excretion greater than $300 \mathrm{mg} / 24$ hours. These definitions are preferably based on the average of two 24-hour urine collections (available for approximately $90 \%$ of the participants).

\section{Validation of measurements}

Validation of measurements is described in the Supplemental Material. 


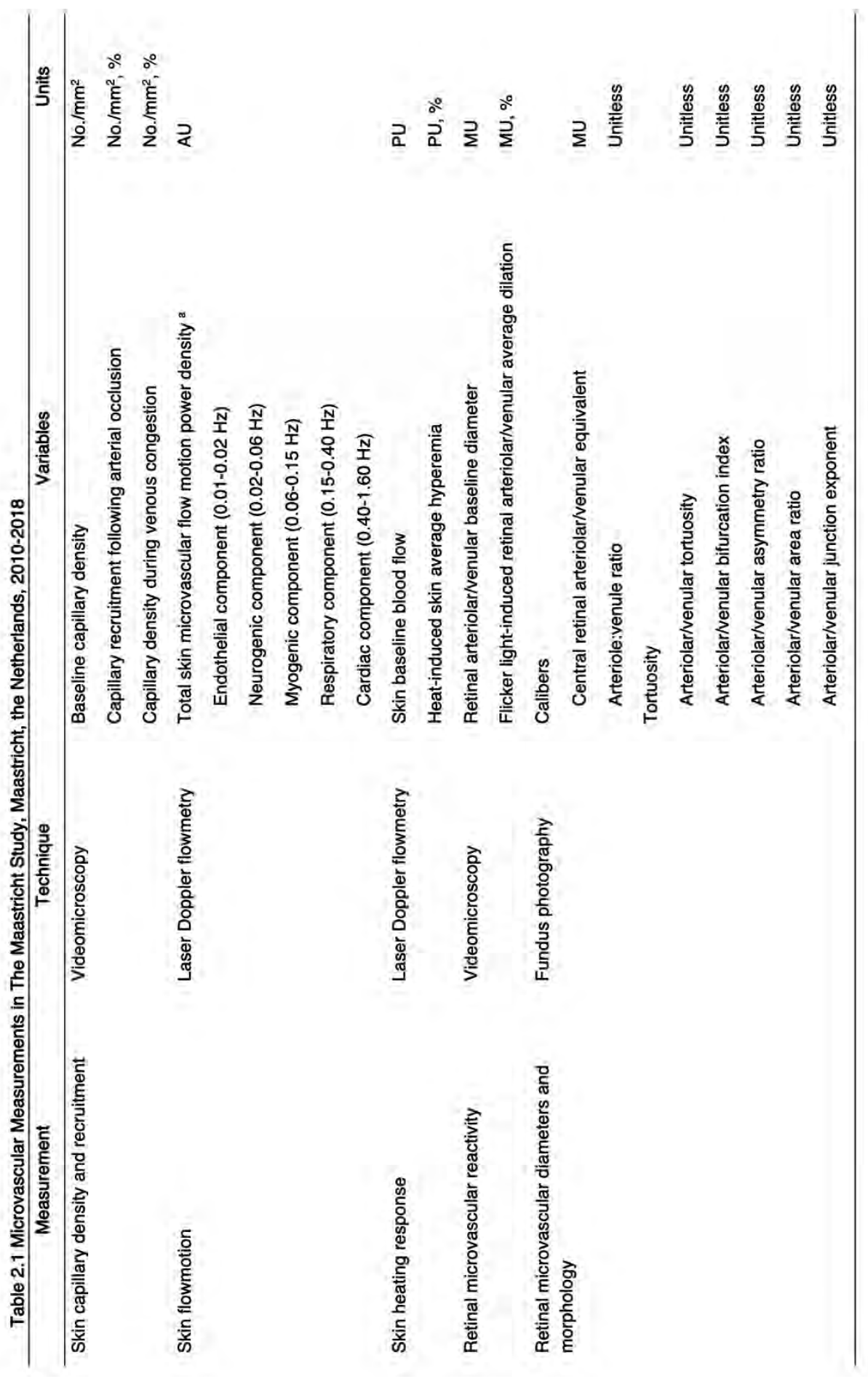




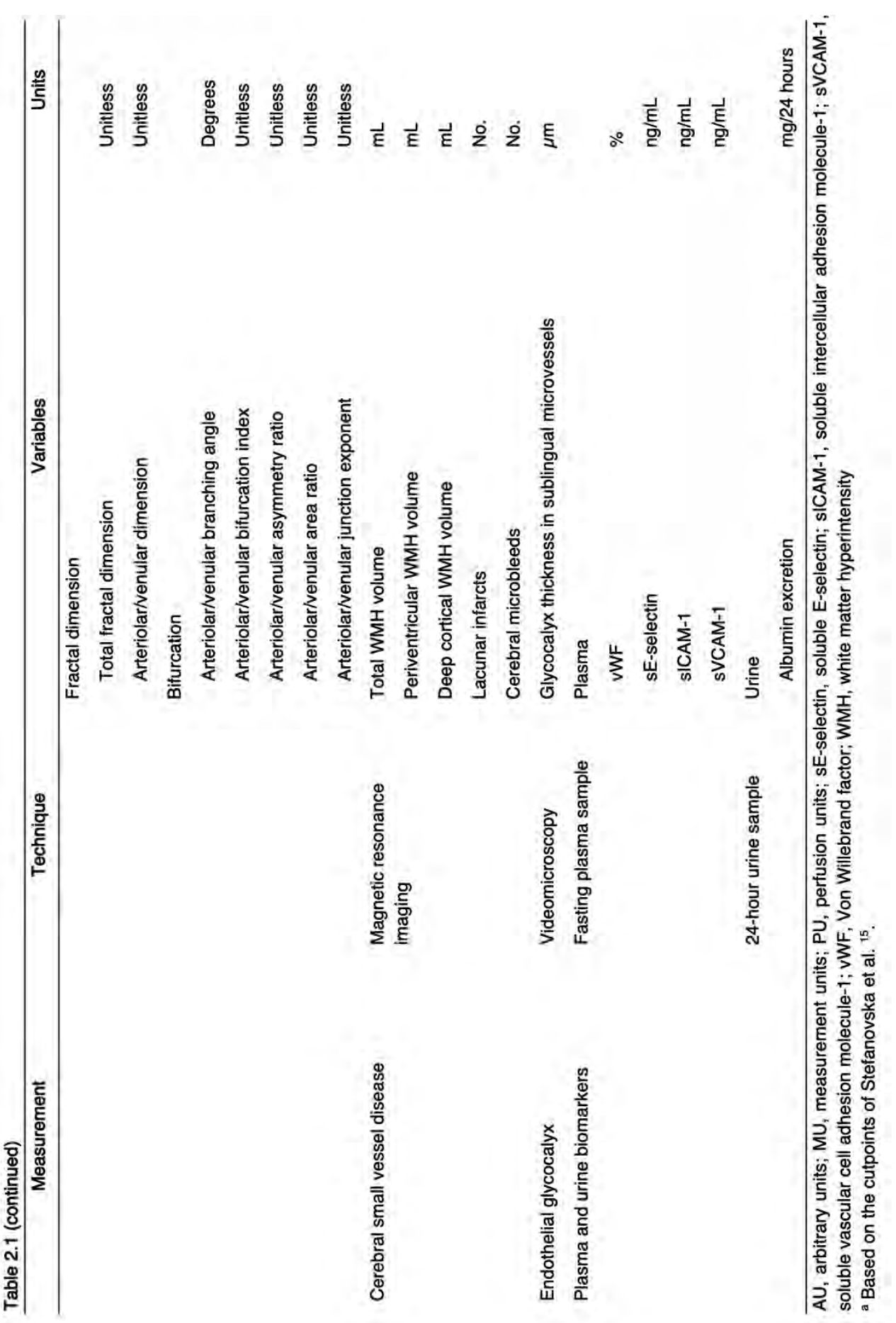




\section{Results}

Currently, we have carried out a number of cross-sectional investigations involving microvascular measurements within the framework of The Maastricht Study and have found that multiple cardiovascular risk factors (age, sex, blood pressure, waist circumference, etc.) and diseases (e.g., (pre)diabetes and depression) are associated with microvascular (dys)function. The findings are summarized in Tables 2.2 and 2.3.

\section{Cardiovascular risk factors and microvascular function}

MVD may be a common pathological phenomenon in cardiovascular diseases that is induced by multiple risk factors. In a preliminary study with a limited number of participants, we used skin flowmotion measurement and found that older age and higher 24-hour systolic blood pressure were associated with a higher total SMF energy, while greater waist circumference and body mass index (weight $(\mathrm{kg}) /$ height $(\mathrm{m})^{2}$ ) were associated with a lower total SMF energy 44 . Further analysis of the 5 frequency components revealed associations of older age with higher energy contributions of the respiratory and cardiac components and of higher 24-hour systolic blood pressure with higher energy contributions of all 5 frequency components, as well as associations of greater waist circumference with lower energy contributions of all of the frequency components ${ }^{44}$.

Evaluating microvascular responses in skin and retina, we observed that older age and higher plasma glucose level were associated with both lower heat-induced skin hyperemia and lower flicker light-induced retinal arteriolar dilation ${ }^{45,46}$. In addition, lower heat-induced skin hyperemia was found in men and in current smokers ${ }^{45}$. Interestingly, we did not find any association of 24-hour systolic blood pressure with microvascular responses in skin or retina. Instead, higher 24-hour pulse pressure was associated with lower heat-induced skin hyperemia, and higher 24-hour diastolic blood pressure was associated with increased flicker light-induced retinal arteriolar dilation ${ }^{45}$. Higher plasma glucose level was associated with the presence of brain lacunar infarcts and larger volumes of WMHs, including deep cortical and periventricular WMHs, but not with the presence of cerebral microbleeds ${ }^{47}$.

In addition, arterial stiffening as determined by carotid-femoral pulse wave velocity was not associated with skin capillary density or recruitment, skin flowmotion, or heat-induced skin hyperemia, as demonstrated in analyses carried out in both The Maastricht Study and Supplementation en Vitamines et Mineraux Antioxydants 2 (SU.VI.MAX2) Study cohorts ${ }^{48}$. 


\section{Chronic diseases and microvascular function}

The "ticking clock" hypothesis postulates that the clock for coronary heart disease development starts ticking before the onset of clinical diabetes ${ }^{49}$. Similarly, T2DM-associated MVD may occur long before T2DM is diagnosed. In view of this, we studied the association between glucose metabolism status and MVD. We found that both impaired flicker light-induced retinal arteriolar dilation and heat-induced skin hyperemia have already occurred in prediabetes (defined as impaired fasting glucose concentration and/or impaired glucose tolerance), and both impairments were more severe in established T2DM ${ }^{46}$. Prediabetes and T2DM were also associated with markers of cerebral small-vessel disease, including the presence of lacunar infarcts, and larger volumes of WMHs, as compared with normal glucose metabolism ${ }^{47}$. In contrast, there were no significant associations of prediabetes and T2DM with the presence of cerebral microbleeds ${ }^{47}$. To explore the underlying mechanism of (pre)diabetes-associated MVD, we further performed mediation analysis and found that, among hyperglycemia, insulin resistance, blood pressure, lipid profile, and low-grade inflammation, hyperglycemia was the main mediator of both the prediabetes-associated and T2DM-associated skin and retinal MVD, with a mediation effect of approximately $50 \%-75 \%{ }^{50}$.

Depression and cognitive decline are thought to be partly related to MVD ${ }^{51}$. In a recent meta-analysis, we provided evidence that not only cerebral forms of MVD but also peripheral MVD, as measured by plasma biomarkers, is associated with incident depression ${ }^{6}$. In The Maastricht Study, we also found higher levels of plasma markers of endothelial dysfunction to be associated with the presence of depressive disorder and a higher depressive symptom score ${ }^{43}$. With regard to cognitive function, albuminuria, defined as urinary albumin excretion $\geqslant$ $30 \mathrm{mg} / 24$ hours, was associated with lower information processing speed, independent of educational level, cardiovascular risk factors, and lifestyle factors ${ }^{52}$. This association tended to be stronger in older individuals ${ }^{52}$.

Albuminuria, normally considered a measure of kidney dysfunction, is also thought to reflect generalized endothelial dysfunction. However, this hypothesis has been tested only with indirect measurements, such as plasma biomarkers of endothelial function ${ }^{53,54}$. 


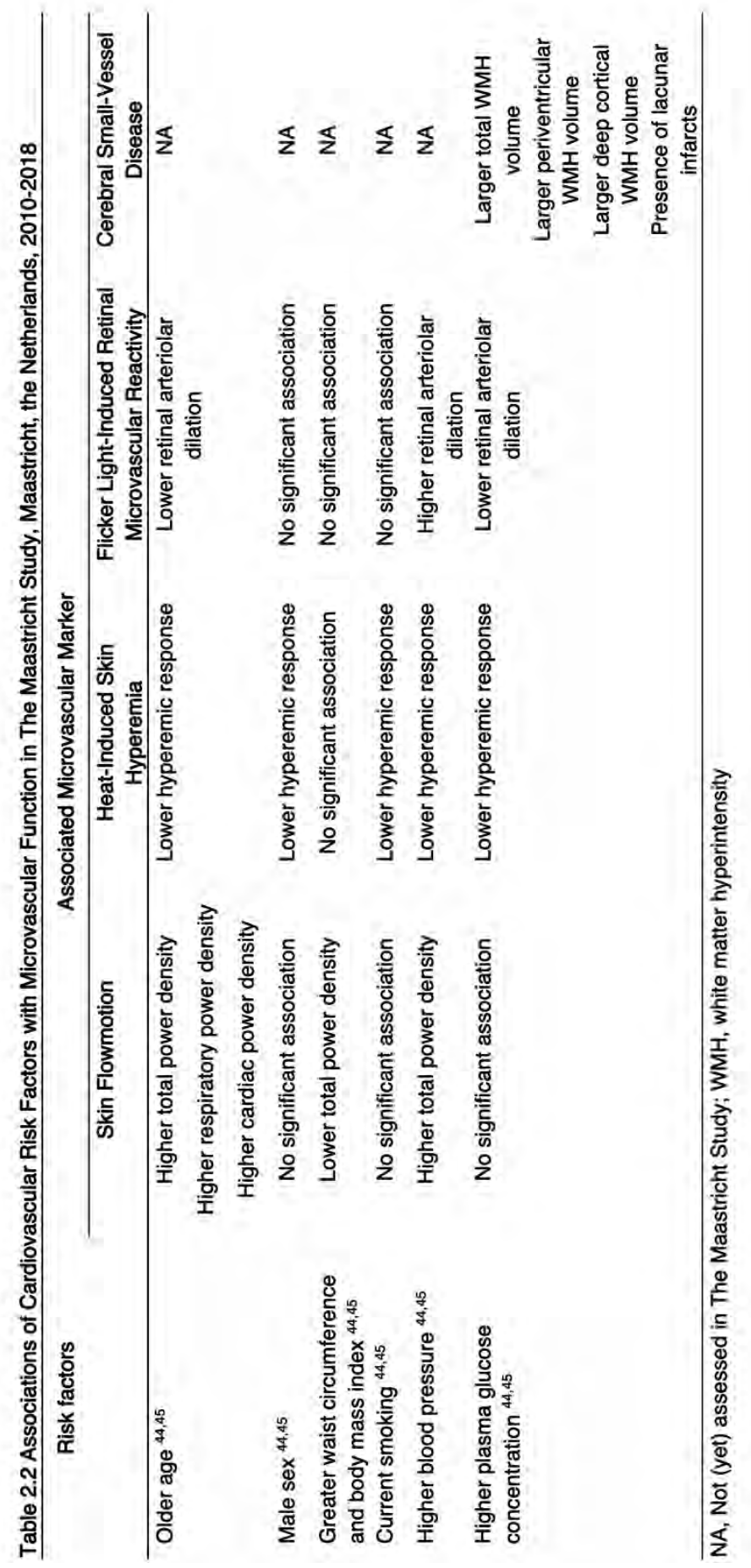


Therefore, we examined the association of direct measurements of MVD in skin and retina with albuminuria. We found that lower skin capillary recruitment following arterial and venous occlusion was associated with the presence of albuminuria ${ }^{55}$. Lower flicker light-induced retinal arteriolar dilation was also associated with albuminuria, and this association was stronger in persons with T2DM. In addition, the association of lower heat-induced skin hyperemic response with albuminuria was present in persons with T2DM only ${ }^{56}$. These findings suggested an interaction effect of T2DM on the association between direct measurements of MVD and albuminuria.

\section{Discussion}

For the development of both prevention and treatment strategies in the general population, we need solid epidemiologic data. To our knowledge, no population-based study has applied a wide scope of microvascular morphological and functional phenotyping. Most studies have applied, at most, a few of the microvascular measurements discussed here, including plasma biomarkers, retinal microvascular diameters, and cerebral small-vessel disease ${ }^{2,6}$. In The Maastricht Study ${ }^{22}$, we combine an array of microvascular measurements in different vascular beds (e.g., low and high flow impedance) with extensive phenotyping of biometric factors, lifestyle and cardiovascular risk factors, and diseases. This approach allows us to study not only the role of generalized MVD in the development and progression of various diseases with a systems physiology approach but also MVD, which is specific for certain organs/tissues.

In The Maastricht Study, we have observed associations of MVD with cardiovascular risk factors, (pre)diabetes, depression, cognitive function, and albuminuria. These results suggest that 1) microvascular function is determined by multiple cardiovascular risk factors ${ }^{44-47}$, 2) MVD occurs prior to the diagnosis of T2DM 46, 47,3) MVD is a systemic pathophysiological phenomenon in T2DM, and 4) MVD is associated with (end)organ dysfunction (e.g., depression, cognitive decline, albuminuria) ${ }^{43,52,55,56 .}$

\section{Strengths of the Maastricht Study}

The combination of an array of microvascular measurements and the extensive phenotyping in The Maastricht Study has several strengths. First, the size of the study population in conjunction with the extensive phenotyping enables detection of independent associations after extensive adjustment for potential confounders. Second, the standard operating procedures and the quality control over time enhance the consistency of the microvascular 


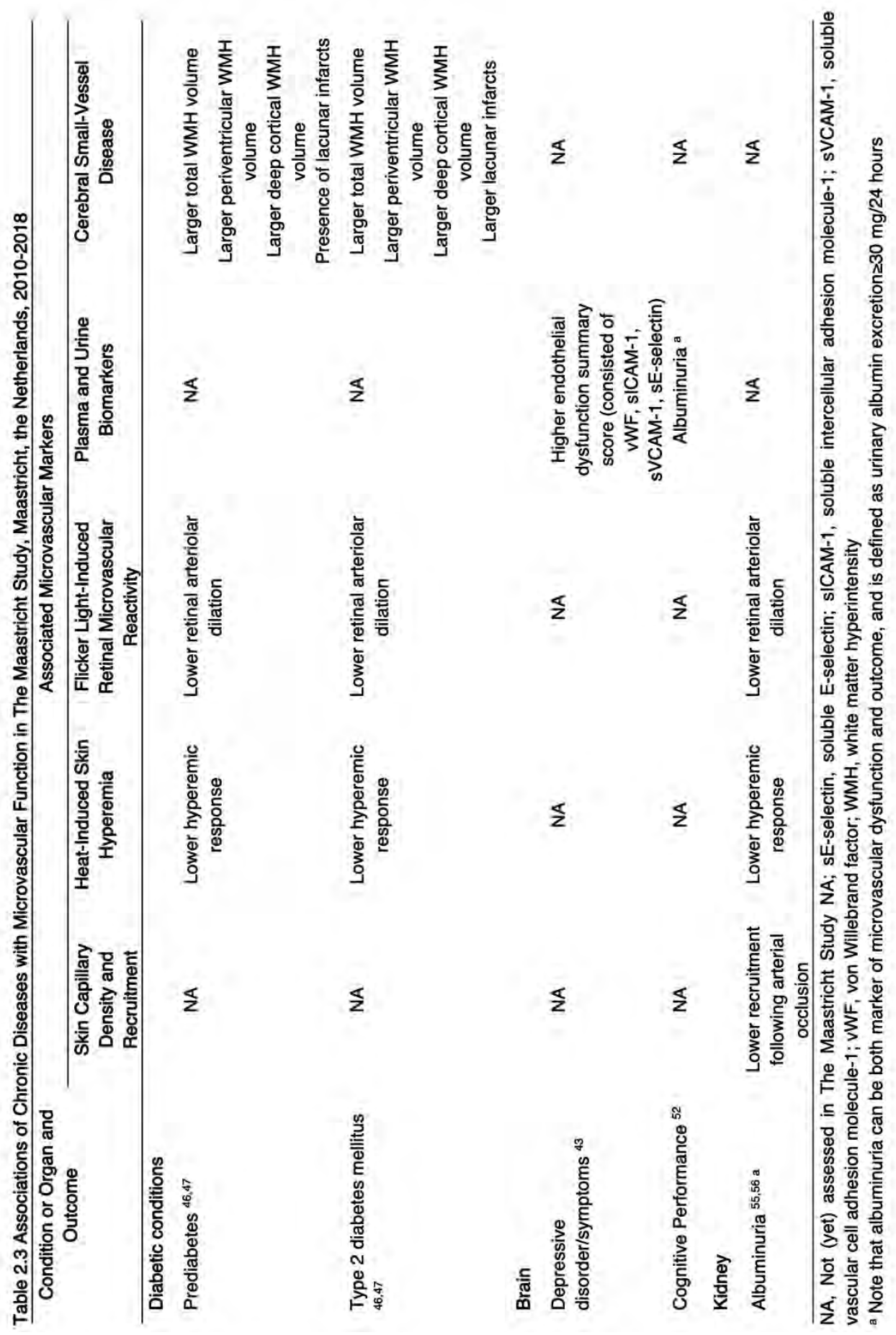


measurements and increase their usability in other studies. Third, the use of multiple microvascular measurements enables comparison of changes in the microvasculature across arterioles, capillaries, and venules, as well as across territories, in order to disentangle the influence of risk factors/diseases on the microvasculature as well as the heterogeneity of the microvasculature responding to different (patho)physiological situations ${ }^{57}$.

\section{Longitudinal studies}

Currently, annual follow-up on disease incidence and mortality is being performed in The Maastricht Study, which will enable longitudinal analyses. Through the cross-sectional studies, we have already found that MVD in multiple territories is present before the diagnosis of T2DM (prediabetes), which implies that MVD is not only a consequence of T2DM but also an essential factor that can precede T2DM and increase the risk of its complications and comorbidities, which are partly of microvascular origin. To confirm this, longitudinal studies are planned to investigate the association of MVD with the incidence of various diseases, such as T2DM, cardiovascular diseases, and cerebral diseases. In addition, microvascular measurements will be included in the follow-up procedure to investigate the microvascular changes with development and progression of diseases.

\section{Fully automated analysis of microvascular imaging}

Several microvascular measurements are based on imaging, of which the analyses are often performed manually. To apply such measurements efficiently in a population-based setting requires fully automated analysis software. Recent technical advances have enabled a transition from manual/semi-automated image analysis to fully automated image analysis and have made this approach more precise and time-saving (e.g., the software for detecting brain WMHs in The Maastricht Study) ${ }^{38}$. In addition, this approach allows identification, extraction, and investigation of novel microvascular features, such as retinal microvascular tortuosity, fractal dimension, and bifurcation features. These developments provide for a more comprehensive observation of microvascular changes as well as better availability and implementation of the microvascular measurements in a large population, for either research or clinical use. Further, the protocols involving image acquisition, processing, and analysis should be standardized across studies, and reproducibility and validity should be carefully documented, for use by other researchers and further applications.

The first wave of data collection in The Maastricht Study (including more than 9,000 participants) continued through 2019. Next, we plan to start follow-up surveys in the same 
cohort. In the coming years, we will develop, validate, and implement fully automated image analysis applications. In that way, a wealth of different microvascular morphological and functional markers of different territories will become available. It is important to assess the associations and role of MVD in relation to disease development in order to assess whether interventions against MVD should be developed for prevention purposes. 


\section{References}

1. Houben A, Martens RJH, Stehouwer CDA. Assessing Microvascular Function in Humans from a Chronic Disease Perspective. J Am Soc Nephrol. 2017;28(12):3461-3472.

2. Muris DM, Houben AJ, Schram MT, Stehouwer CD. Microvascular dysfunction is associated with a higher incidence of type 2 diabetes mellitus: a systematic review and meta-analysis. Arterioscler Thromb Vasc Biol. 2012;32(12):3082-3094.

3. Stehouwer CD. Microvascular Dysfunction and Hyperglycemia: A Vicious Cycle With Widespread Consequences. Diabetes. 2018;67(9):1729-1741.

4. Lee JF, Barrett-O'Keefe Z, Garten RS, Nelson AD, Ryan JJ, Nativi JN, et al. Evidence of microvascular dysfunction in heart failure with preserved ejection fraction. Heart. 2016;102(4):278-284.

5. Stehouwer CD, Smulders YM. Microalbuminuria and risk for cardiovascular disease: Analysis of potential mechanisms. J Am Soc Nephrol. 2006;17(8):2106-2111.

6. van Agtmaal MJM, Houben A, Pouwer F, Stehouwer CDA, Schram MT. Association of Microvascular Dysfunction With Late-Life Depression: A Systematic Review and Meta-analysis. JAMA Psychiatry. 2017;74(7):729-739.

7. Danese S, Dejana E, Fiocchi C. Immune regulation by microvascular endothelial cells: directing innate and adaptive immunity, coagulation, and inflammation. J Immunol. 2007;178(10):6017-6022.

8. Drachman DA, Smith TW, Alkamachi B, Kane K. Microvascular changes in Down syndrome with Alzheimer's-type pathology: Insights into a potential vascular mechanism for Down syndrome and Alzheimer's disease. Alzheimers Dement. 2017;13(12):1389-1396.

9. De Boer MP, Meijer RI, Wijnstok NJ, Jonk AM, Houben AJ, Stehouwer CD, et al. Microvascular dysfunction: a potential mechanism in the pathogenesis of obesity-associated insulin resistance and hypertension. Microcirculation. 2012;19(1):5-18.

10. Houben AJ, Eringa EC, Jonk AM, Serne EH, Smulders YM, Stehouwer CD. Perivascular Fat and the Microcirculation: Relevance to Insulin Resistance, Diabetes, and Cardiovascular Disease. Curr Cardiovasc Risk Rep. 2012;6(1):80-90.

11. Levy BI, Ambrosio G, Pries AR, Struijker-Boudier HA. Microcirculation in hypertension: a new target for treatment? Circulation. 2001;104(6):735-740.

12. Aird WC. Phenotypic heterogeneity of the endothelium: I. Structure, function, and mechanisms. Circ Res. 2007;100(2):158-173.

13. Gronenschild EH, Muris DM, Schram MT, Karaca U, Stehouwer CD, Houben AJ. Semi-automatic assessment of skin capillary density: proof of principle and validation. Microvasc Res. 2013;90:192-198.

14. Kvandal P, Landsverk SA, Bernjak A, Stefanovska A, Kvernmo HD, Kirkeboen KA. Low-frequency oscillations of the laser Doppler perfusion signal in human skin. Microvasc Res. 2006;72(3):120-127.

15. Stefanovska A, Bracic M, Kvernmo HD. Wavelet analysis of oscillations in the peripheral blood circulation measured by laser Doppler technique. IEEE Trans Biomed Eng. 1999;46(10):1230-1239.

16. Nagel E, Vilser W. Flicker observation light induces diameter response in retinal arterioles: a clinical methodological study. Br J Ophthalmol. 2004;88(1):54-56.

17. Romeny BMT, Bekkers EJ, Zhang J, Abbasi-Sureshjani S, Huang F, Duits R, et al. Brain-inspired algorithms for retinal image analysis. Mach Vision Appl. 2016;27(8):1117-1135.

18. Bekkers E, Duits R, Berendschot T, Romeny BT. A Multi-Orientation Analysis Approach to Retinal Vessel Tracking. J Math Imaging Vis. 2014;49(3):583-610.

19. Wardlaw JM, Smith EE, Biessels GJ, Cordonnier C, Fazekas F, Frayne R, et al. Neuroimaging standards for research into small vessel disease and its contribution to ageing and neurodegeration. Lancet Neurol. 2013;12(8):822-838.

20. Nieuwdorp M, Meuwese MC, Mooij HL, Ince C, Broekhuizen LN, Kastelein JJ, et al. Measuring endothelial glycocalyx dimensions in humans: a potential novel tool to monitor vascular vulnerability. J Appl Physiol (1985). 2008;104(3):845-852.

21. Schram MT, Stehouwer CD. Endothelial dysfunction, cellular adhesion molecules and the metabolic syndrome. Horm Metab Res. 2005;37 Suppl 1:49-55. 
22. Schram MT, Sep SJ, van der Kallen CJ, Dagnelie PC, Koster A, Schaper N, et al. The Maastricht Study: an extensive phenotyping study on determinants of type 2 diabetes, its complications and its comorbidities. Eur J Epidemiol. 2014;29(6):439-451.

23. Dorner GT, Garhofer G, Kiss B, Polska E, Polak K, Riva CE, Schmetterer L. Nitric oxide regulates retinal vascular tone in humans. Am J Physiol Heart Circ Physiol. 2003;285(2):H631-636.

24. Garhofer G, Bek T, Boehm AG, Gherghel D, Grunwald J, Jeppesen P, et al. Use of the retinal vessel analyzer in ocular blood flow research. Acta Ophthalmol. 2010;88(7):717-722.

25. Nagel E, Vilser W, Lanzl I. Age, blood pressure, and vessel diameter as factors influencing the arterial retinal flicker response. Invest Ophthalmol Vis Sci. 2004;45(5):1486-1492.

26. Kotliar KE, LanzI IM, Schmidt-Trucksäss A, Sitnikova D, Ali M, Blume K, et al. Dynamic retinal vessel response to flicker in obesity: A methodological approach. Microvasc Res. 2011;81(1):123-128.

27. Nagel E, Vilser W, Fink A, Riemer T. [Variance of retinal vessel diameter response to flicker light. A methodical clinical study]. Varianz der Netzhautgefassreaktion auf Flickerlicht. Eine klinisch-methodische Studie. Ophthalmologe. 2006;103(2):114-119.

28. Williams TD, Wilkinson JM. Position of the fovea centralis with respect to the optic nerve head. Optom Vis Sci. 1992;69(5):369-377.

29. Knudtson MD, Lee KE, Hubbard LD, Wong TY, Klein R, Klein BE. Revised formulas for summarizing retinal vessel diameters. Curr Eye Res. 2003;27(3):143-149.

30. Bekkers EJ, Zhang J, Duits R, ter Haar Romeny BM. Curvature based biomarkers for diabetic retinopathy via exponential curve fits in SE (2). In: Chen X, Garvin MK, Liu JJ, et al., eds. Proceedings of the Ophthalmic Medical Image Analysis Second International Workshop, OMIA 2015, Held in Conjunction with MICCAI 2015, Munich, Germany, October 9, 2015. lowa City, IA: University of lowa; 2016:113-120.

31. Masters BR. Fractal analysis of the vascular tree in the human retina. Annu Rev Biomed Eng. 2004;6:427-452.

32. Al-Diri B, Hunter A, Steel D, Habib M. Manual measurement of retinal bifurcation features. Conf Proc IEEE Eng Med Biol Soc. 2010;2010:4760-4764.

33. Hellmann M, Roustit M, Cracowski JL. Skin microvascular endothelial function as a biomarker in cardiovascular diseases?. Pharmacol Rep. 2015;67(4):803-810.

34. Thorn CE, Kyte H, Slaff DW, Shore AC. An association between vasomotion and oxygen extraction. Am J Physiol Heart C. 2011;301(2):H442-H449.

35. Braverman IM, Schechner JS, Silverman DG, Keh-Yen A. Topographic mapping of the cutaneous microcirculation using two outputs of laser-Doppler flowmetry: flux and the concentration of moving blood cells. Microvasc Res. 1992;44(1):33-48.

36. Graaff R, Morales F, Smit AJ, de Jong ED, de Mul FFM, Rakhorst G. Normalization of vasomotion in laser Doppler perfusion monitoring. Conf Proc IEEE Eng Med Biol Soc. 2007;2007:4076-4079.

37. Choi PJ, Brunt VE, Fujii N, Minson CT. New approach to measure cutaneous microvascular function: an improved test of NO-mediated vasodilation by thermal hyperemia. J Appl Physiol (1985). 2014;117(3):277-283.

38. De Boer R, Vrooman HA, Van Der Lijn F, Vernooij MW, Ikram MA, Van Der Lugt A, et al. White matter lesion extension to automatic brain tissue segmentation on MRI. Neuroimage. 2009;45(4):1151-1161.

39. Kim KW, MacFall JR, Payne ME. Classification of white matter lesions on magnetic resonance imaging in elderly persons. Biol Psychiatry. 2008;64(4):273-280.

40. Decarli C, Fletcher E, Ramey V, Harvey D, Jagust WJ. Anatomical mapping of white matter hyperintensities (wmh) exploring the relationships between periventricular $\mathrm{WMH}$, deep $\mathrm{WMH}$, and total $\mathrm{WMH}$ burden.Stroke. 2005;36(1):50-55.

41. Gregoire SM, Chaudhary UJ, Brown MM, Yousry TA, Kallis C, Jäger HR, Werring DJ. The microbleed anatomical rating scale (MARS) reliability of a tool to map brain microbleeds. Neurology. 2009;73(21):1759-1766.

42. Lee DH, Dane MJC, van den Berg BM, Boels MG, Van Teeffelen JW, De Mutsert R, et al. Deeper penetration of erythrocytes into the endothelial glycocalyx is associated with impaired microvascular perfusion. PLoS One. 2014;9(5):e96477.

43. van Dooren FEP, Schram MT, Schalkwijk CG, Stehouwer CD, Henry RM, Dagnelie PC, et al. Associations of low grade inflammation and endothelial dysfunction with depression-The Maastricht Study. Brain Behav Immun. 2016;56:390-396. 
44. Muris DM, Houben AJ, Kroon AA, Henry RM., van der Kallen CJ, Sep SJ, et al. Age, waist circumference, and blood pressure are associated with skin microvascular flow motion: the Maastricht Study. J Hypertens. 2014;32(12):2439-2449.

45. Sörensen BM, Houben AJHM, Berendschot TTJM, Schouten JS, Kroon AA, van der Kallen CJ, et al. Cardiovascular risk factors as determinants of retinal and skin microvascular function: The Maastricht Study. PLoS One. 2017;12(10):e0187324.

46. Sörensen BM, Houben AJHM, Berendschot TTJM, Schouten JS, Kroon AA, van der Kallen CJ, et al. Prediabetes and Type 2 Diabetes Are Associated With Generalized Microvascular Dysfunction: The Maastricht Study. Circulation. 2016;134(18):1339-1352.

47. van Agtmaal MJ, Houben AJHM, de Wit V, Henry RM, Schaper NC, Dagnelie PC, et al. Prediabetes Is Associated With Structural Brain Abnormalities: The Maastricht Study. Diabetes care. 2018;41(12):2535-2543.

48. van Sloten TT, Czernichow S, Houben AJ, Protogerou AD, Henry RM, Muris DM, et al. Association Between Arterial Stiffness and Skin Microvascular Function: The SUVIMAX2 Study and The Maastricht Study. Am J Hypertens. 2015;28(7):868-876.

49. Wong MS, Gu K, Heng D, Chew SK, Chew LS, Tai ES. The Singapore impaired glucose tolerance follow-up study: does the ticking clock go backward as well as forward?. Diabetes Care. 2003;26(11):3024-3030.

50. Sörensen BM, Houben AJHM, Berendschot TTJM, Schouten JS, Kroon AA, van der Kallen CJ, et al. Hyperglycemia Is the Main Mediator of Prediabetes- and Type 2 Diabetes-Associated Impairment of Microvascular Function: The Maastricht Study. Diabetes Care. 2017;40(8):e103-105.

51. Taylor WD, Aizenstein HJ, Alexopoulos GS. The vascular depression hypothesis: mechanisms linking vascular disease with depression. Mol Psychiatry.2013;18(9):963.

52. Martens RJ, Kooman JP, Stehouwer CD, Dagnelie PC, van der Kallen CJ, Koster A, et al. Estimated GFR, Albuminuria, and Cognitive Performance: The Maastricht Study. Am J Kidney Dis. 2017;69(2):179-191.

53. Persson F, Rossing P, Hovind P, Stehouwer CD, Schalkwijk CG, Tarnow L, Parving HH. Endothelial dysfunction and inflammation predict development of diabetic nephropathy in the Irbesartan in Patients with Type 2 Diabetes and Microalbuminuria (IRMA 2) study. Scand J Clin Lab Invest. 2008;68(8):731-738.

54. Stehouwer CDA, Gall MA, Twisk JW, Knudsen E, Emeis JJ, Parving HH. Increased urinary albumin excretion, endothelial dysfunction, and chronic low-grade inflammation in type 2 diabetes: progressive, interrelated, and independently associated with risk of death. Diabetes. 2002;51(4):1157-1165.

55. Martens RJ, Henry RM, Houben AJ, van der Kallen CJ, Kroon AA, Schalkwijk CG, et al. Capillary Rarefaction Associates with Albuminuria: The Maastricht Study. J Am Soc Nephrol. 2016;27(12):3748-3757.

56. Martens RJ, Houben AJ, Kooman JP, Berendschot TT, Dagnelie PC, van der Kallen CJ, et al. Microvascular endothelial dysfunction is associated with albuminuria: the Maastricht Study. J Hypertens. 2018;36(5):1178-1187.

57. Aird WC. Phenotypic heterogeneity of the endothelium: II. Representative vascular beds. Circ Res. 2007;100(2):174-190. 


\section{Supplemental Material to Chapter 2}

\section{Study population and design}

The microvascular studies are conducted within the framework of The Maastricht Study, an ongoing observational prospective population-based cohort study. The rationale and methodology have been described previously ${ }^{1}$. In brief, the study focuses on the etiology, pathophysiology, complications and comorbidities of type 2 diabetes mellitus (T2DM) and is characterized by an extensive phenotyping approach. Eligible for participation are all individuals aged between 40 and 75 years and living in the southern part of the Netherlands. The baseline assessment started in November 2010 and is currently ongoing. An annual follow-up on disease incidence and mortality is in progress. The study has been approved by the institutional medical ethical committee (NL31329.068.10) and the Netherlands Health Council under the Dutch “Law for Population Studies" (permit 131088-105234-PG). All participants give written informed consent.

\section{Data collection}

All measurements are executed by trained research assistants according to standardized protocols. In principle, all procedures apply to all participants included, unless clinically contraindicated. Participants are studied while on medication. All participants are asked to refrain from smoking and drinking caffeine-containing beverages 3 hours before the measurement. A light meal (breakfast or lunch), low in fat content, is allowed at least 90 minutes before the start of the measurements. Room temperature is kept at $24^{\circ} \mathrm{C}$. General and disease-specific measurements have been illustrated elsewhere ${ }^{1}$.

\section{Validation of the microvascular measurements}

For the quantification of skin capillary density and recruitment, a semi-automatic image analysis application (CapiAna) has been developed. Analyses with CapiAna have a good consistency with the manual counting procedure, with a Pearson's correlation coefficient $(r)$ of 0.95 $(p<0.001)$ and a Deming regression coefficient of 1.01 (95\% confidence interval $(\mathrm{Cl}): 0.91,1.10)$

2. Overall intra- and interobserver coefficients of variation for CapiAna were $2.5 \%$ and $5.6 \%$, respectively ${ }^{2}$. For the heat-induced skin hyperemic response, the interobserver correlation coefficient of the hyperemic curves $(n=1,760)$ between two observers was $0.839^{3}$. For retinal microvascular reactivity, interobserver correlation coefficient of retinal arteriolar baseline 
diameter, venular baseline diameter, percentage arteriolar dilation, and percentage venular dilation $(n=9)$ between two randomly selected observers were $0.980,0.972,0.796$, and 0.871 , respectively. For retinal microvascular diameters, the intraclass correlation coefficient for the central retinal arteriolar equivalent (CRAE) was 0.910 and that for the central retinal venular equivalent (CRVE) was 0.897 between RHINO software analyses with manual identification of arterioles and venules versus without it. We also calculated relative errors, which were $3.91 \%$ (5 acquisitions of 12 subjects) and 5.00\% (5 acquisitions of 12 subjects) for CRAE and CRVE, respectively ${ }^{4}$. For cerebral small vessel disease, the interclass correlation coefficients of lacunar infarcts and cerebral microbleeds $(n=50)$ between 3 observers were $0.84(95 \% \mathrm{Cl}: 0.74$, $0.91)$ and $0.83(95 \% \mathrm{Cl}: 0.72,0.90)$, respectively ${ }^{5}$. With regard to plasma biomarkers, intraand interassay coefficients of variation were $3.5 \%$ and $5.9 \%$, respectively, for soluble vascular cell adhesion molecule-1 (sVCAM-1), 2.5\% and 5.3\% for soluble intercellular adhesion molecule-1 (sICAM-1), 6.4\% and $6.0 \%$ for soluble E-selectin, and $3.2 \%$ and $5.4 \%$ for von Willebrand factor.

For the glycocalyx thickness measurements we use the standardized approach of the Glycocheck device. Previous studies have reported an interclass correlation coefficient of endothelial glycocalyx thickness between the physician's measurements of 0.77 (95\% Cl: 0.52 , $0.89)^{6}$. 


\section{$\underline{\text { References }}$}

1. Schram MT, Sep SJ, van der Kallen CJ, Dagnelie PC, Koster A, Schaper N, et al. The Maastricht Study: an extensive phenotyping study on determinants of type 2 diabetes, its complications and its comorbidities. Eur J Epidemiol. 2014;29(6):439-451.

2. Gronenschild EH, Muris DM, Schram MT, Karaca U, Stehouwer CD, Houben AJ. Semi-automatic assessment of skin capillary density: proof of principle and validation. Microvasc Res. 2013;90:192-198.

3. Sörensen BM, Houben AJHM, Berendschot TTJM, Schouten JS, Kroon AA, van der Kallen CJ, et al. Prediabetes and Type 2 Diabetes Are Associated With Generalized Microvascular Dysfunction: The Maastricht Study. Circulation. 2016;134(18):1339-1352.

4. Huang F, Dashtbozorg B, Zhang J, Yeung A, Berendschot TT, ter Haar Romeny BM. Validation study on retinal vessel caliber measurement technique. In: European Congress on Computational Methods in Applied Sciences and Engineering, Porto, Portugal, October 18-20. New York, NY: Springer Publishing Company; 2017:818-826.

5. van Agtmaal MJ, Houben AJHM, de Wit V, Henry RM, Schaper NC, Dagnelie PC, et al. Prediabetes Is Associated With Structural Brain Abnormalities: The Maastricht Study. Diabetes care. 2018;41(12):2535-2543.

6. Rovas A, Lukasz AH, Vink H, Urban M, Sackarnd J, Pavenstädt H, Kümpers P. Bedside analysis of the sublingual microvascular glycocalyx in the emergency room and intensive care unit-the GlycoNurse Study. Scand J Trauma Resusc Emerg Med. 2018;26(1):16. 


\section{Chapter 3}

Type 2 Diabetes and HbA1c are Independently Associated with Wider Retinal Arterioles:

The Maastricht Study

Wenjie Li, Miranda T Schram, Tos TJM Berendschot, Carroll AB Webers, Abraham A Kroon, Carla JH van der Kallen, Ronald MA Henry, Nicolaas C Schaper, Fan Huang, Behdad Dashtbozorg, Tao Tan, Jiong Zhang, Samaneh Abbasi-Sureshjani, Bart M ter Haar Romeny, Coen DA Stehouwer *, Alfons JHM Houben * *These authors contributed equally to the manuscript 


\section{Abstract}

\section{Background}

Retinal microvascular diameters are biomarkers of cardio-metabolic risk. However, the association of (pre)diabetes with retinal microvascular diameters remains unclear. We aimed to investigate the association of prediabetes (impaired fasting glucose or impaired glucose tolerance) and type 2 diabetes with retinal microvascular diameters in a predominantly white population.

\section{Methods}

In a population-based cohort study with oversampling of type 2 diabetes $(\mathrm{N}=2876 ; \mathrm{n}=1630$ normal glucose metabolism [NGM], $n=433$ prediabetes and $n=813$ type 2 diabetes, $51.2 \%$ men, aged $59.8 \pm 8.2$ years; $98.6 \%$ white), we determined retinal microvascular diameters (measurement unit as measured by retinal health information and notification system [RHINO] software) and glucose metabolism status (using OGTT). Associations were assessed with multivariable regression analyses adjusted for age, sex, waist circumference, smoking, systolic blood pressure, lipid profile and the use of lipid-modifying and/or antihypertensive medication.

\section{$\underline{\text { Results }}$}

Multivariable regression analyses showed a significant association for type 2 diabetes but not for prediabetes with arteriolar width (versus NGM; prediabetes: $\mathrm{B}=0.62$ [95\% $\mathrm{Cl}-1.58,2.83$ ]; type 2 diabetes: 2.89 [0.69, 5.08]; measurement unit); however, there was a linear trend for the arteriolar width across glucose metabolism status ( $p$ for trend=0.013). The association with wider venules was not statistically significant (prediabetes: 2.40 [-1.03, 5.84]; type 2 diabetes: $2.87[-0.55,6.29], p$ for trend=0.083; measurement unit). Higher $\mathrm{HbA} 1 \mathrm{c}$ levels were associated with wider retinal arterioles (standardized $\mathrm{B}=0.043[95 \% \mathrm{Cl} 0.00002,0.085] ; p=0.050$ ) but the association with wider venules did not reach statistical significance $(0.037[-0.006,0.080]$; $p=0.092$ ) after adjustment for potential confounders.

\section{Conclusions}

Type 2 diabetes, higher levels of $\mathrm{HbA} 1 \mathrm{c}$ and, possibly, prediabetes, are independently associated with wider retinal arterioles in a predominantly white population. These findings indicate that microvascular dysfunction is an early phenomenon in impaired glucose metabolism. 


\section{Introduction}

The worldwide epidemic of diabetes and its complications necessitates identification of early pathophysiological changes in the development of complications, as an essential requirement for risk assessment as well as for the design of interventions.

In recent studies, retinal microvascular diameters have been shown to be closely related to incidence of complications of diabetes, including retinopathy, nephropathy and stroke ${ }^{1,2}$, suggesting a role for early retinal changes in assessment of risk of these complications. However, the association of (pre)diabetes with retinal microvascular diameters remains unclear. Although type 2 diabetes has been associated with wider retinal arterioles in the majority of studies, an association of type 2 diabetes with wider retinal venules has only been found in non-white individuals ${ }^{3-9}$. Moreover, few studies have investigated the association of prediabetes with retinal microvascular diameters; those that have, also found that prediabetes was associated with wider retinal venules in non-white individuals only ${ }^{3-6}$. However, these studies ${ }^{3-6}$ had significant limitations. For example, only one study used the gold standard of oral glucose tolerance test (OGTT), rather than fasting glucose level or random glucose level, to define prediabetes and diabetes in a multi-ethnic population ${ }^{5}$. In addition, none adjusted for use of medication that is associated with glucose metabolism and microvascular function, such as antihypertensive drugs.

As it has been suggested that (pre)diabetes may be associated with both wider retinal arterioles and venules, the question arises whether, and, if so, how, these changes are related. Theoretically, wider arterioles could lead to wider venules via transmittance of greater microvascular pressure. Alternatively, or additionally, wider venules (if they are proven to be a marker for arteriole-venule shunting) could lead to wider arterioles through local tissue hypoxia. Recent studies on a multi-ethnic Asian population found that the association of (pre)diabetes with wider retinal arterioles was independent of retinal venular diameters, while the association with wider retinal venules was not independent of retinal arteriolar diameters ${ }^{4,7,8}$, which supports the hypothesis that (pre)diabetes-associated retinal venular dilation is linked to retinal arteriolar dilation. However, these associations have not been studied in a white population.

Therefore, in this population-based cohort study, we investigated the associations of OGTT-based glucose metabolism status (normal glucose status, prediabetes, type 2 diabetes) and measures of blood glucose with retinal microvascular diameters in a predominantly white population, taking into account a broad array of potential confounders. In addition, we explored whether retinal arteriolar and venular diameters were mutually related. 


\section{Methods}

\section{Study population and design}

We used data from The Maastricht Study, an observational, prospective population based cohort study. The rationale and methodology have been described previously ${ }^{10}$. In brief, the study focuses on the etiology, pathophysiology, complications and comorbidities of type 2 diabetes, and is characterized by an extensive phenotyping approach. All individuals aged between 40 and 75 years and living in the southern part of the Netherlands were eligible to participate. Participants were recruited through mass media campaigns and from the municipal registries and the regional Diabetes Patient Registry by postal mailing. Recruitment was stratified according to known type 2 diabetes status, with an oversampling of individuals with type 2 diabetes for reasons of efficiency. The present report includes cross-sectional data from the first 3451 participants, who completed the baseline survey between November 2010 and September 2013. The baseline examinations of each participant in the study were performed within a time window of 3 months (except for some participants in whom fundus photography was initially unavailable or in whom photos were of low quality; in these participants, fundus photography was obtained later; see below). The study was approved by the medical ethical committee of the Maastricht University Medical Center (NL31329.068.10) and the Minister of Health, Welfare and Sports of the Netherlands (permit 131088-105234-PG). All participants gave written informed consent. From the initial 3451 participants included, those with types of diabetes other than type 2 diabetes were excluded $(n=41)$. Of the remaining 3410 participants, retinal microvascular diameter data were available for 2924 participants, 48 of whom had data missing for one or more covariates. The main reasons for missing data were logistic (no equipment, no trained researcher available or technical failure), contraindications for the eye drops or fundus photographs of insufficient quality. The retinal microvascular diameter study population thus consisted of 2876 participants (Supplemental Figure S3.1); fundus photography was obtained within the time window of 3 months in 2700 participants and after a mean of 47 months (range 34-57) after the date on which the retinal measurement was planned in 176 participants.

\section{Assessment of glucose metabolism status}

To assess glucose metabolism status, all participants (except those who used insulin) underwent a standardized 2-hour $75 \mathrm{~g}$ OGTT after an overnight fast. For safety reasons, participants with a fasting glucose level above $11.0 \mathrm{mmol} / \mathrm{L}$, as determined by a finger prick 
test, did not undergo the OGTT. For these individuals, fasting glucose level and information about diabetes medication use were used to assess glucose metabolism status. Glucose metabolism status was defined according to the WHO 2006 criteria as normal glucose metabolism (NGM, fasting glucose<6.1 mmol/L; 2-hour postload glucose $<7.8 \mathrm{mmol} / \mathrm{L}$ ), impaired fasting glucose and/or impaired glucose tolerance (combined as prediabetes, fasting glucose 6.1-7.0 mmol/L or 2-hour postload glucose 7.8-11.1 $\mathrm{mmol} / \mathrm{L}$ ) and type 2 diabetes (fasting glucose $\geq 7.0 \mathrm{mmol} / \mathrm{L}$ or 2 -hour postload glucose $\geq 11.1 \mathrm{mmol} / \mathrm{L}$ ) ${ }^{11}$.

\section{$\underline{\text { Retinal photography and measurement of retinal microvascular diameters }}$}

All participants were asked to refrain from smoking and drinking caffeine-containing beverages for 3 hours before the measurement. Participants were allowed to consume a light meal (breakfast or lunch) low in fat content at least 90 minutes before the start of the measurement ${ }^{12}$. For retinal measurements, fundus photography of both eyes was performed 15 minutes after the pupils had been dilated with tropicamide $0.5 \%$ and phenylephrine $2.5 \%$ (wt/vol.).

All fundus photographs were taken with an auto-focus, auto-shot and auto-tracking fundus camera (Model AFC-230; Nidek, Gamagori, Japan) in an optic disc-centered field of view of $45^{\circ}$ in a darkened room. Static retinal vessel analysis (one image of the left or right eye was randomly chosen per participant) was performed using the retinal health information and notification system (RHINO) software developed by the RetinaCheck group of the Technical University of Eindhoven (Eindhoven, the Netherlands) ${ }^{13,14}$. Optic disc detection and arteriole/venule classification were corrected manually. Retinal vessel diameters were measured at 0.5-1.0 disc diameter away from the optic disc margin and were presented as central retinal arteriolar equivalent and central retinal venular equivalent (CRAE and CRVE, respectively) in measurement units (MU). The scale factor is based on the optic disc diameter, which is assumed to be $1800 \mu \mathrm{m}^{15}$, i.e., $1 \mathrm{MU}=1$ pixel sizex $1800 \mu \mathrm{m} /$ pixel size of optic disc diameter. CRAE and CRVE represent the equivalent single-vessel parent diameter for the six largest arterioles and largest venules in the region of interest, respectively. The calculations were based on the improved Knudtson-Parr-Hubbard formula ${ }^{16}$.

Fundus photographs of insufficient quality, e.g., obstructed by lashes or defocused, were evaluated and discussed with a second observer and excluded on mutual agreement. We calculated the intraclass correlation coefficients for CRAE and CRVE to assess the agreement between analyses of the RHINO software with versus without manual identification of arterioles and venules using 2556 images. The intraclass correlation coefficient of CRAE was 0.910 and that of CRVE was 0.897 . 


\section{Measurement of general characteristics and covariates}

History of cardiovascular disease, duration of diabetes, physical activity (hours/week), smoking status (never, former, current) and alcohol intake (none/low/high) were assessed by questionnaire ${ }^{10}$. Use of lipid-modifying, antihypertensive and glucose-lowering medication was assessed during a medication interview in which the generic name, dose and frequency were recorded ${ }^{10}$. We measured weight, height, BMI, waist circumference, office and ambulatory 24-hour blood pressure, plasma glucose levels, serum creatinine, 24-hour urinary albumin excretion (twice), peripheral vibration perception threshold, $\mathrm{HbA} 1 \mathrm{c}$ and plasma lipid profile, as described elsewhere ${ }^{10}$. eGFR (in $\mathrm{ml} \mathrm{min}^{-1}\left[1.73 \mathrm{~m}^{-2}\right.$ ) was calculated with the Chronic Kidney Disease Epidemiology Collaboration equation based on both serum creatinine and serum cystatin $C^{17}$. The presence of retinopathy was assessed in both eyes by use of fundus photographs taken with the same fundus camera (Model AFC-230; Nidek, Gamagori, Japan) as used for measurement of retinal microvascular diameters ${ }^{10}$. Plasma biomarkers of inflammation included high-sensitivity C-reactive protein, serum amyloid A, interleukin-6, interleukin-8, and tumor necrosis factor- $\alpha$ and were measured in ethylenediaminetetraacetic acid plasma samples with commercially available 4-plex sandwich immunoassay kits (Meso Scale Discovery, Rockville, MD, USA).

\section{Statistical analysis}

Multiple linear regression analysis was used to determine the association of glucose metabolism status (NGM, prediabetes and type 2 diabetes) and measures of blood glucose (HbA1c, fasting glucose, 2-hour postload glucose levels) with retinal vessel diameters. For linear trend analyses, the categorical variable glucose metabolism status ( $N G M=0$, prediabetes $=1$, and type 2 diabetes $=2$ ) was used in the regression models. To estimate the difference in retinal microvascular diameters between individuals with prediabetes and type 2 diabetes compared with NGM, we performed analyses with dummy variables for prediabetes and type 2 diabetes. We used the likelihood ratio test to compare models in which glucose metabolism status was treated as a categorical or continuous variable ${ }^{18}$. Model 1 was adjusted for age and sex; Model 2 was additionally adjusted for cardiovascular risk factors that have previously been associated with retinal microvascular diameters (waist circumference, smoking status, office systolic blood pressure, use of antihypertensive and/or lipid-modifying drugs, fasting triglycerides and total-to-high-density-lipoprotein [HDL] cholesterol ratio). We also performed a range of additional analyses (see Results for details). A standardized sum score was calculated for plasma markers of inflammation as follows: for each individual 
biomarker, a z score was calculated according to the formula (individual value-population mean)/population standard deviation and the resulting individual biomarker $z$ scores were then averaged. A $p$ value of $<0.05$ was considered statistically significant. Interactions of glucose metabolism status and measures of blood glucose with sex and left versus right eye (with regard to the associations between glucose metabolism status with retinal diameters) were tested by incorporating interaction terms (e.g., prediabetes $\times$ sex) in the regression models. $A$ $p$ for interaction of $<0.10$ was considered statistically significant. Statistical analyses were performed by use of the Statistical Package for Social Sciences (Version 25.0; IBM, Chicago, IL, USA), except for the likelihood ratio test, which was performed using Stata (Version 14.1; StataCorp, College Station, TX, USA).

\section{Results}

\section{Characteristics of the study population}

Table 3.1 shows the general characteristics of the study population stratified by glucose metabolism status. The study population consisted of 2876 individuals ( $98.6 \%$ white) with a mean age of $59.8 \pm 8.2$ years; $51.2 \%$ were men, and $28.3 \%$ had type 2 diabetes (by design), including both previously diagnosed type 2 diabetes (24.5\%) and newly diagnosed type 2 diabetes (3.7\%). Individuals with type 2 diabetes and prediabetes, compared with those with NGM, were older ( $p<0.001$, ANOVA test), more often male $\left(p<0.001, x^{2}\right.$ test) and a current smoker $(p<0.001)$, and had a higher BMI $(p<0.001)$, waist circumference $(p<0.001)$, systolic and diastolic blood pressure ( $p<0.001$ for both), fasting plasma glucose $(p<0.001)$, 2-hour postload glucose ( $p<0.001), \mathrm{HbA1c}(p<0.001)$ and triglycerides levels $(p<0.001)$, lower level of physical activity $(p<0.001)$ and lower eGFR $(p<0.001)$. The group of individuals with missing data on retinal microvascular measurements or covariates were generally quite similar to those included, but had a higher total-to-HDL cholesterol ratio, more current smokers and insulin use, and smaller CRAE (Supplemental Table S3.1).

\section{Association of glucose metabolism status with retinal microvascular diameters}

Retinal arterioles were wider (CRAE measured in MU) in individuals with type 2 diabetes compared with those with NGM in the age- and sex-adjusted model (Model 1: $B=2.29$ [0.52, 4.06]; Figure 3.1A). The association of prediabetes with CRAE was non-significant (Model 1: $B=0.42,[95 \% \mathrm{Cl}-1.73,2.57]$; Figure $3.1 \mathrm{~A})$, whereas CRAE showed a linear trend across 
Table 3.1 General Characteristics of the Study Population According to Glucose Metabolism Status

\begin{tabular}{|c|c|c|c|}
\hline Characteristics & $\begin{array}{c}\text { NGM } \\
n=1630\end{array}$ & $\begin{array}{c}\text { Prediabetes } \\
n=433 \\
\end{array}$ & $\begin{array}{c}\text { Type } 2 \text { diabetes } \\
\mathrm{n}=813\end{array}$ \\
\hline Age (years) & $57.9 \pm 8.1$ & $61.6 \pm 7.5$ & $62.6 \pm 7.7$ \\
\hline Women (n, \%) & $937(57.5)$ & $202(46.7)$ & $265(32.6)$ \\
\hline Diabetes duration (years) ${ }^{a}$ & - & - & $5.0[1.0-11.0]$ \\
\hline BMI $\left(\mathrm{kg} / \mathrm{m}^{2}\right)$ & $25.5 \pm 3.6$ & $27.6 \pm 4.2$ & $29.9 \pm 5.0$ \\
\hline \multicolumn{4}{|l|}{ Waist circumference $(\mathrm{cm})$} \\
\hline Men & $96.2 \pm 9.6$ & $102.1 \pm 10.3$ & $107.8 \pm 12.5$ \\
\hline Women & $85.8 \pm 10.0$ & $93.0 \pm 12.7$ & $102.0 \pm 14.2$ \\
\hline History of cardiovascular disease (n, \%) & $191(11.7)$ & $56(12.9)$ & $226(27.8)$ \\
\hline Office SBP $(\mathrm{mmHg})$ & $130.6 \pm 17.0$ & $137.3 \pm 16.8$ & $142.0 \pm 18.0$ \\
\hline Office DBP $(\mathrm{mmHg})$ & $75.2 \pm 9.9$ & $77.8 \pm 9.4$ & $77.4 \pm 9.6$ \\
\hline Ambulatory 24-hour SBP $(\mathrm{mmHg})^{\mathrm{b}}$ & $117.3 \pm 10.9$ & $120.1 \pm 11.1$ & $122.4 \pm 12.1$ \\
\hline Ambulatory 24-hour DBP $(\mathrm{mmHg})^{\mathrm{b}}$ & $73.9 \pm 7.1$ & $74.5 \pm 7.0$ & $73.5 \pm 7.3$ \\
\hline Hypertension (n, \%) & $659(40.4)$ & $274(63.3)$ & $680(83.6)$ \\
\hline Smoking (\% never/former/current) & $39.8 / 48.7 / 11.5$ & $29.1 / 58.7 / 12.2$ & $28.9 / 55.1 / 16.0$ \\
\hline Alcohol intake (\% none/low/high) & 13.6/59.2/27.3 & $15.2 / 54.7 / 30.0$ & $30.6 / 51.0 / 18.3$ \\
\hline Physical activity (hours/week) ${ }^{c}$ & $6.2 \pm 4.5$ & $5.2 \pm 4.1$ & $4.2 \pm 3.9$ \\
\hline Fasting glucose (mmol/L) & $5.2 \pm 0.4$ & $5.9 \pm 0.6$ & $7.9 \pm 2.0$ \\
\hline 2-hour postload glucose $(\mathrm{mmol} / \mathrm{L})^{d}$ & $5.4 \pm 1.1$ & $8.1 \pm 1.7$ & $14.4 \pm 3.9$ \\
\hline $\mathrm{HbA1c}(\mathrm{mmol} / \mathrm{mol})$ & $35.9 \pm 3.7$ & $38.6 \pm 4.5$ & $51.9 \pm 11.2$ \\
\hline HbA1c (\%) & $5.4 \pm 0.3$ & $5.7 \pm 0.4$ & $6.9 \pm 1.0$ \\
\hline Triglycerides (mmol/L) & $1.2 \pm 0.6$ & $1.6 \pm 1.0$ & $1.8 \pm 1.0$ \\
\hline Total-to-HDL cholesterol ratio & $3.6 \pm 1.1$ & $3.8 \pm 1.2$ & $3.7 \pm 1.1$ \\
\hline Total cholesterol (mmol/L) & $5.6 \pm 1.0$ & $5.5 \pm 1.1$ & $4.4 \pm 1.0$ \\
\hline $\mathrm{HDL}(\mathrm{mmol} / \mathrm{L})$ & $1.7 \pm 0.5$ & $1.5 \pm 0.4$ & $1.3 \pm 0.4$ \\
\hline LDL (mmol/L) & $3.4 \pm 0.9$ & $3.3 \pm 1.0$ & $2.4 \pm 0.9$ \\
\hline Antihypertensive medication use $(n, \%)$ & $364(22.3)$ & $199(46.0)$ & $598(73.6)$ \\
\hline Lipid-modifying medication use (n, \%) & $270(16.6)$ & $154(35.6)$ & $609(74.9)$ \\
\hline Diabetes medication use (n, \%) & $0(0)$ & $0(0)$ & $641(78.8)$ \\
\hline Insulin & - & - & $167(20.5)$ \\
\hline Oral medication only & - & - & $600(73.8)$ \\
\hline
\end{tabular}


Table 3.1 continued

\begin{tabular}{|c|c|c|c|}
\hline Characteristics & $\begin{array}{c}\text { NGM } \\
n=1630\end{array}$ & $\begin{array}{c}\text { Prediabetes } \\
n=433\end{array}$ & $\begin{array}{c}\text { Type } 2 \text { diabetes } \\
n=813\end{array}$ \\
\hline eGFR $\left(\mathrm{ml} \mathrm{min} \min ^{-1}\left[1.73 \mathrm{~m}^{-2}\right)\right.$ & $90.3 \pm 13.1$ & $86.7 \pm 14.3$ & $84.8 \pm 16.9$ \\
\hline Albuminuria $(n, \%){ }^{e}$ & $66(4.1)$ & $29(6.7)$ & $148(18.4)$ \\
\hline Retinopathy (n, \%) & $1(0.1)$ & $1(0.2)$ & $34(4.3)$ \\
\hline Neuropathy $(n, \%)^{f}$ & $93(6.4)$ & $37(9.9)$ & $147(20.5)$ \\
\hline \multicolumn{4}{|l|}{ CRAE (MU) } \\
\hline Crude & $142.9 \pm 20.1$ & $141.2 \pm 20.2$ & $142.0 \pm 21.0$ \\
\hline Age- and sex-adjusted & $156.0 \pm 0.49$ & $156.3 \pm 0.94$ & $158.1 \pm 0.73$ \\
\hline Age-,sex-and office SBP-adjusted & $173.1 \pm 0.48$ & $174.0 \pm 0.93$ & $176.2 \pm 0.73$ \\
\hline \multicolumn{4}{|l|}{ CRVE (MU) } \\
\hline Crude & $213.9 \pm 30.7$ & $215.9 \pm 31.4$ & $215.6 \pm 32.5$ \\
\hline Age- and sex-adjusted & $223.0 \pm 0.75$ & $226.5 \pm 1.50$ & $227.2 \pm 1.13$ \\
\hline Age-, sex- and office SBP-adjusted & $228.1 \pm 0.75$ & $231.8 \pm 1.50$ & $232.6 \pm 1.13$ \\
\hline
\end{tabular}

Data are reported as mean \pm SD or $n(\%)$ as appropriate, except diabetes duration, which is reported as median [interquartile range], and adjusted CRAE and CRVE which are reported as mean \pm SEM

Data present the study population for regression models 1 and 2

CRAE, central retinal arteriolar equivalent; CRVE, central retinal venular equivalent; DBP, diastolic blood pressure; eGFR, estimated glomerular filtration rate; HbA1c, hemoglobin A1c; HDL, high density lipoprotein; LDL, low density lipoprotein; MU: Measurement unit; SBP, systolic blood pressure

${ }^{a}$ Available for 673 individuals with type 2 diabetes; ${ }^{b}$ Available for 722 individuals with type 2 diabetes; ${ }^{c}$ Available for 685 individuals with type 2 diabetes; ${ }^{d}$ Available for 623 individuals with type 2 diabetes; ${ }^{\text {e }}$ Albuminuria was defined as a urinary albumin excretion of $>30 \mathrm{mg}$ per 24 hours; ${ }^{\mathrm{f}}$ Neuropathy was defined as a vibration perception threshold $>25 \mathrm{~V}$; data were available for 718 individuals with type 2 diabetes

glucose metabolism status (Model 1: $p$ for trend=0.013; $p$ for likelihood ratio test=0.49). After further adjustment for cardiovascular risk factors (Model 2), the difference in CRAE between type 2 diabetes and NGM became somewhat larger (prediabetes $B=0.62[-1.58,2.83]$; type 2 diabetes $\mathrm{B}=2.89$ [0.69, 5.08]; Figure 3.1A). The linear trend for CRAE across glucose metabolism status remained (Model 2: $p$ for trend=0.013; $p$ for likelihood ratio test $=0.43$ ).

Retinal venules were wider (CRVE measured in MU) in individuals with prediabetes and type 2 diabetes, compared with those with NGM, in the age- and sex-adjusted model (Model 1: prediabetes $B=3.84[0.50,7.18]$; type 2 diabetes $B=4.68$ [1.93, 7.43]; Figure 3.1B), and the CRVE showed a linear trend across glucose metabolism status (Model $1: p$ for trend $=0.001 ; p$ for likelihood ratio test=0.36). The difference in CRVE was attenuated and non-significant after adjustment for cardiovascular risk factors (Model 2: prediabetes $B=2.40[-1.03,5.84]$; type 2 
diabetes $B=2.87$ [-0.55, 6.29]; Figure 3.1B). CRVE no longer showed a linear trend across glucose metabolism status (Model 2: $p$ for trend=0.083; $p$ for likelihood ratio test $=0.55$ ).
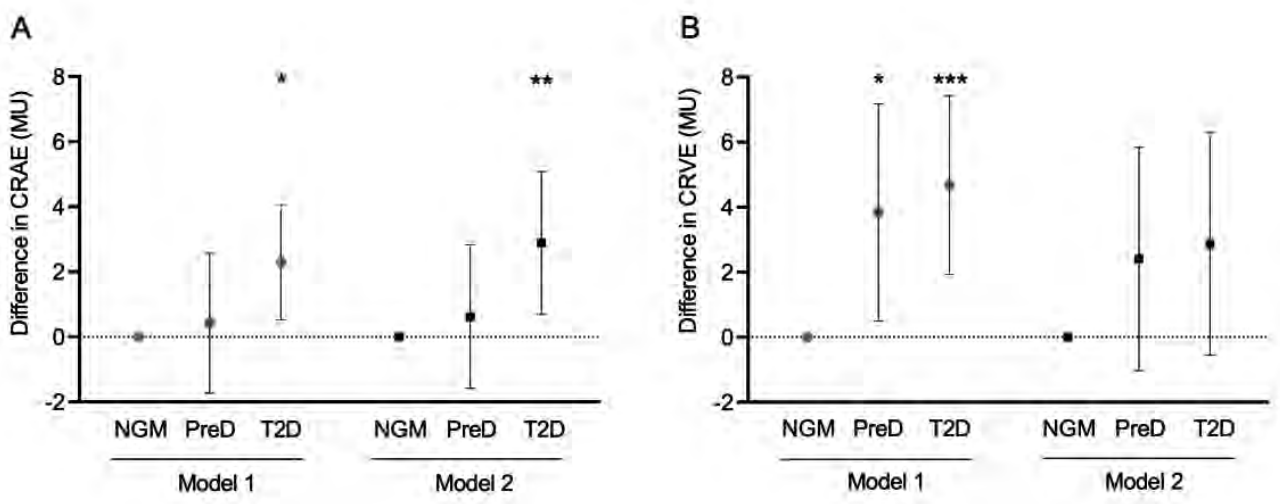

Figure 3.1 Multivariable-adjusted differences in retinal microvascular diameters between individuals with prediabetes and type 2 diabetes compared with NGM. (A) Difference in CRAE. (B) Difference in CRVE. Point estimates (B) and $95 \% \mathrm{Cls}$ represent the difference in retinal microvascular diameters in CRAE and CRVE as compared with NGM. NGM is the reference and is set to zero. Model 1: adjusted for age and sex; Model 2: additional adjustment for waist circumference, smoking status, systolic blood pressure, triglycerides, total-to-HDL cholesterol ratio, and use of antihypertensive and/or lipid-modifying drugs. PreD, prediabetes; T2D, type 2 diabetes; MU, measurement unit. * $p<0.05^{* *} p<0.01{ }^{\star \star *} p<0.001$ versus NGM in corresponding model

\section{Associations of measures of blood glucose with retinal microvascular diameters}

Higher levels of $\mathrm{HbA1c}$ were associated with greater CRAE after adjustment for age and sex (Model 1; Figure 3.2A and 3.3A), and also after further adjustment for cardiovascular risk factors (Model 2; Figure 3.2A). Higher levels of fasting glucose and 2-hour postload glucose were not statistically significantly associated with greater CRAE (Figure 3.2A).

Higher levels of $\mathrm{HbA1C}$ were associated with greater CRVE after adjustment for age and sex (Model 1; Figure 3.2B and 3.3B). The association was attenuated and non-significant after further adjustment for cardiovascular risk factors (Model 2; Figure 3.2B). Higher fasting glucose and 2-hour postload glucose were not statistically significantly associated with greater CRVE (Figure 3.2B). 


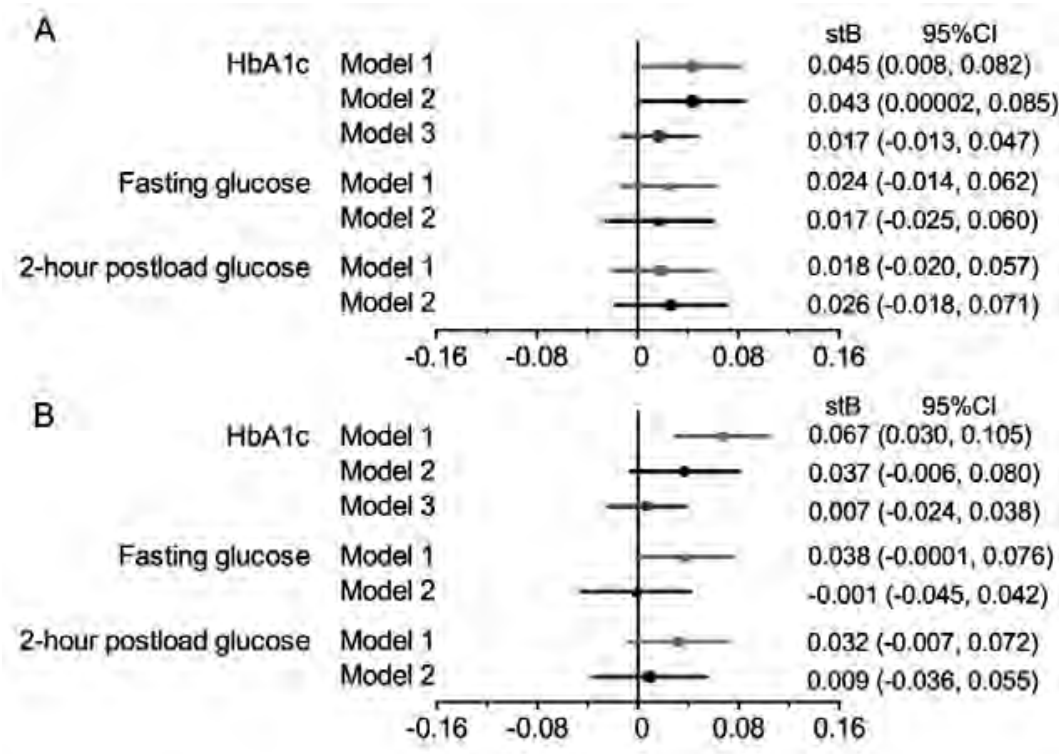

Figure 3.2 Multivariable-adjusted associations of measures of blood glucose with retinal microvascular diameters. (A) Associations of measures of blood glucose with CRAE. (B) Associations of measures of blood glucose with CRVE. Point estimates (standardized B [stB]) and 95\%Cls represent the difference (in SD) in retinal microvascular diameters per SD increase in the measure of blood glucose. Model 1: adjusted for age and sex; Model 2: additional adjustment for waist circumference, smoking status, systolic blood pressure, triglycerides, total-to-HDL cholesterol ratio, and use of antihypertensive and/or lipid-modifying drugs. Model 3: additional adjustment for CRVE in models of CRAE and adjustment for CRAE in models of CRVE

\section{Additional analyses}

Further analyses to assess the robustness of our observations are described in the Supplemental Material (Supplemental Tables S3.2-S3.7); in general, these analyses confirmed the observations reported above. To explore whether retinal diameters are intrinsically linked, we analyzed venular diameters as a function of arteriolar diameters. We found that retinal arteriolar diameters were positively associated with retinal venular diameters after adjustment for age and $\operatorname{sex}(B=1.09$ [1.05, 1.13], $p<0.001$; Supplemental Figure S3.2). The association remained similar after further adjustment for height, body surface area, systolic blood pressure and $\mathrm{HbA} 1 \mathrm{c}$ level $(\mathrm{B}=1.09$ [1.05, 1.13], $p<0.001)$. In addition, to explore whether the associations of glucose metabolism status and measures of blood glucose with CRAE and CRVE are linked, we additionally adjusted for CRVE in models of CRAE and for CRAE in models of CRVE. We found that further adjustment for CRVE attenuated the difference in CRAE in prediabetes and type 2 diabetes versus NGM (prediabetes $B=-0.46$ $[-2.03,1.11]$; type 2 diabetes $B=1.60[0.03,3.16] ; p$ for trend=0.073), while further adjustment for CRAE completely eliminated the difference in CRVE (prediabetes $B=1.72[-0.73,4.18]$; 
type 2 diabetes $B=-0.28[-2.73,2.16] ; p$ for trend=0.984). Similarly, the association of $\mathrm{HbA} 1 \mathrm{C}$ with CRAE was attenuated after further adjustment for CRVE, while the association with CRVE was eliminated after further adjustment for CRAE (Model 3; Figure S3.2).

We did not find any significant associations between duration of type 2 diabetes and retinal microvascular diameters (available for $n=673$ individuals; Supplemental Tables S3.8).

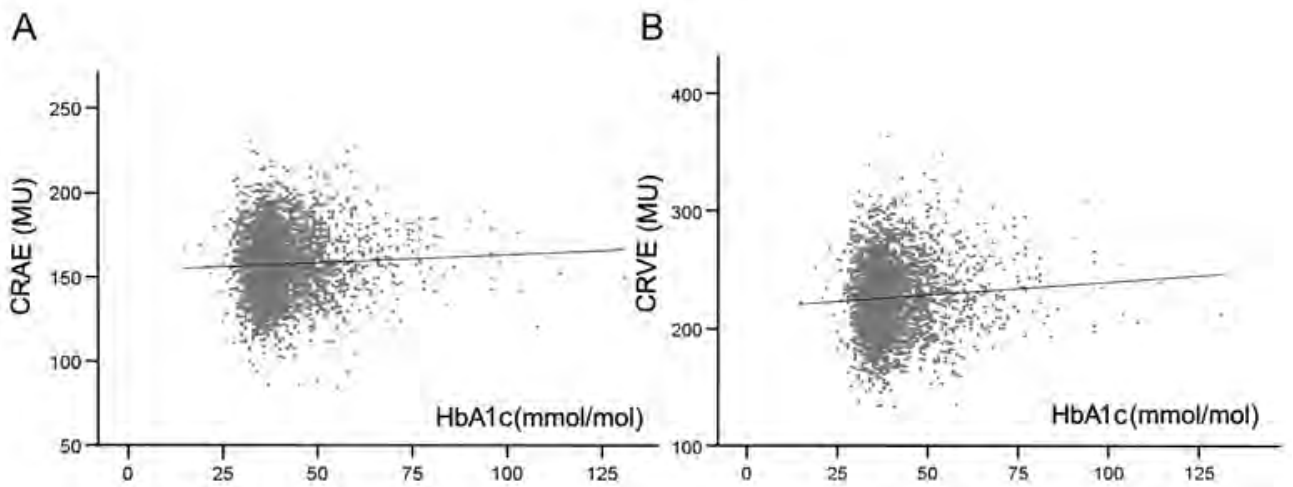

Figure 3.3 Age- and sex-adjusted association of HbA1c with retinal microvascular diameters. (A) Association between $\mathrm{HbA} 1 \mathrm{c}$ and $\mathrm{CRAE}(\mathrm{B}=0.0995 \% \mathrm{Cl}[0.02,0.17])$; (B) Association between $\mathrm{HbA} 1 \mathrm{c}$ and $\mathrm{CRVE}$ $(B=0.22[0.10,0.34])$. Regression coefficients $(B)$ indicate the age- and sex-adjusted mean difference and $95 \% \mathrm{Cl}$ in CRAE and CRVE per $1 \mathrm{mmol} / \mathrm{mol}$ increase in $\mathrm{HbA1c}$

\section{Discussion}

This study shows that type 2 diabetes, higher levels of $\mathrm{HbA1c}$ and, possibly, prediabetes are associated with wider retinal arteriolar diameters in a predominantly white population. Notably, the associations with retinal arteriolar diameters are independent of a broad array of potential confounders. These findings indicate that retinal microvascular changes already occur prior to the diagnosis of type 2 diabetes. In addition, retinal arteriolar diameters are associated with retinal venular diameters, independently of age, sex, height, body surface area, blood pressure and blood glucose, which suggests a close link between arteriolar and venular dilation in general and, thus, also in (pre)diabetes.

Our results indicate that type 2 diabetes and, possibly, prediabetes are independently associated with wider retinal arteriolar diameters, which is consistent with previous cross-sectional studies ${ }^{3-9}$. Compared with these studies, we used OGTT and HbA1c, which are more accurate measurements for classifying glucose metabolism status than measuring 
fasting glucose, random glucose, and $\mathrm{HbA1c}$ levels only ${ }^{19}$. In addition, we showed that the associations were independent of a broad array of cardiovascular risk factors. Notably, we found that age, sex and systolic blood pressure had strong confounding effects. For example, older age, male sex and higher blood pressure were associated with both narrower arterioles and (pre)diabetes. Unsurprisingly, eliminating these confounders through statistical adjustment reversed the direction of association between (pre)diabetes and retinal arteriolar diameters (Table S3.1). Note also that we included ambulatory 24-hour blood pressure as a confounder in our additional analyses, as it is more accurate than office blood pressure ${ }^{20}$ and has not been used in previous studies ${ }^{3-9}$, making residual confounding by inaccurately measured blood pressure much less likely in our study. With regard to the outcomes, we measured diameters with semi-automated software (RHINO), which was validated manually and had a relative error that was comparable to that of Interactive Vessel Analysis (IVAN) software ${ }^{21}$. Finally, we used linear trend analyses, as we hypothesized that the difference in retinal microvascular diameters from NGM to prediabetes to type 2 diabetes is of a continuous nature. The results of these analyses favor the interpretation that arteriolar widening occurs in both type 2 diabetes and prediabetes. In support of this, HbA1c, a continuous measure of blood glucose, was significantly associated with retinal arteriolar diameters. Although we cannot exclude the possibility that there is no true association between prediabetes and greater arteriolar diameter, we attribute the lack of statistical significance of the difference between prediabetes and NGM with regard to retinal arteriolar diameters to a type 2 statistical error, because the power of between-group comparisons was reduced compared with the power of trend analyses.

Retinal arteriolar dilation in (pre)diabetes is thought to be a result of impaired arteriolar autoregulation ${ }^{22}$. Lacking neuronal innervation, retinal arterioles are affected mainly by local autoregulation through the release of vasoactive substances by microvascular endothelium and the myogenic response of smooth muscle cells ${ }^{23}$. For example, in retinal arteriolar smooth muscle cells, hyperglycemia and hypoxia can cause endothelin-1 resistance and inhibit $\mathrm{Ca}^{2+}$ influx channels ${ }^{24,25}$. In addition, death and insufficient renewal of endothelial cells, smooth muscle cells and pericytes can further weaken arteriolar wall and boost dilation.

The associations of prediabetes and type 2 diabetes with retinal venular diameters were directionally similar to those for arterioles even though they were not statistically significant after adjustment for cardiovascular risk factors. The nonsignificance of the associations may be explained by four factors. First, the relatively larger measurement error of venular versus arteriolar diameters ${ }^{21}$ decreases the precision of the association with blood glucose and thus 
increases the confidence interval ${ }^{26}$. Second, our additional analyses (Figure 3.2 and Supplemental Figure S3.2) are consistent with the concept that (glucose-related) arteriolar widening drives venular widening to an important extent, possibly by greater transmission of blood pressure. Such mediation will tend to bias the association between blood glucose and venular diameters towards the null ${ }^{27}$. Third, longitudinal studies ${ }^{28-30}$ have suggested that widening of retinal venules may also occur before prediabetes, which may reduce the difference in venular diameter between (pre)diabetes and NGM. Fourth, our fully adjusted model may have been over-adjusted as a result of the inclusion of waist circumference, since obesity may be on the causal pathway between (pre)diabetes and retinal venular dilation ${ }^{31}$.

In general, studies on the associations between diabetes or blood glucose and retinal venular diameters have not shown consistent results ${ }^{3-9}$, although venular widening has been much more consistently observed among Asian populations ${ }^{3,4,6-8}$ than among white populations ${ }^{3,5,9}$. These inconsistent results may be attributed to ethnicity but also to differences in classification of glucose metabolism status, insufficient adjustment for confounding and different types of software used.

The pathophysiological mechanisms that explain retinal venular dilation in (pre)diabetes remain unclear. Retinal venules have been proposed to dilate in response to diabetes-associated inflammation ${ }^{3,32}$, but the association was unchanged after adjustment for inflammation in our study and a previous study ${ }^{3}$. As alluded to above (Figure 3.2 and Supplemental Figure S3.2), our results are consistent with the hypothesis that retinal venular dilation is, at least in part, a direct consequence of arteriolar dysfunction ${ }^{24}$. However, we cannot exclude the possibility that, alternatively or additionally, wider venules could lead to wider arterioles, for example, through arteriole to venule shunting and local tissue hypoxia.

Retinal arteriolar dilation is associated with progression of retinopathy ${ }^{33}$ and presence of neuropathy ${ }^{34}$. Retinal venular dilation is similarly associated with incidence and progression of retinopathy ${ }^{35}$, incidence of nephropathy ${ }^{36}$, prevalence and incidence of stroke ${ }^{37,38}$ and progression of cerebral small vessel disease ${ }^{39}$. Taken together with our findings, these results may explain why such complications are commonly present at diagnosis of type 2 diabetes or sometimes before. Retinal microvascular dilation seems to be reversible ${ }^{40-42}$; however, whether this improvement in retinal microvascular dilation will translate into an improved prognosis with respect to complications of diabetes needs further investigation.

Strengths of our study include the population-based design with oversampling of individuals with type 2 diabetes; the use of OGTT to characterize glucose metabolism status; 
the extensive phenotyping, which enables detection of independent associations after extensive adjustments for potential confounders; and the broad array of additional analyses, which gave deeper insight into the associations. Our study also has limitations. First, the cross-sectional data cannot definitively establish a causal link between (pre)diabetes and retinal microvascular features. Nevertheless, there is extensive evidence that hyperglycemia causes microvascular dysfunction, and that the association may in fact be bidirectional ${ }^{43,44}$. Second, our study population was 40-75 years of age, predominantly white, with relatively well-controlled blood glucose and cardiovascular risk factors, which should be taken into consideration when the findings are extrapolated to other populations. Third, although treating glucose metabolism status as a continuous variable increased statistical power to detect the associations of (pre)diabetes with retinal microvascular diameters and the results of likelihood ratio test confirmed the feasibility of this approach, it may also introduce bias into the estimates of associations, which are largely influenced by the difference in retinal microvascular diameters between the two extreme groups, i.e., the NGM and type 2 diabetes groups. Fourth, our fully adjusted model may have been over-adjusted, as a result of the inclusion of waist circumference, since for retinal venular diameters, and therefore the association of (pre)diabetes with retinal microvascular diameters may have been underestimated. Fifth, although investigational procedures were standardized, participants were allowed a light meal, which will increase variation in retinal microvascular diameters and thus bias associations towards the null. Sixth, although we adjusted for major potential confounders, there is still a possibility of residual confounding by variables that were not included in the analyses.

In summary, this study has demonstrated that type 2 diabetes, higher levels of $\mathrm{HbA1C}$, and, possibly, prediabetes are associated with wider retinal arterioles, independent of major cardiovascular risk factors, in a predominantly white population. These results support the 'ticking clock' hypothesis, which postulates that microvascular dysfunction precedes the clinical diagnosis of type 2 diabetes ${ }^{43,44}$, and may partly explain the occurrence of complications related to microvascular dysfunction in prediabetes and in early type 2 diabetes. Thus, microvascular dysfunction can be considered an early marker of (pre)diabetes and a potential target for intervention. 


\section{References}

1. Nguyen TT, Wong TY. Retinal vascular manifestations of metabolic disorders. Trends Endocrinol Metab. 2006;17(7):262-268.

2. Cheung CY, Ikram MK, Klein R, Wong TY. The clinical implications of recent studies on the structure and function of the retinal microvasculature in diabetes. Diabetologia. 2015;58(5):871-885.

3. Nguyen TT, Wang JJ, Sharrett AR, Islam FA, Klein R, Klein BE, et al. Relationship of retinal vascular caliber with diabetes and retinopathy: the Multi-Ethnic Study of Atherosclerosis (MESA). Diabetes Care. 2008;31(3):544-549.

4. Jeganathan VS, Sabanayagam C, Tai ES, Lee J, Lamoureux E, Sun C, et al. Retinal vascular caliber and diabetes in a multiethnic Asian population. Microcirculation. 2009;16(6):534-543.

5. Tikellis G, Wang JJ, Tapp R, Simpson R, Mitchell P, Zimmet PZ, et al. The relationship of retinal vascular calibre to diabetes and retinopathy: the Australian Diabetes, Obesity and Lifestyle (AusDiab) study. Diabetologia. 2007;50(11):2263-2271.

6. Cheung CY, Lamoureux E, Ikram MK, Sasongko MB, Ding J, Zheng Y, et al. Retinal vascular geometry in Asian persons with diabetes and retinopathy. J Diabetes Sci Technol. 2012;6(3):595-605.

7. Islam FM, Nguyen TT, Wang JJ, Tai ES, Shankar A, Saw SM, et al. Quantitative retinal vascular calibre changes in diabetes and retinopathy: the Singapore Malay eye study. Eye (Lond). 2009; 23(8):1719-1724.

8. Tsai AS, Wong TY, Lavanya R, Zhang R, Hamzah H, Tai ES, Cheung CY. Differential association of retinal arteriolar and venular caliber with diabetes and retinopathy. Diabetes Res Clin Pract. 2011; 94(2):291-298.

9. Kifley A, Wang JJ, Cugati S, Wong TY, Mitchell P. Retinal vascular caliber, diabetes, and retinopathy. Am J Ophthalmol. 2007;143(6):1024-1026.

10. Schram MT, Sep SJ, van der Kallen CJ, Dagnelie PC, Koster A, Schaper N, et al. The Maastricht Study: an extensive phenotyping study on determinants of type 2 diabetes, its complications and its comorbidities. Eur J Epidemiol. 2014;29(6):439-451.

11. World Health Organization. Definition and diagnosis of diabetes mellitus and intermediate hyperglycaemia: report of a WHO/IDF consultation. WHO, Geneva, 2006

12. Sörensen BM, Houben AJHM, Berendschot TTJM, Schouten JS, Kroon AA, van der Kallen CJ, et al. Prediabetes and Type 2 Diabetes Are Associated With Generalized Microvascular Dysfunction: The Maastricht Study. Circulation. 2016;134(18):1339-1352.

13. Romeny BMT, Bekkers EJ, Zhang J, Abbasi-Sureshjani S, Huang F, Duits R, et al. Brain-inspired algorithms for retinal image analysis. Mach Vision Appl. 2016;27(8):1117-1135.

14. Bekkers E, Duits R, Berendschot T, Romeny BT. A Multi-Orientation Analysis Approach to Retinal Vessel Tracking. J Math Imaging Vis. 2014;49(3):583-610.

15. Jonas JB, Gusek GC, Naumann GO. Optic disc, cup and neuroretinal rim size, configuration and correlations in normal eyes. Invest Ophthalmol Vis Sci. 1989;29(7):1151-1158.

16. Knudtson MD, Lee KE, Hubbard LD, Wong TY, Klein R, Klein BE. Revised formulas for summarizing retinal vessel diameters. Curr Eye Res. 2003;27(3):143-149.

17. Inker LA, Schmid CH, Tighiouart H, Eckfeldt JH, Feldman HI, Greene T, et al. Estimating glomerular filtration rate from serum creatinine and cystatin C. N Engl J Med. 2012;367(1):20-29.

18. Kirkwood BR, Sterne JA. Chapter 29: regression modelling. In: Kirkwood BR, Sterne JAC (eds), Essential Medical statistics. Blackwell Science, Hoboken, New York. 2003:315-342.

19. Inzucchi SE. Diagnosis of diabetes. N Engl J Med. 2012; 367(6):542-550.

20. Melville S, Byrd JB. Monitoring blood pressure outside of the doctor's office. JAMA. 2018;320(17):1830.

21. Huang F, Dashtbozorg B, Zhang J, Yeung A, Berendschot TT, ter Haar Romeny BM. Validation study on retinal vessel caliber measurement technique. In: European Congress on Computational Methods in Applied Sciences and Engineering, Porto, Portugal, October 18-20. New York, NY: Springer Publishing Company; 2017:818-826.

22. Kohner EM, Patel V, Rassam SM. Role of blood flow and impaired autoregulation in the pathogenesis of diabetic retinopathy. Diabetes. 1995;44(6):603-607.

23. Luo X, Shen YM, Jiang MN, Lou XF, Shen Y. Ocular blood flow autoregulation mechanisms and methods. J Ophthalmol. 2015;2015:864871. 
24. Gardiner TA, Archer DB, Curtis TM, Stitt AW. Arteriolar involvement in the microvascular lesions of diabetic retinopathy: implications for pathogenesis. Microcirculation. 2007;14:25-38.

25. Matsushita K, Fukumoto M, Kobayashi T, Kobayashi M, Ishizaki E, Minami M, et al. Diabetes-induced inhibition of voltage-dependent calcium channels in the retinal microvasculature: role of spermine. Invest Ophthalmol Vis Sci. 2010;51:5979-5990.

26. Hutcheon JA, Chiolero A, Hanley JA. Random measurement error and regression dilution bias. BMJ 2010;340:c2289.

27. Jager KJ, Zoccali C, Macleod A, Dekker FW. Confounding: what it is and how to deal with it. Kidney Int. 2008;73(3):256-260.

28. Sabanayagam C, Lye WK, Klein R, Klein BE, Cotch MF, Wang JJ, et al. Retinal microvascular calibre and risk of diabetes mellitus: a systematic review and participant-level meta-analysis. Diabetologia. 2015;58(11):2476-2485.

29. Ikram MK, Janssen JA, Roos AM, Rietveld I, Witteman J C, Breteler M M, et al. Retinal vessel diameters and risk of impaired fasting glucose or diabetes: the Rotterdam study. Diabetes. 2006; 55(2):506-510.

30. Kifley A, Wang JJ, Cugati S, Wong TY, Mitchell P. Retinal vascular caliber and the long-term risk of diabetes and impaired fasting glucose: the Blue Mountains Eye Study. Microcirculation. 2008;15(5):373-377.

31. Schisterman EF, Cole SR, Platt RW. Overadjustment bias and unnecessary adjustment in epidemiologic studies. Epidemiology (Cambridge, Mass.). 2009;20(4):488.

32. Klein R, Klein BE, Knudtson MD, Wong TY, Tsai MY. Are inflammatory factors related to retinal vessel caliber? The Beaver Dam Eye Study. Arch Ophthalmol. 2006;124:87-94.

33. Klein R, Klein BEK, Moss SE, Wong TY, Hubbard L, Cruickshanks KJ, Palta M. The relation of retinal vessel caliber to the incidence and progression of diabetic retinopathy: Xix: the Wisconsin Epidemiologic Study of Diabetic Retinopathy. Arch Ophthalmol. 2004; 122(1):76-83.

34. Sabanayagam C, Tai ES, Lee J, Lim SC, Wong TY. Retinal vessel caliber and peripheral neuropathy in diabetic participants. Microcirculation. 2010;17(4):297-302.

35. Ikram MK, Cheung CY, Lorenzi M, Klein R, Jones TL, Wong TY. Retinal vascular caliber as a biomarker for diabetes microvascular complications. Diabetes care. 2013; 36(3):750-759.

36. Klein R, Klein BEK, Moss S E, Wong TY. Retinal vessel caliber and microvascular and macrovascular disease in type 2 diabetes: XXI: the Wisconsin Epidemiologic Study of Diabetic Retinopathy. Ophthalmology. 2007;114(10):1884-1892.

37. Ong YT, De Silva DA, Cheung CY, Chang HM, Chen CP, Wong MC, et al. Microvascular structure and network in the retina of patients with ischemic stroke. Stroke. 2013;44(8):2121-2127.

38. Cheung CY, Tay WT, Ikram MK, Ong YT, De Silva DA, Chow KY, Wong TY. Retinal microvascular changes and risk of stroke: the Singapore Malay Eye Study. Stroke. 2013;44(9):2402-2408.

39. Ikram MK, De Jong FJ, Van Dijk EJ, Prins ND, Hofman A, Breteler MM, De Jong PT. Retinal vessel diameters and cerebral small vessel disease: the Rotterdam Scan Study. Brain. 2006;129(1):182-188.

40. Pedersen L, Jeppesen P, Knudsen ST, Poulsen PL, Bek T. Improvement of mild retinopathy in type 2 diabetic patients correlates with narrowing of retinal arterioles. A prospective observational study. Graefes Arch Clin Exp Ophthalmol. 2014;252(10):1561-1567.

41. Braun G, Hafner B, Königstein K, Infanger D, Klenk C, Rossmeissl A, et al. Association of cardiorespiratory fitness with retinal vessel diameters as a biomarker of cardiovascular risk. Microvasc Res. 2018;120:36-40.

42. Tilma KK, Bek T. Topical treatment for 1 week with latanoprost but not diclofenac reduces the diameter of dilated retinal arterioles in patients with type 1 diabetes mellitus and mild retinopathy. Acta Ophthalmol. 2012;90(8):750-755.

43. Stehouwer CDA. Microvascular dysfunction and hyperglycemia: a vicious cycle with widespread consequences. Diabetes. 2018;67:1729-1741.

44. Muris DM, Houben AJ, Schram MT, Stehouwer CD. Microvascular dysfunction is associated with a higher incidence of type 2 diabetes mellitus: a systematic review and meta-analysis. Arterioscler Thromb Vasc Biol. 2012; 32(12):3082-3094. 


\section{Supplemental Material to Chapter 3}

\section{Additional analyses}

Associations remained similar when we replaced office systolic pressure with 24-hour ambulatory systolic blood pressure (available in 2545 individuals; Supplemental Table S3.2), or further specified blood pressure-lowering medication into renin-angiotensin-aldosterone system (RAAS) inhibitors and other types of antihypertensives (available in 2876 individuals; Supplemental Table S3.2) in the regression models. Associations also remained similar when we replaced waist circumference with BMI (available in 2875 individuals; Supplemental Table S3.3).

Associations again remained similar after additional adjustment for presence of retinopathy, presence of neuropathy, eGFR and albumin excretion, or history of cardiovascular disease (available in 2328 individuals; Supplemental Table S3.4). The associations also remained when physical activity and alcohol intake (available in 2535 individuals, Supplemental Table S3.5) were added to the models. Additional adjustment for plasma markers of inflammation (high-sensitivity C-reactive protein, serum amyloid $A$, interleukin-6, interleukin-8, and tumor necrosis factor-a) and their standardized sum score did not materially change the associations (available in 2848 individuals; Supplemental Table S3.6).

Associations also remained similar when we excluded participants with outliers (defined as $<3 S D$ or $>3 S D$ ) in retinal microvascular diameters $(n=18$; Supplemental Table S3.7), excluded participants with retinopathy ( $n=36$; Supplemental Table S3.7), excluded participants with catch-up fundus photography ( $n=176$; Supplemental Table S3.7), or excluded non-white population ( $n=41$; Supplemental Table S3.7). Finally, we did not find any significant interactions with sex ( $p$ for interaction $>0.440$ ) or left versus right eye ( $p$ for interaction $>0.579$ ) with regard to the associations between glucose metabolism variables on the one hand and retinal outcomes on the other. 
Supplemental Table S3.1 General characteristics of the study population and individuals excluded from the analyses due to missing values

\begin{tabular}{|c|c|c|c|c|}
\hline Characteristic & $\begin{array}{l}\text { Study population } \\
(\mathrm{N}=\mathbf{2 8 7 6})\end{array}$ & Missing & $\begin{array}{l}\text { Excluded due to missing } \\
\text { values } \\
(\mathrm{N}=534)\end{array}$ & $p$-value \\
\hline Age (years) & $59.8 \pm 8.2$ & 0 & $59.9 \pm 8.6$ & 0.736 \\
\hline Women $(n, \%)$ & $1404(48.8)$ & 0 & $250(46.8)$ & 0.397 \\
\hline Glucose metabolism status ( $\mathrm{n}, \%)$ & & 0 & & 0.624 \\
\hline - Normal glucose metabolism & $1630(56.7)$ & 0 & $294(55.1)$ & \\
\hline - Prediabetes & $433(15.1)$ & 0 & $78(14.6)$ & \\
\hline - Type 2 diabetes & $813(28.3)$ & 0 & $162(30.3)$ & \\
\hline Diabetes duration (years) ${ }^{a}$ & $5.0[1.0-11.0]$ & 177 & $5.0[1.5-11.0]$ & 0.601 \\
\hline Body mass index $\left(\mathrm{kg} / \mathrm{m}^{2}\right)$ & $27.1 \pm 4.5$ & 3 & $27.4 \pm 4.8$ & 0.166 \\
\hline Waist circumference $(\mathrm{cm})$ & & 4 & & \\
\hline - Men & $101.5 \pm 12.1$ & 2 & $102.2 \pm 12.5$ & 0.340 \\
\hline - Women & $89.9 \pm 12.9$ & 2 & $91.0 \pm 13.5$ & 0.234 \\
\hline History of cardiovascular disease $(n, \%)$ & $473(16.6)$ & 65 & $88(18.0)$ & 0.431 \\
\hline Office SBP (mmHg) & $134.8 \pm 18.0$ & 2 & $136.1 \pm 19.2$ & 0.174 \\
\hline Office DBP (mmHg) & $76.2 \pm 9.8$ & 2 & $76.0 \pm 9.8$ & 0.678 \\
\hline Ambulatory 24-hour SBP $(\mathrm{mmHg})^{\mathrm{b}}$ & $119.2 \pm 11.5$ & 416 & $119.6 \pm 13.1$ & 0.507 \\
\hline Ambulatory 24-hour DBP $(\mathrm{mmHg})^{\mathrm{b}}$ & $73.9 \pm 7.2$ & 416 & $74.1 \pm 7.1$ & 0.561 \\
\hline Hypertension (n,\%) & $1613(56.1)$ & 6 & $302(56.9)$ & 0.775 \\
\hline Physical activity (hours/week) ${ }^{c}$ & $5.5 \pm 4.3$ & 432 & $5.8 \pm 4.7$ & 0.136 \\
\hline Smoking (\%never/former/current) & $35.1 / 52.0 / 12.9$ & 49 & $31.5 / 49.9 / 18.6$ & 0.003 \\
\hline Alcohol intake (\%none/low/high) & $18.6 / 56.2 / 25.2$ & 47 & $19.4 / 51.3 / 29.2$ & 0.099 \\
\hline Fasting glucose (mmol/L) & $6.1 \pm 1.6$ & 1 & $6.1 \pm 1.8$ & 0.285 \\
\hline 2-hour postload glucose $(\mathrm{mmol} / \mathrm{L})^{d}$ & $7.9 \pm 4.3$ & 251 & $7.7 \pm 4.0$ & 0.168 \\
\hline $\mathrm{HbA1c}(\mathrm{mmol} / \mathrm{mol})$ & $40.8 \pm 9.8$ & 13 & $42.5 \pm 10.8$ & $<0.001$ \\
\hline $\mathrm{HbA1c}(\%)$ & $5.9 \pm 0.9$ & 13 & $6.0 \pm 1.0$ & $<0.001$ \\
\hline Triglycerides (mmol/L) & $1.4 \pm 0.8$ & 4 & $1.5 \pm 0.9$ & 0.243 \\
\hline Total-to-HDL cholesterol ratio & $3.6 \pm 1.2$ & 4 & $4.0 \pm 1.2$ & $<0.001$ \\
\hline Total cholesterol (mmol/L) & $5.2 \pm 1.2$ & 4 & $5.2 \pm 1.2$ & 0.701 \\
\hline HDL cholesterol (mmol/L) & $1.5 \pm 0.5$ & 4 & $1.4 \pm 0.4$ & $<0.001$ \\
\hline LDL cholesterol (mmol/L) & $3.1 \pm 1.0$ & 4 & $3.2 \pm 1.0$ & 0.026 \\
\hline Antihypertensive medication use $(n, \%)$ & $1161(40.4)$ & 0 & $208(39.0)$ & 0.564 \\
\hline Lipid-modifying medication use $(\mathrm{n}, \%)$ & $1033(35.9)$ & 0 & $198(37.1)$ & 0.624 \\
\hline Diabetes medication use $(n, \%)$ & $641(22.3)$ & 0 & $125(23.4)$ & 0.573 \\
\hline -Insulin & $167(5.8)$ & 0 & $49(9.2)$ & 0.005 \\
\hline -Oral medication only & $600(20.9)$ & 0 & $114(21.3)$ & 0.817 \\
\hline
\end{tabular}


Supplemental Table S3.1 continued

\begin{tabular}{|c|c|c|c|c|}
\hline Characteristic & $\begin{array}{c}\text { Study population } \\
(\mathrm{N}=\mathbf{2 8 7 6})\end{array}$ & Missing & $\begin{array}{l}\text { Excluded due to missing values } \\
\qquad(\mathrm{N}=534)\end{array}$ & $p$-value \\
\hline eGFR $\left(\mathrm{ml} / \mathrm{min} / 1.73 \mathrm{~m}^{2}\right)$ & $88.2 \pm 14.7$ & 33 & $87.5 \pm 15.9$ & 0.314 \\
\hline Albuminuria $(n, \%){ }^{e}$ & $243(8.5)$ & 42 & $48(9.4)$ & 0.732 \\
\hline Retinopathy (n,\%) & $36(1.3)$ & 587 & $4(3.0)$ & 0.114 \\
\hline Neuropathy $(n, \%)^{f}$ & $277(10.9)$ & 470 & $49(12.2)$ & 0.441 \\
\hline CRAE (MU) & $142.3 \pm 20.4$ & 486 & $136.4 \pm 21.5$ & 0.045 \\
\hline CRVE (MU) & $214.7 \pm 31.3$ & 486 & $214.0 \pm 33.3$ & 0.875 \\
\hline
\end{tabular}

Data are reported as mean \pm SD or number (percentages \%) as appropriate, except diabetes duration, which is reported as median [interquartile range]. Student's $t$ and chi-square tests were used to compare continuous and categorical variables between the study population and individuals excluded due to missing values, respectively. The Mann-Whitney test was used to compare diabetes duration between the two populations

CRAE, central retinal arteriolar equivalent; CRVE, central retinal venular equivalent; DBP, diastolic blood pressure; eGFR, estimated glomerular filtration rate; HbA1c, hemoglobin A1c; HDL, high density lipoprotein; LDL, low density lipoprotein; MU: Measurement unit; SBP, systolic blood pressure

${ }^{\text {a }}$ Available in 673 in the study population and 125 in the excluded group

${ }^{b}$ Available in 2545 in the study population and 449 in the excluded group

${ }^{c}$ Available in 2535 in the study population and 443 in the excluded group

${ }^{d}$ Available in 2685 in the study population and 474 in the excluded group

${ }^{e}$ Albuminuria was defined as a urinary albumin excretion of $>30 \mathrm{mg}$ per 24 hours

${ }^{\dagger}$ Neuropathy was defined as a vibration perception threshold $>25 \mathrm{~V}$, and data were available in 2539 in the study population and 401 in the excluded group 
Supplemental Table S3.2 Multivariable-adjusted difference in retinal vascular diameters in individuals with prediabetes and type 2 diabetes versus normal glucose metabolism (NGM) with replacement of office by 24-hour systolic ambulatory blood pressure in regression models

\begin{tabular}{cccc}
\hline Characteristic & $\begin{array}{c}\text { Prediabetes }^{\text {a }} \\
\text { B (95\%Cl) }\end{array}$ & $\begin{array}{c}\text { Type 2 diabetes } \\
\text { B (95\%Cl) }\end{array}$ & $p$ for trend \\
\hline CRAE (MU) & & $1.67(-0.21,3.55)$ & 0.096 \\
Model 1 & $0.02(-2.29,2.32)$ & $2.27(-0.05,4.58)$ & 0.069 \\
Model 2a & $0.12(-2.24,2.48)$ & $2.09(-0.22,4.39)$ & 0.094 \\
Model 2b & $0.03(-2.33,2.38)$ & & 0.002 \\
CRVE (MU) & & $4.43(1.50,7.36)$ & 0.099 \\
Model 1 & $3.47(-0.12,7.05)$ & $2.93(-0.67,6.53)$ & 0.110 \\
Model 2a & $2.03(-1.65,5.71)$ & $2.83(-0.76,6.43)$ & \\
Model 2b & $1.98(-1.69,5.66)$ & &
\end{tabular}

Regression coefficients $(\mathrm{B})$ indicate the mean difference $(95 \% \mathrm{Cl})$ in retinal microvascular diameters with normal glucose metabolism as reference

$\mathrm{Cl}$, confidence interval; CRAE, central retinal arteriolar equivalent; CRVE, central retinal venular equivalent; MU: Measurement unit

a 24-h systolic ambulatory blood pressure was available in $n=2545$ of the study population (375 individuals with prediabetes and 722 individuals with type 2 diabetes)

Model 1: adjustment for age and sex

Model 2a: Model 1+adjustment for waist circumference, triglyceride levels, total-to-high-density-lipoprotein ratio, smoking status, office systolic blood pressure, use of antihypertensive medication and/or lipid-modifying medication

Model 2b: Model 1+adjustment for waist circumference, triglyceride levels, total-to-high-density-lipoprotein ratio, smoking status, 24-hour systolic ambulatory blood pressure, use of antihypertensive medication and/or lipid-modifying medication 
Supplemental Table S3.3 Multivariable-adjusted difference in retinal vascular diameters in individuals with prediabetes and type 2 diabetes versus normal glucose metabolism (NGM) with adjustment for renin-angiotensin-aldosterone system (RAAS)-inhibiting antihypertensives ${ }^{a}$ and other types of antihypertensives or replacement of waist circumference by BMI in regression models

\begin{tabular}{cccc}
\hline Characteristic & $\begin{array}{c}\text { Prediabetes } \\
\text { B }(\mathbf{9 5 \%} \mathbf{C l})\end{array}$ & $\begin{array}{c}\text { Type 2 diabetes } \\
\text { B (95\% Cl) }\end{array}$ & $\boldsymbol{p}$ for trend \\
\hline CRAE (MU) & & & \\
Model 1 & $0.42(-1.73,2.57)$ & $2.29(0.52,4.06)$ & 0.013 \\
Model 2a & $0.62(-1.58,2.83)$ & $2.89(0.69,5.08)$ & 0.013 \\
Model 2b & $0.60(-1.60,2.80)$ & $2.83(0.64,5.03)$ & 0.014 \\
Model 2c & $0.64(-1.57,2.84)$ & $2.86(0.67,5.06)$ & 0.013 \\
Model 2d & $0.53(-1.67,2.73)$ & $2.69(0.52,4.87)$ & 0.019 \\
CRVE (MU) & & & \\
Model 1 & $3.84(0.50,7.18)$ & $4.68(1.93,7.43)$ & 0.001 \\
Model 2a & $2.40(-1.03,5.84)$ & $2.87(-0.55,6.29)$ & 0.083 \\
Model 2b & $2.37(-1.06,5.80)$ & $2.89(-0.53,6.31)$ & 0.081 \\
Model 2c & $2.38(-1.06,5.82)$ & $2.90(-0.53,6.32)$ & 0.080 \\
Model 2d & $2.39(-1.04,5.82)$ & $2.87(-0.52,6.25)$ & 0.080 \\
\hline
\end{tabular}

Regression coefficients $(B)$ indicate the mean difference $(95 \% \mathrm{Cl})$ in retinal microvascular diameters with normal glucose metabolism as reference

$\mathrm{Cl}$, confidence interval; CRAE, central retinal arteriolar equivalent; CRVE, central retinal venular equivalent; MU: Measurement unit

a RAAS-inhibiting antihypertensives included angiotensin-converting-enzyme inhibitors, angiotensin receptor blockers, and renin blockers

Model 1: adjustment for age and sex

Model 2a: Model 1+adjustment for waist circumference, triglyceride levels, total-to-high-density-lipoprotein ratio, smoking status, office systolic blood pressure, use of antihypertensive medication and/or lipid-modifying medication

Model 2b: Model 1+adjustment for waist circumference, triglyceride levels, total-to-high-density-lipoprotein ratio, smoking status, office systolic blood pressure, use of RAAS-inhibiting antihypertensives, and use of lipid-modifying medication

Model 2c: Model 1+adjustment for waist circumference, triglyceride levels, total-to-high-density-lipoprotein ratio, smoking status, office systolic blood pressure, use of RAAS-inhibiting antihypertensives, use of non-RAAS-inhibiting antihypertensives and use of lipid-modifying medication

Model 2d: Model 1+adjustment for BMI, triglyceride levels, total-to-high-density-lipoprotein ratio, smoking status, office systolic blood pressure, use of antihypertensive medication and/or lipid-modifying medication 
Supplemental Table S3.4 Multivariable-adjusted difference in retinal vascular diameters in individuals with prediabetes and type 2 diabetes versus normal glucose metabolism (NGM) with additional adjustment for presence of retinopathy, presence of neuropathy, estimated glomerular filtration rate (eGFR) and albumin excretion, and history of cardiovascular disease

\begin{tabular}{|c|c|c|c|}
\hline Characteristic & $\begin{array}{c}\text { Prediabetes }^{a} \\
\text { B }(95 \% \mathrm{Cl})\end{array}$ & 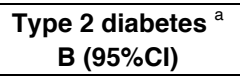 & $p$ for trend \\
\hline \multicolumn{4}{|l|}{ CRAE (MU) } \\
\hline Model 1 & $1.85(-0.52,4.23)$ & $1.92(-0.002,3.84)$ & 0.040 \\
\hline Model 2a & $2.16(-0.26,4.59)$ & $2.40(0.05,4.76)$ & 0.034 \\
\hline Model 2b & $2.17(-0.26,4.59)$ & $2.37(0.001,4.74)$ & 0.036 \\
\hline Model 2c & $2.16(-0.26,4.59)$ & $2.31(-0.07,4.69)$ & 0.042 \\
\hline Model 2d & $2.41(-0.01,4.82)$ & $2.51(0.14,4.89)$ & 0.026 \\
\hline Model $2 e$ & $2.51(0.09,4.93)$ & $2.54(0.16,4.92)$ & 0.024 \\
\hline \multicolumn{4}{|l|}{ CRVE (MU) } \\
\hline Model 1 & $4.41(0.70,8.13)$ & $4.80(1.80,7.81)$ & 0.001 \\
\hline Model 2a & $3.31(-0.49,7.11)$ & $3.10(-0.60,6.80)$ & 0.075 \\
\hline Model 2b & $3.33(-0.47,7.13)$ & $2.89(-0.83,6.61)$ & 0.094 \\
\hline Model 2c & $3.33(-0.48,7.13)$ & $2.88(-0.86,6.61)$ & 0.096 \\
\hline Model 2d & $3.75(-0.05,7.54)$ & $3.17(-0.55,6.90)$ & 0.065 \\
\hline Model 2e & $3.89(0.09,7.69)$ & $3.21(-0.52,6.94)$ & 0.061 \\
\hline
\end{tabular}

Regression coefficients $(\mathrm{B})$ indicate the mean difference $(95 \% \mathrm{Cl})$ in retinal microvascular diameters with normal glucose metabolism as reference

$\mathrm{Cl}$, confidence interval; CRAE, central retinal arteriolar equivalent; CRVE, central retinal venular equivalent; MU: Measurement unit

${ }^{\text {a }}$ Data were available in $n=2328$ of the study population (344 individuals with prediabetes and 683 individuals with type 2 diabetes)

Model 1: adjustment for age and sex

Model 2a: Model 1+adjustment for waist circumference, triglyceride levels, total-to-high-density-lipoprotein ratio, smoking status, office systolic blood pressure, use of antihypertensive medication and/or lipid-modifying medication

Model 2b: Model 2a+adjustment for retinopathy

Model 2c: Model 2b+adjustment for neuropathy (vibration perception thresholds $>25 \mathrm{~V}$ )

Model 2d: Model 2c+adjustment for eGFR and albumin excretion

Model 2e: Model 2d+adjustment for history of cardiovascular disease 
Supplemental Table S3.5 Multivariable-adjusted difference in retinal vascular diameters in individuals with prediabetes and type 2 diabetes versus normal glucose metabolism (NGM) with additional adjustment for physical activity and alcohol intake

\begin{tabular}{cccc}
\hline Characteristic & $\begin{array}{c}\text { Prediabetes }^{\text {a }} \\
\text { B (95\% }\end{array}$ & $\begin{array}{c}\text { Type 2 diabetes } \\
\text { B (95\% }\end{array}$ & $p$ for trend \\
\hline CRAE (MU) & $0.46(-1.78,2.70)$ & $1.92(0.05,3.79)$ & 0.049 \\
Model 1 & $0.72(-1.58,3.02)$ & $2.63(0.32,4.95)$ & 0.030 \\
Model 2a & $0.71(-1.59,3.01)$ & $2.62(0.30,4.94)$ & 0.031 \\
Model 2b & $0.66(-1.63,2.96)$ & $2.17(-0.18,4.52)$ & 0.076 \\
Model 2c & & & \\
CRVE (MU) & $3.94(0.43,7.45)$ & $3.39(0.46,6.33)$ & 0.014 \\
Model 1 & $2.53(-1.08,6.15)$ & $1.98(-1.67,5.63)$ & 0.226 \\
Model 2a & $2.53(-1.09,6.15)$ & $1.99(-1.67,5.64)$ & 0.227 \\
Model 2b & $2.50(-1.12,6.12)$ & $1.68(-2.01,5.38)$ & 0.293 \\
\hline Model 2c & & & \\
\hline
\end{tabular}

Regression coefficients $(B)$ indicate the mean difference $(95 \% \mathrm{Cl})$ in retinal microvascular diameters with normal glucose metabolism as reference

$\mathrm{CI}$, confidence interval; CRAE, central retinal arteriolar equivalent; CRVE, central retinal venular equivalent; $\mathrm{MU}$, Measurement unit

${ }^{a}$ Data were available in $n=2535$ of the study population (387 individuals with prediabetes and 685 individuals with type 2 diabetes)

Model 1: adjustment for age and sex

Model 2a: Model 1+adjustment for waist circumference, triglyceride levels, total-to-high-density-lipoprotein ratio, smoking status, office systolic blood pressure, use of antihypertensive medication and/or lipid-modifying medication

Model 2b: Model 2a+adjustment for physical activity

Model 2c: Model 2b+adjustment for alcohol intake 
Supplemental Table S3.6 Multivariable-adjusted difference in retinal vascular diameters in individuals with prediabetes and type 2 diabetes versus normal glucose metabolism (NGM) with additional adjustment for inflammation

\begin{tabular}{cccc}
\hline Characteristic & $\begin{array}{c}\text { Prediabetes }^{\text {a }} \\
\text { B (95\%Cl) }\end{array}$ & $\begin{array}{c}\text { Type 2 diabetes } \\
\text { B (95\%Cl) }\end{array}$ & $p$ for trend \\
\hline $\begin{array}{c}\text { CRAE (MU) } \\
\text { Model 1 }\end{array}$ & $0.32(-1.83,2.48)$ & $2.29(0.51,4.07)$ & 0.014 \\
Model 2a & $0.55(-1.66,2.76)$ & $2.88(0.68,5.09)$ & 0.013 \\
Model 2b & $0.54(-1.67,2.76)$ & $2.87(0.67,5.08)$ & 0.014 \\
CRVE (MU) & & & \\
Model 1 & $3.53(0.19,6.87)$ & $4.77(2.01,7.52)$ & $<0.001$ \\
Model 2a & $2.17(-1.27,5.61)$ & $3.01(-0.42,6.44)$ & 0.074 \\
Model 2b & $2.06(-1.38,5.50)$ & $2.87(-0.57,6.31)$ & 0.089 \\
\hline
\end{tabular}

Regression coefficients $(\mathrm{B})$ indicate the mean difference $(95 \% \mathrm{Cl})$ in retinal microvascular diameters with normal glucose metabolism as reference

$\mathrm{Cl}$, confidence interval; CRAE, central retinal arteriolar equivalent; CRVE, central retinal venular equivalent; MU, Measurement unit

a Inflammation was available in $n=2848$ of the study population (430 individuals with prediabetes and 803 individuals with type 2 diabetes)

Model 1: adjustment for age and sex

Model 2a: Model 1+adjustment for waist circumference, triglyceride levels, total-to-high-density-lipoprotein ratio, smoking status, office systolic blood pressure, use of antihypertensive medication and/or lipid-modifying medication

Model 2b: Model 2+adjustment for sum score of inflammation 
Supplemental Table S3.7 Multivariable-adjusted difference in retinal vascular diameters in individuals with prediabetes and type 2 diabetes versus normal glucose metabolism (NGM) excluding outliers in retinal microvascular diameters, participants with retinopathy, participants with catch-up fundus photography, or non-white population

\begin{tabular}{lccc}
\hline & Prediabetes & Type 2 diabetes & $p$ for trend \\
Characteristic & $\mathrm{B}(95 \% \mathrm{Cl})$ & $\mathrm{B}(95 \% \mathrm{Cl})$ & \\
\hline
\end{tabular}

Excluding outliers (defined as $<3 S D$ or $>3 S D$ ) in retinal microvascular diameters $(n=18)$ CRAE (MU)

$\begin{array}{rrrr}\text { Model 1 } & 0.74(-1.37,2.84) & 2.50(0.77,4.24) & 0.005 \\ \text { Model 2 } & 0.87(-1.29,3.03) & 3.00(0.84,5.15) & 0.008 \\ \text { Model 1 } & & & \\ \text { Model 2 } & 3.89(0.60,7.18) & 4.99(2.28,7.71) & <0.001 \\ \text { RVE }(\mathrm{MU}) & 2.47(-0.91,5.86) & 3.28(-0.09,6.66) & 0.046\end{array}$

Excluding participants with retinopathy $(n=36)$

CRAE (MU)

$\begin{array}{llll}\text { Model } 1 & 0.41(-1.75,2.56) & 2.27(0.47,4.06) & 0.016 \\ \text { Model } 2 & 0.59(-1.62,2.80) & 2.80(0.58,5.02) & 0.017\end{array}$

CRVE (MU)

$\begin{array}{llll}\text { Model } 1 & 3.77(0.42,7.11) & 4.43(1.65,7.22) & 0.001 \\ \text { Model } 2 & 2.28(-1.16,5.72) & 2.53(-0.93,5.98) & 0.125\end{array}$

Excluding participants with catch-up fundus photography $(n=176)$

CRAE (MU)

$\begin{array}{llll}\text { Model } 1 & 0.56(-1.65,2.77) & 2.41(0.61,4.22) & 0.010 \\ \text { Model } 2 & 0.78(-1.49,3.04) & 3.04(0.81,5.27) & 0.009\end{array}$

CRVE (MU)

$\begin{array}{llll}\text { Model } 1 & 3.67(0.22,7.13) & 4.80(1.98,7.62) & 0.001 \\ \text { Model 2 } & 2.26(-1.29,5.82) & 2.99(-0.52,6.49) & 0.082\end{array}$

Excluding non-white population $(n=41)$

CRAE (MU)

$\begin{array}{llll}\text { Model } 1 & 0.43(-1.73,2.59) & 2.24(0.45,4.03) & 0.017\end{array}$

$\begin{array}{llll}\text { Model } 2 & 0.65(-1.57,2.86) & 2.91(0.69,5.13) & 0.013\end{array}$

CRVE (MU)

$\begin{array}{llll}\text { Model } 1 & 3.74(0.39,7.10) & 4.32(1.54,7.10) & 0.001\end{array}$

Model 2

$2.39(-1.06,5.84)$

$2.62(-0.84,6.08)$

0.112

Regression coefficients (B) indicate the mean difference $(95 \% \mathrm{Cl})$ in retinal microvascular diameters with normal glucose metabolism as reference

$\mathrm{Cl}$, confidence interval; CRAE, central retinal arteriolar equivalent; CRVE, central retinal venular equivalent; $\mathrm{MU}$, Measurement unit

Model 1: adjustment for age and sex

Model 2: additional adjustment for waist circumference, triglyceride levels, total-to-high-density-lipoprotein ratio, smoking status, office systolic blood pressure, use of antihypertensive medication and/or lipid-modifying medication 
Supplemental Table S3.8 Multivariable-adjusted association between duration of type 2 diabetes and retinal microvascular diameters

\begin{tabular}{|c|c|c|c|}
\hline \multirow[b]{2}{*}{ Characteristic } & \multicolumn{2}{|c|}{ Duration of type 2 diabetes ${ }^{a}$} & \multirow[b]{2}{*}{$p$ for trend } \\
\hline & $\begin{array}{l}\text { 2nd tertile } \\
\text { B }(95 \% \mathrm{Cl})\end{array}$ & $\begin{array}{l}\text { 3rd tertile } \\
\text { B }(95 \% \mathrm{Cl})\end{array}$ & \\
\hline \multicolumn{4}{|l|}{ CRAE (MU) } \\
\hline Model 1 & $-1.59(-5.11,1.93)$ & $0.09(-3.43,3.61)$ & 0.711 \\
\hline Model 2 & $-0.95(-4.53,2.62)$ & $1.43(-2.20,5.06)$ & 0.315 \\
\hline \multicolumn{4}{|l|}{ CRVE (MU) } \\
\hline Model 1 & $-3.60(-9.08,1.88)$ & $-4.01(-9.50,1.47)$ & 0.441 \\
\hline Model 2 & $-2.48(-7.99,3.02)$ & $-2.09(-7.69,3.51)$ & 0.868 \\
\hline
\end{tabular}

Regression coefficients (B) indicate the mean difference $(95 \% \mathrm{Cl})$ in retinal microvascular diameters with the lowest tertile as reference

$\mathrm{Cl}$, confidence interval; CRAE, central retinal arteriolar equivalent; CRVE, central retinal venular equivalent; MU, Measurement unit

${ }^{a}$ Data were available in 673 individuals

Model 1: adjustment for age and sex

Model 2: Model 1+adjustment for waist circumference, triglyceride levels, total-to-high-density-lipoprotein ratio, smoking status, office systolic blood pressure, use of antihypertensive medication and/or lipid-modifying medication

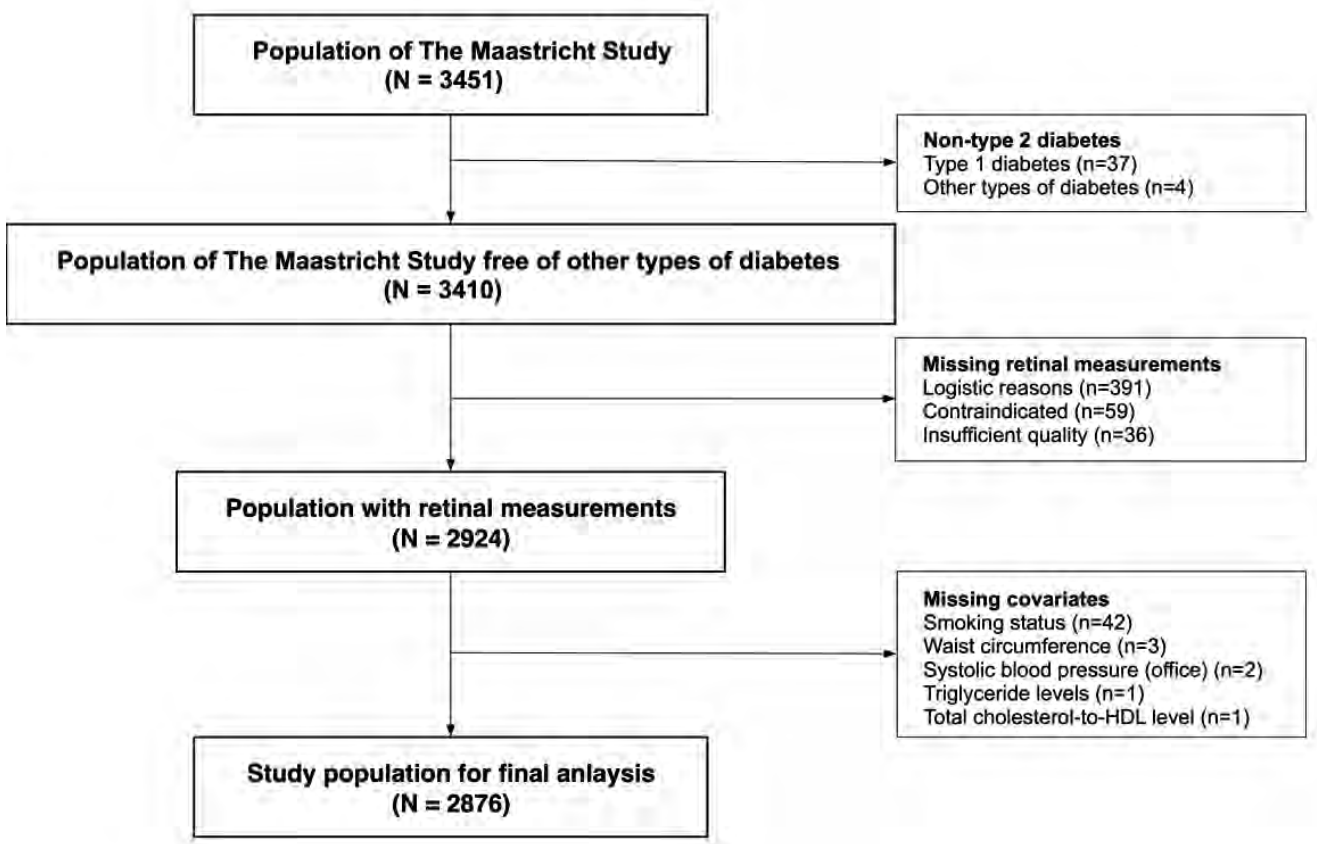

Supplemental Figure S3.1 Study population selection 


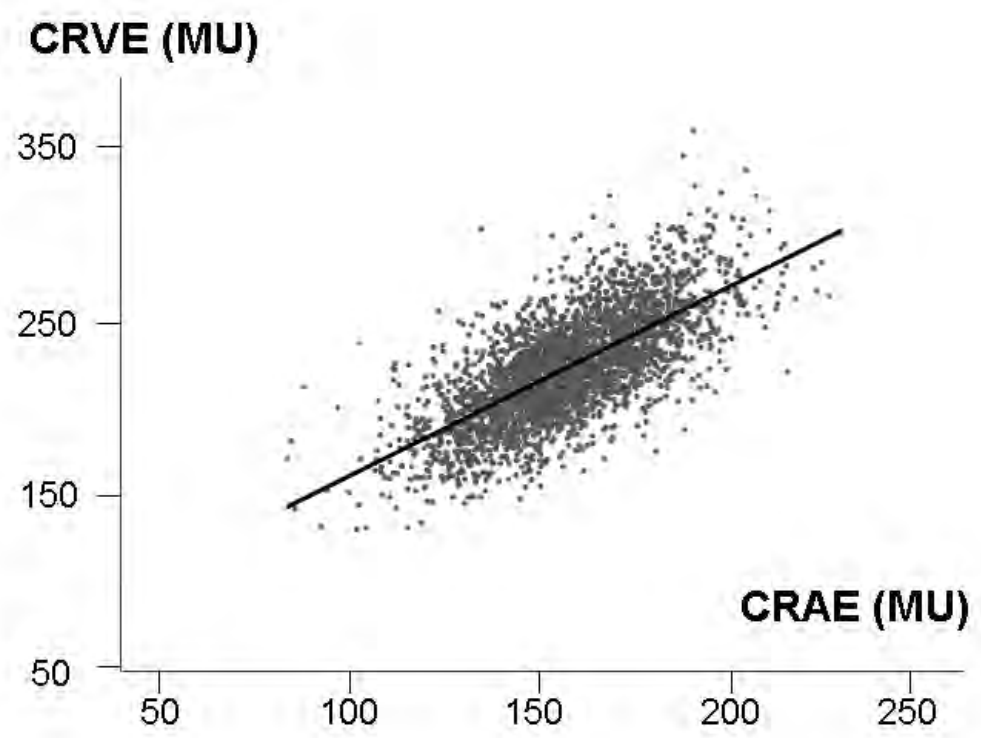

Supplemental Figure S3.2 Age- and sex-adjusted association between retinal arteriolar diameters and retinal venular diameters. CRAE, central retinal arteriolar equivalent; CRVE, central retinal venular equivalent; $\mathrm{MU}$, measurement unit 


\section{Chapter 4}

Microvascular Dysfunction is Associated with

Altered Beta Cell Function: The Maastricht Study

Wenjie LI, Miranda T Schram, Simone JS Sep, Tos TJM Berendschot, Carroll AB Webers, Abraham A Kroon, Carla JH van der Kallen, Ronald MA Henry, Simone JPM Eussen, Nicolaas C Schaper, Pieter C Dagnelie, Marleen MJ van Greevenbroek, Casper G Schalkwijk, Coen DA Stehouwer, Alfons JHM Houben 


\section{Chapter 5}

Microvascular Dysfunction is Associated with Higher CardiovascularRisk: The Maastricht Study

Wenjie Li, Miranda T Schram, Ronald MA Henry, Simone JPM Eussen, Abraham A Kroon, Annemarie Koster, Tos TJM Berendschot, Carroll AB Webers, Carla JH van der Kallen, Nicolaas C Schaper, Pieter C Dagnelie, Marleen MJ van Greevenbroek, Casper G Schalkwijk, Alfons JHM Houben, Coen DA Stehouwer 


\section{Chapter 6}

\section{Accelerometer-Measured Sedentary Time and}

Physical Activity and Incident Cardiovascular Disease: The Maastricht Study

Annemarie Koster *, Wenjie Li *, Miranda T Schram, Alfons JHM Houben, Pieter C Dagnelie, Sebastian Köhler, Carla JH van der Kallen, Simone JPM Eussen, Martien CJM van Dongen, Anke Wesselius, Nicolaas C Schaper, Hans HCM Savelberg, Coen DA Stehouwer

*These authors contributed equally to the manuscript 


\section{Chapter 7}

Summary and General Discussion

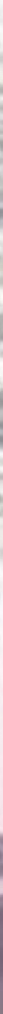




\section{Summary}

In Chapter 1, we have described the worldwide epidemic of cardiometabolic diseases, which leads to lower quality of life, additional healthcare expenditure, and risk of early death ${ }^{1,2}$. Investigations on the etiology can provide evidence for effective prevention and treatment. Microvascular dysfunction and physical (in)activity may play an important role in the development of cardiometabolic diseases, which, however, has not been well elucidated. Therefore, we aimed to investigate the association among microvascular dysfunction, physical (in)activity, and cardiometabolic diseases in a population-based study, The Maastricht Study ${ }^{3}$. In this dissertation, we applied advanced technologies which enabled more accurate and comprehensive assessments of microvascular function and physical behavior. The description of measurement protocols is necessary for researchers to identify whether differences in results across studies are based on differences in methodologies, especially for the measurements that are yet to be standardized. In Chapter 2, we described the protocols of the microvascular measurements applied in The Maastricht Study, including non-invasive measurements in skin, retina, brain, and sublingual tissue as well as plasma and urine biomarker assessments. The use of these measurements enables the study of microvascular changes in various (patho)physiological conditions, as well as their similarity and difference across the territories. Following this, we summarized the main findings in The Maastricht Study involving these microvascular measurements up to 2018. These cross-sectional studies have demonstrated associations between multiple cardiovascular risk factors (age, sex, blood pressure, waist circumference, etc.) and diseases (e.g. (pre)diabetes and depression) and microvascular (dys)function ${ }^{4-13}$. Finally, we provide a brief perspective of future microvascular investigations in The Maastricht Study, including fully automated analysis of microvascular imaging and longitudinal studies. We can already see some remarkable progress in the following chapters of this dissertation.

In Chapter 3, we investigated whether (pre)diabetes and plasma glucose levels were associated with retinal microvascular diameters. We performed a cross-sectional study in the framework of The Maastricht Study, including 2876 participants ( $n=1630$ normal glucose metabolism, $n=433$ prediabetes, and $n=813$ type 2 diabetes). We used oral glucose tolerance test (OGTT) to define the glucose metabolism status. We took fundus photographs of each participant and used a semi-automated software (retinal health information and notification system [RHINO]) to determine retinal arteriolar and venular diameters. Multivariable regression analyses were performed and adjusted for age, sex, waist circumference, smoking status, systolic blood pressure, lipid profile, and the use of lipid-modifying and/or antihypertensive 
medication. The results showed that type 2 diabetes, higher levels of hemoglobin A1c (HbA1c), and, possibly, prediabetes were significantly associated with wider retinal arteriolar diameters in a predominantly white population, independently of a broad array of potential confounders. The associations of (pre)diabetes and $\mathrm{HbA} 1 \mathrm{c}$ with retinal venular diameters were directionally similar to those for arterioles, even though they were not statistically significant after adjustment for potential confounders. We additionally explored the association between retinal arteriolar and venular diameters, and found that retinal arteriolar diameters were associated with retinal venular diameters, independently of age, sex, height, body surface area, systolic blood pressure, and $\mathrm{HbA} 1 \mathrm{c}$ level. Through more accurate assessments of the exposure and outcome, extensive adjustments for potential confounders, and the broad array of additional analyses, this study provided robust evidence and supported the concept that retinal microvascular changes already occur before the diagnosis of type 2 diabetes.

In Chapter 4, we explored the association of generalized microvascular dysfunction with beta cell function in 2275 participant without history of diabetes in The Maastricht Study. We used 7-point OGTT to assess the fasting insulin secretion and glucose-stimulated insulin secretion. We assessed microvascular function by plasma biomarkers of endothelial function, urinary albumin excretion, retinal microvascular diameters, flicker light-induced retinal microvascular dilation, heat-induced skin hyperemia and calculated a composite score. The results showed that higher plasma biomarkers, higher urinary albumin excretion, and wider retinal microvascular diameters were significantly associated with higher insulin secretion in the fasting state. Higher levels of plasma endothelial biomarkers and urinary albumin excretion were associated with higher glucose-stimulated insulin secretion in the late phase. Notably, these associations are independent of insulin sensitivity and other potential confounders. Our study is the first population-based study to show a close relationship between microvascular dysfunction and beta cell function in humans in vivo. The findings support the hypothesis that islet microvascular dysfunction may contribute to altered insulin secretion. In contrast, most of previous animal and in vitro studies have shown an attenuated glucose-stimulated insulin secretion induced by islet microvascular dysfunction. We may attribute the inconsistency to species differences. In addition, most of our study population had normal glucose tolerance.

In Chapter 5, we investigated whether systemic microvascular dysfunction was associated with incident cardiovascular disease, and if so, whether the associations differ across different vascular beds. Among 2531 participants in The Maastricht Study, we assessed microvascular function in multiple territories, including brain, retina, skin, plasma and kidney. A composite score of microvascular dysfunction was calculated. The follow-up of cardiovascular disease 
was performed by use of an annual questionnaire. After a median follow-up of 5 years, we found that a higher composite score was associated with a higher risk of incident cardiovascular disease in the fully adjusted Cox regression model. In addition, the associations were not significantly different with regard to outcomes in coronary, cerebral, and peripheral arteries. Based on these findings, systemic microvascular dysfunction may play an important role in the development of cardiovascular diseases in different vascular beds.

In Chapter 6, we examined the association between the volume and the pattern of sedentary behavior and physical activity with incident cardiovascular disease. We included 4706 participants without history of cardiovascular disease ( $n=336$ had incident events) in The Maastricht Study. We used the activPAL3 activity monitor to assess physical variables, including sedentary time, light-intensity physical activity (LIPA), moderate-to-vigorous-intensity physical activity (MVPA), vigorous-intensity physical activity (VPA), number of sedentary breaks, number of prolonged sedentary bouts ( $\geqslant 30$ minutes), average sedentary bout duration, and physical activity pattern. We performed a follow-up of cardiovascular disease using an annual questionnaire (median follow-up=5.1 years). The results showed a significant sex difference in the association of volume of sedentary behavior and physical activity with incident cardiovascular disease. In women, more MVPA was associated with an increased risk of developing cardiovascular disease. The association was not independent of mobility limitation and body mass index (BMI). In men, more LIPA was associated with a higher risk of cardiovascular disease, independently of potential confounders and mediators. This study is the first prospective study including middle to older aged population to investigate the association of accelerometer-measured sedentary behavior and physical activity with incident cardiovascular disease and show the shape of dose-response relations in sex subgroups. The linear association of MVPA with incident cardiovascular disease in women supports the advice on MVPA in the current guidelines, though meeting guidelines of $>150$ minutes/week of MVPA was not significantly associated with incident cardiovascular disease. In addition, the association of LIPA with incident cardiovascular disease in men may suggest a potential role of occupational physical activity in the development of cardiovascular disease.

\section{Methodological considerations}

Internal validity

This dissertation was aimed to enhance our knowledge on the role of microvascular dysfunction and physical activity in cardiometabolic diseases. However, the results could deviate from the 
truth due to methodological limitations (systemic error). Therefore, we should cautiously consider the limitations and their influence when interpreting our findings.

\section{Selection bias}

Selection bias occurs when the sample is not representative of the source population. Among a variety of selection bias, sampling bias and attrition bias may be involved in this dissertation. On one hand, The Maastricht Study is oversampled with type 2 diabetes $^{3}$, which was designed to increase statistical power to detect the difference between individuals with and without diabetes (Chapter 3). However, the association of microvascular dysfunction with incident cardiovascular disease did not differ with diabetes status (Chapter 5), indicating that the results may not be biased due to the oversampling. On the other, the participants were recruited through mass media campaigns and from the municipal registries and the regional Diabetes Patient Registry by mailings, suggesting that a majority of participants with diabetes in The Maastricht Study were well treated. In addition, participation in The Maastricht Study required three and a half days for multiple measurements. Therefore, individuals with a relatively healthy condition and higher educational level were more likely to participate, and led to underestimated associations and limited external validity.

The complete-case analysis approach in our studies can cause attrition bias ${ }^{14}$. We excluded participants with missing data on exposures (microvascular dysfunction and physical behavior), outcomes (beta cell function and incident cardiovascular disease), and/or covariates. First, most of the missings on microvascular measures were of logistics reasons. As the microvascular measurements were implemented gradually in The Maastricht Study, it is conceivable that only participants recruited after the implementation underwent the measurements (Chapter 2). In this dissertation, individuals with and without data on retinal microvascular diameters $(n=486)$ and confounders $(n=48)$ had a highly comparable cardiometabolic profile (Chapter 3). In addition, for those who had not the measurement, we attempted to perform catch-up fundus photography. Previous investigations also showed that excluding individuals without data on flicker light-induced retinal microvascular dilation, heatinduced skin hyperemia and/or physical activity may not affect the results ${ }^{7,15}$. However, it was reported that participants without measurement of cerebral small vessel disease had a worse cardiometabolic profile ${ }^{8}$. Therefore the association may be distorted in our study including the brain marker as measure of microvascular dysfunction (Chapter 5). Second, we excluded 249 participants due to missing data on beta cell function (Chapter 4). As these data were unavailable mostly in participants with diabetes, who were already excluded by intention, we assumed it unlikely to influence the results. Third, in the longitudinal studies (Chapter 5, 6), 5\% 
of the participants did not have any follow-up data on incident cardiovascular disease. The loss to follow-up can result from adverse cardiovascular conditions. However, incident events within the first year of follow-up may suggest a reverse association. We therefore considered a limited influence on our results.

\section{Information bias}

Measurement errors occur in a differential or nondifferential manner to all study subjects. These errors may cause bias in the estimation of associations, i.e., information bias ${ }^{16}$. The differential errors can lead to both overestimation and underestimation of the true association. Nondifferential errors, especially that of an exposure variable, can also bias the estimates of assassinations to null ${ }^{17}$.

In investigating the association between (pre)diabetes and retinal microvascular diameters (Chapter 3), we used OGTT to define glucose metabolism status. Compared with fasting plasma glucose, random plasma glucose and HbA1c, OGTT is more sensitive to an impaired glucose metabolism, more pathophysiologically indicative, and is the gold standard for diagnosis of diabetes ${ }^{18}$. Considering its relatively poor day-to-day reproducibility which may cause undifferential error and underestimation of associations, we also used measures of glycemia to confirm the association, and the results were consistent.

In the studies of microvascular dysfunction as an exposure (Chapter 4,5 ) or outcome (Chapter 3), the measurements were performed by well-trained researchers (Chapter 2). We had specific requirements regarding effects of smoking, diet, exercise, and room temperature on microvascular function ${ }^{3,19,20}$. What's more, we used multiple measurements and a composite score of microvascular dysfunction, considering the biological variability and heterogeneity across different microvascular beds (Chapter 5). Also because of the heterogeneity ${ }^{21}$, we should take caution when inferring the results in other territories to islet microvasculature (Chapter 4). In the measurement of retinal microvascular diameters (Chapter 3), we applied a semi-automated analysis, which is more reproducible than manual procedure 22. As the fundus photograph of only one eye was analyzed (randomly chosen), differences between left and right eye may exist. However, we did not find significant difference in the association. In addition, we used a revised Knudtson-Parr-Hubbard formula ${ }^{23}$, and therefore the observed diameters were not influenced by number of microvessels in the calculation. Assuming that there were more errors in measuring retinal microvascular diameters in participants with retinopathy, we excluded these patients in the sensitivity analysis and found similar results. Nevertheless, the reproducibility was not perfect and we did not apply repeated 
measurements. This may cause bias that resulted in nonsignificant and underestimated associations.

Similar to the microvascular measurements, there is no consensus regarding which indices reflect the beta cell function best. The physiological mechanism underlying insulin secretion was different between fasting and glucose-stimulated states, as well as the early and late phase after the glucose stimulation ${ }^{24}$. We therefore measured beta cell function by fasting insulin secretion and glucose-stimulated insulin secretion in the early and late phase (Chapter 4). The use of these indices may provide a more comprehensive understanding of physiological insulin secretory response to glucose ingestion and microvascular alternation. Considering the effects of glucose levels and insulin clearance on insulin concentration in the circulation, we measured C-peptide instead of insulin levels and adjusted for glucose levels. The results based on these simple indices were relatively easy for understanding and comparing with results of animal experiments. However, use of these indices can also cause information bias. For example, we measured C-peptide and glucose levels in the circulation, and therefore the indices may not reflect the true beta cell function.

In Chapter 6, we used activPAL3 activity monitor to measure daily physical activity and sedentary behavior, which was more accurate than self-reported questionnaires and hip-worn accelerometers ${ }^{25-27}$. However, the accelerometer may underestimate the physical activity and cause misclassification, as it cannot well capture some activities, such as balance and resistance training ${ }^{28}$. Regarding the awareness of wearing the device, which may influence the physical behavior, we excluded those with accelerometer data less than 4 valid days $(n=211,8$ consecutive days in total) and found that the results were similar.

In the prospective studies (Chapter 5, 6), we used an annual self-reported questionnaire for follow-up of cardiovascular disease. We did not include cardiovascular death in the outcome. As cardiovascular disease is a major cause of death in the general population ${ }^{29}$, the association may be underestimated. In addition, use of self-reported questionnaire may cause misclassification due to misunderstanding of the questions and reporting bias ${ }^{30,31}$. We validated the self-reported cardiovascular diseases with medical records in The Maastricht Study (Chapter 5). The sensitivity and specificity were 0.80 and 0.89 respectively. However, $52 \%$ of self-reported cardiovascular diseases were not recorded in the medical data, most of which were reported as peripheral vascular disease. Although this inconsistency may be due to misunderstanding, there was a possibility that the participants went to other hospital for diagnosis and treatment. Additionally, a reporting lag may exist between the onset of symptoms and diagnosis, as well as between the diagnosis by general practitioner and recording on file. 
This is supported by the finding in other cohort that self-reported peripheral vascular disease was associated with future vascular events (myocardial infarction, ischemic stroke, and vascular death) ${ }^{32}$.

Errors can also occur in the measurement of confounders, which increases the possibility of residual confounding (see confounding and overadjustment section).

\section{Confounding and overadjustment}

Extensive phenotyping in The Maastricht Study has enabled detection of independent associations after adjustment for potential confounders, i.e., a third variable that is associated with both exposure and outcome variables and thus affect their association ${ }^{16}$. For example, glucose-lowering interventions, such as diet and metformin, can affect both microvascular function and beta cell function ${ }^{33-35}$. To avoid this potential confounding, we excluded individuals with a history of diabetes (Chapter 4). Ignoring the potential confounding may increase the chance of type 1 error. The confounding effect can also be controlled in the multivariable regression analysis. However, residual confounding by inaccurate measurement of potential confounders can increase the chance of type 1 error. In particular, 24-hour ambulatory blood pressure is a more accurate measure of blood pressure ${ }^{36}$, as it can eliminate the 'white coat' effect that occurs in measuring office blood pressure (Chapter 3,4,5). The Dutch Healthy Diet Index 2015 (Chapter 5,6) may be an accurate assessment of the diet quality of our study population, as it was based on the data of local inhabitants ${ }^{37,38}$. In Chapter 4, we used the Matsuda index as a measure of insulin sensitivity. Despite its good correlation with the 'gold standard' hyperinsulinemic-euglycemic clamp in individuals without diabetes ${ }^{39}$, the inaccurate assessment of insulin sensitivity may lead to residual confounding in the association of microvascular (dys)function and beta cell function.

Overadjustment bias may have occurred in our fully-adjusted models ${ }^{40}$. For example, weight gain (measured as BMI and waist circumference) can be on the causal pathway between microvascular dysfunction and type 2 diabetes (Chapter 3). Therefore, we conservatively interpreted the association of (pre)diabetes with retinal venular diameters, which was statistically nonsignificant. In Chapter 6, we constructed a separate model to adjust the association for mobility limitation and BMI, since both of them can be on the pathway between physical (in)activity and cardiovascular disease.

\section{External validity}

The findings in The Maastricht Study can be generalized to a population with similar characteristics, i.e., middle- to older-aged white population with well-controlled cardiometabolic 
risk factors (Chapter 3, 5, 6). Additionally, our finding in the association of microvascular dysfunction with beta cell function was restricted to the population without treated diabetes (Chapter 4). Nevertheless, we found a similar association in the population of The Cohort on Diabetes and Atherosclerosis Maastricht (CODAM) Study. The participants of the CODAM had worse cardiometabolic profiles than the participants of The Maastricht Study. Besides, the observed associations in this dissertation were similar for the population without retinopathy (Chapter 3), for the population with normal glucose metabolism (Chapter 4), and for the population without a history of cardiovascular disease (Chapter 5). Therefore, the findings may be applicable to a broader population. Indeed, the associations of diabetes with retinal microvascular diameters have been found in other studies on non-Whites as well ${ }^{41-47}$. In general, the primary goal of this dissertation was to provide robust evidence for a better understanding of the role of microvascular function and physical behavior in cardiometabolic diseases. The demonstration of valid results with minimum bias was in the highest priority.

\section{Temporality}

In Chapters 3 and 4, we used cross-sectional data of The Maastricht Study, which cannot build a solid causal link between the exposures and the outcomes in our hypotheses. For instance, we cannot determine whether microvascular dysfunction preceded greater insulin secretion, and evidence of previous experimental studies also favors the reverse relationship ${ }^{48,49}$, i.e., hyperinsulinemia can impair microvascular function. Nevertheless, we at least show a possibility that the influence of microvascular dysfunction on beta cell function in humans may differ from that has been found in animal and in vitro studies. In addition, the bidirectional relationship may exist in both studies and construct a vicious circle (Chapter 3, 4). In Chapters 5 and 6, we used longitudinal data and thus the reverse causality can be excluded ${ }^{16,50}$. Note that in Chapter 6 we excluded the cardiovascular events that occurred within the first year of follow-up, which made the causal relationship more valid. As addressed previously, the observed associations in this dissertation were adjusted for a broad array of potential confounders, and the associations remained in most cases. Although we cannot exclude the possibility of residual confounding, these results strengthen our hypothesis that the associations were causal ${ }^{50}$.

\section{Conclusion and future directions}

Taken together, the results in this dissertation show that both microvascular dysfunction and physical (in)activity may play an important role in cardiometabolic diseases (Figure 7.1). The 
findings support the 'ticking clock' hypothesis ${ }^{51}$ that the risk of cardiovascular disease already increases before the diagnosis of type 2 diabetes. More specifically, impaired glucose metabolism can lead to microvascular dysfunction. The effect can be systematic, as the association exists not only for the microvasculature in retina but also for that in skin and brain ${ }^{7,8}$. In addition, the association between microvascular dysfunction and (pre)diabetes can be bidirectional. In individuals without a history of diabetes, we found that generalized microvascular dysfunction is associated with greater insulin secretion. This finding, consistent with a hyperbola relationship between insulin sensitivity and beta cell function ${ }^{52}$, may support the concept of beta-cell exhaustion that type 2 diabetes could be a consequence of insulin depletion, rather than beta cell dysfunction ${ }^{53}$. We also found associations of microvascular dysfunction (in general population) and physical inactivity (in women) with higher risk of cardiovascular disease. According to a previous finding in The Maastricht Study ${ }^{15}$, physical inactivity can be a determinant of microvascular dysfunction and associated with greater odds for metabolism syndrome and type 2 diabetes ${ }^{54}$. Therefore, physical activity may reduce the risk of cardiometabolic diseases via protecting microvascular function.

Further investigations are still needed. First, regarding the bias due to loss to follow-up, we need to include (cardiovascular) mortality in the outcome data. Second, we investigated the association between microvascular dysfunction and beta cell function only with cross-sectional data. Therefore, longitudinal studies are needed to strengthen the causality. In addition, a more accurate measurement of islet microvascular function needs to be developed. Third, there is a need for studies that investigate potential interventions to counter the effects of microvascular dysfunction on the adverse cardiometabolic outcomes. For instance, whether the physical activity-improved microvascular function can reduce the risk of cardiovascular disease remains unknown. Finally, some findings in this dissertation (e.g., the association of microvascular dysfunction with beta cell function) have not been validated with other populations. The associations are assumed to be qualitatively similar but in different degrees due to the different distribution of cardiometabolic risk factors across populations. The suggestions based on these studies may be more tailored to local conditions. 


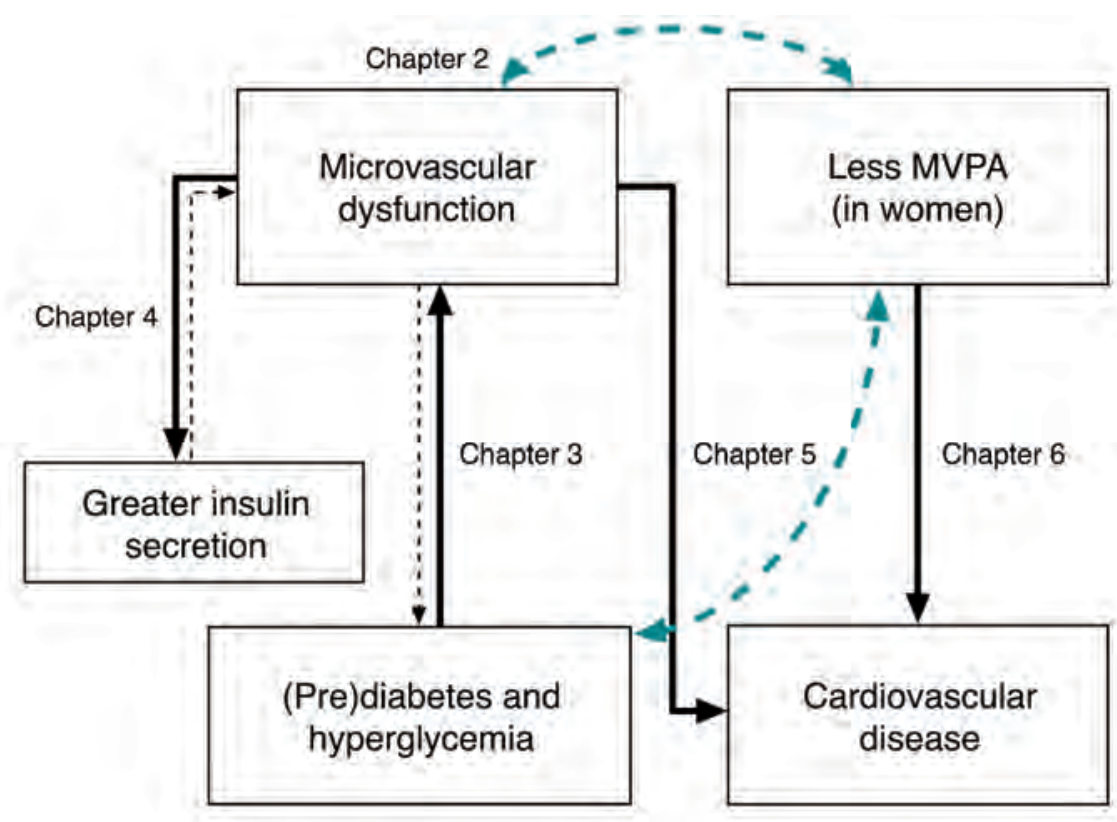

Figure 7.1 Associations of microvascular dysfunction and physical activity with cardiometabolic diseases. Solid arrows indicate associations found in the present dissertation. Black dashed lines represent potential reverse associations. Blue dashed lines represent associations in previous analyses from The Maastricht Study 


\section{References}

1. International Diabetes Federation. IDF Diabetes Atlas Ninth Edition. 2019.

2. Mendis S, Puska P, Norrving B, World Health Organization. Global atlas on cardiovascular disease prevention and control. World Health Organization. 2011.

3. Schram MT, Sep SJ, van der Kallen CJ, Dagnelie PC, Koster A, Schaper N, et al. The Maastricht Study: an extensive phenotyping study on determinants of type 2 diabetes, its complications and its comorbidities. Eur J Epidemiol. 2014;29(6):439-451.

4. van Dooren FEP, Schram MT, Schalkwijk CG, Stehouwer CD, Henry RM, Dagnelie PC, et al. Associations of low grade inflammation and endothelial dysfunction with depression-The Maastricht Study. Brain Behav Immun. 2016;56:390-396.

5. Muris DM, Houben AJ, Kroon AA, Henry RM., van der Kallen CJ, Sep SJ, et al. Age, waist circumference, and blood pressure are associated with skin microvascular flow motion: the Maastricht Study. J Hypertens. 2014;32(12):2439-2449.

6. Sörensen BM, Houben AJHM, Berendschot TTJM, Schouten JS, Kroon AA, van der Kallen CJ, et al. Cardiovascular risk factors as determinants of retinal and skin microvascular function: The Maastricht Study. PLoS One. 2017;12(10):e0187324.

7. Sörensen BM, Houben AJHM, Berendschot TTJM, Schouten JS, Kroon AA, van der Kallen CJ, et al. Prediabetes and Type 2 Diabetes Are Associated With Generalized Microvascular Dysfunction: The Maastricht Study. Circulation. 2016;134(18):1339-1352.

8. van Agtmaal MJ, Houben AJHM, de Wit V, Henry RM, Schaper NC, Dagnelie PC, et al. Prediabetes Is Associated With Structural Brain Abnormalities: The Maastricht Study. Diabetes care. 2018;41(12):25352543.

9. van Sloten TT, Czernichow S, Houben AJ, Protogerou AD, Henry RM, Muris DM, et al. Association Between Arterial Stiffness and Skin Microvascular Function: The SUVIMAX2 Study and The Maastricht Study. Am J Hypertens. 2015;28(7):868-876.

10. Sörensen BM, Houben AJHM, Berendschot TTJM, Schouten JS, Kroon AA, van der Kallen CJ, et al. Hyperglycemia Is the Main Mediator of Prediabetes- and Type 2 Diabetes-Associated Impairment of Microvascular Function: The Maastricht Study. Diabetes Care. 2017;40(8):e103-105.

11. Martens RJ, Kooman JP, Stehouwer CD, Dagnelie PC, van der Kallen CJ, Koster A, et al. Estimated GFR, Albuminuria, and Cognitive Performance: The Maastricht Study. Am J Kidney Dis. 2017;69(2):179-191.

12. Martens RJ, Henry RM, Houben AJ, van der Kallen CJ, Kroon AA, Schalkwijk CG, et al. Capillary Rarefaction Associates with Albuminuria: The Maastricht Study. J Am Soc Nephrol. 2016;27(12):3748-3757.

13. Martens RJ, Houben AJ, Kooman JP, Berendschot TT, Dagnelie PC, van der Kallen CJ, et al. Microvascular endothelial dysfunction is associated with albuminuria: the Maastricht Study. J Hypertens. 2018;36(5):11781187.

14. Juni $\mathrm{P}$, Egger M. Empirical evidence of attrition bias in clinical trials (vol 34, pg 87, 2006). Int J Epidemiol. 2006;35(6), 1595-1595.

15. Sörensen BM, van der Heide FC, Houben AJ, Koster A., Berendschot TTJM, Schouten JSAG, et al. Higher levels of daily physical activity are associated with better skin microvascular function in type 2 diabetes-The Maastricht Study. Microcirculation. 2020: e12611.

16. Rothman KJ, Greenland S, Lash TL. (Eds.). Modern epidemiology. Lippincott Williams \& Wilkins. 2008.

17. Hutcheon JA, Chiolero A., Hanley JA. Random measurement error and regression dilution bias. Bmj. 2010: 340 .

18. Inzucchi SE. Diagnosis of diabetes. N Engl J Med. 2012; 367(6):542-550.

19. Garhöfer G, Resch H, Sacu S, Weigert G, Schmidl D, Lasta M, Schmetterer L. Effect of regular smoking on flicker induced retinal vasodilatation in healthy subjects. Microvasc Res. 2011;82(3):351-355.

20. Jonk AM, Houben AJ, Schaper NC, de Leeuw PW, Serné EH, Smulders YM, Stehouwer CD. Meal-related increases in microvascular vasomotion are impaired in obese individuals: a potential mechanism in the pathogenesis of obesity-related insulin resistance. Diabetes Care. 2011;34(Supplement 2):S342-348.

21. Aird WC. Phenotypic heterogeneity of the endothelium: I. Structure, function, and mechanisms. Circ Res. 2007;100(2):158-173. 
22. Huang F, Dashtbozorg B, Zhang J, Yeung A, Berendschot TT, ter Haar Romeny BM. Validation study on retinal vessel caliber measurement technique. In: European Congress on Computational Methods in Applied Sciences and Engineering, Porto, Portugal, October 18-20. New York, NY: Springer Publishing Company; 2017:818-826.

23. Knudtson MD, Lee KE, Hubbard LD, Wong TY, Klein R, Klein BE. Revised formulas for summarizing retinal vessel diameters. Curr Eye Res. 2003;27(3):143-149.

24. Cersosimo, E., Solis-Herrera, C., E Trautmann, M., Malloy, JL, Triplitt, C. Assessment of pancreatic $\beta$-cell function: review of methods and clinical applications. Curr Diabetes Rev. 2014;10(1):2-42.

25. Downs, A., Van Hoomissen J, Lafrenz A, Julka DL. Accelerometer-measured versus self-reported physical activity in college students: Implications for research and practice. J Am Coll Health. 2014;62(3):204-212.

26. Atkin AJ, Gorely T, Clemes SA, Yates T, Edwardson C, Brage S, et al. Methods of measurement in epidemiology: sedentary behaviour. Int J Epidemiol. 2012;41(5):1460-1471.

27. Kozey-Keadle S, Libertine A, Lyden K, Staudenmayer J, Freedson PS. Validation of wearable monitors for assessing sedentary behavior. Med Sci Sports Exerc. 2011;43(8):1561-1567.

28. Gomersall SR, Skinner TL, Winkler E, Healy GN, Eakin E, Fjeldsoe B. Feasibility, acceptability and efficacy of a text message-enhanced clinical exercise rehabilitation intervention for increasing 'whole-of-day'activity in people living with and beyond cancer. BMC public health. 2019;19(2):542.

29. OECD/European Observatory on Health Systems and Policies (2017), Netherlands: Country Health Profile 2017, State of Health in the EU, OECD Publishing, Paris/European Observatory on Health Systems and Policies, Brussels.

30. Short ME, Goetzel RZ, Pei X, Tabrizi MJ, Ozminkowski RJ, Gibson TB, et al. How accurate are self-reports? Analysis of self-reported health care utilization and absence when compared with administrative data. Journal of occupational and environmental medicine. 2009;51(7):786-796.

31. Reijneveld SA, Stronks K. The validity of self-reported use of health care across socioeconomic strata: a comparison of survey and registration data. Int J Epidemiol. 2001;30(6):1407-1414.

32. Salameh MJ, Rundek T, Boden-Albala B, Jin Z, Ratchford EV, Di Tullio MR, et al. Self-reported peripheral arterial disease predicts future vascular events in a community-based cohort. J Gen Intern Med. 2008;23(9):1423.

33. Klonizakis M, Grammatikopoulou MG, Theodoridis X, Milner M, Liu Y, Chourdakis M. Effects of Long-Versus Short-Term Exposure to the Mediterranean Diet on Skin Microvascular Function and Quality of Life of Healthy Adults in Greece and the UK. Nutrients. 2019;11(10):2487.

34. Diabetes Prevention Program Research Group. Long-term effects of lifestyle intervention or metformin on diabetes development and microvascular complications over 15-year follow-up: the Diabetes Prevention Program Outcomes Study. Lancet Diabetes Endocrinol. 2015;3(11), 866-875.

35. Top W, Stehouwer C, Lehert P, Kooy A.. Metformin and $\beta$-cell function in insulin-treated patients with type 2 diabetes: A randomized placebo-controlled 4.3-year trial. Diabetes Obes Metab. 2018;20(3):730-733.

36. Melville S, Byrd JB. Monitoring blood pressure outside of the doctor's office. JAMA. 2018;320(17):1830.

37. van Lee L, Geelen A, van Huysduynen EH, de Vries JH, van't Veer P, Feskens EJ. Associations between company at dinner and daily diet quality in Dutch men and women from the NQplus study. Eur J Clin Nutr. 2016;70:1368-1373.

38. Looman M, Feskens EJ, de Rijk M, Meijboom S, Biesbroek S, Temme EH, et al. Development and evaluation of the Dutch Healthy Diet index 2015. Public Health Nutr. 2017;20(13):2289-2299.

39. Gutch M, Kumar S, Razi SM, Gupta KK, Gupta A. Assessment of insulin sensitivity/resistance. Indian J Endocrinol Metab. 2015;19(1):160.

40. Schisterman EF, Cole SR, Platt RW. Overadjustment bias and unnecessary adjustment in epidemiologic studies. Epidemiology (Cambridge, Mass.). 2009;20(4):488.

41. Nguyen TT, Wang JJ, Sharrett AR, Islam FA, Klein R, Klein BE, et al. Relationship of retinal vascular caliber with diabetes and retinopathy: the Multi-Ethnic Study of Atherosclerosis (MESA). Diabetes Care. 2008;31(3):544-549.

42. Jeganathan VS, Sabanayagam C, Tai ES, Lee J, Lamoureux E, Sun C, et al. Retinal vascular caliber and diabetes in a multiethnic Asian population. Microcirculation. 2009;16(6):534-543. 
43. Tikellis G, Wang JJ, Tapp R, Simpson R, Mitchell P, Zimmet PZ, et al. The relationship of retinal vascular calibre to diabetes and retinopathy: the Australian Diabetes, Obesity and Lifestyle (AusDiab) study. Diabetologia. 2007;50(11):2263-2271.

44. Cheung CY, Lamoureux E, Ikram MK, Sasongko MB, Ding J, Zheng Y, et al. Retinal vascular geometry in Asian persons with diabetes and retinopathy. J Diabetes Sci Technol. 2012;6(3):595-605.

45. Islam FM, Nguyen TT, Wang JJ, Tai ES, Shankar A, Saw SM, et al. Quantitative retinal vascular caliber changes in diabetes and retinopathy: the Singapore Malay eye study. Eye (Lond). 2009; 23(8):1719-1724.

46. Tsai AS, Wong TY, Lavanya R, Zhang R, Hamzah H, Tai ES, Cheung CY. Differential association of retinal arteriolar and venular caliber with diabetes and retinopathy. Diabetes Res Clin Pract. 2011; 94(2):291-298.

47. Kifley A, Wang JJ, Cugati S, Wong TY, Mitchell P. Retinal vascular caliber, diabetes, and retinopathy. Am J Ophthalmol. 2007;143(6):1024-1026.

48. Iredahl F, Högstedt A, Henricson J, Sjöberg F, Tesselaar E, Farnebo S. Skin glucose metabolism and microvascular blood flow during local insulin delivery and after an oral glucose load. Microcirculation. 2016;23(7):597-605.

49. Arcaro G, Cretti A, Balzano S, Lechi A, Muggeo M, Bonora E, Bonadonna RC. Insulin causes endothelial dysfunction in humans: sites and mechanisms. Circulation. 2002;105(5):576-582.

50. Stehouwer CD. Microvascular dysfunction and hyperglycemia: a vicious cycle with widespread consequences. Diabetes. 2018;67(9):1729-1741.

51. Wong MS, Gu K, Heng D, Chew SK, Chew LS, Tai ES. The Singapore impaired glucose tolerance follow-up study: does the ticking clock go backward as well as forward?. Diabetes Care. 2003;26(11):3024-3030.

52. Cobelli C, Toffolo GM, Man CD, Campioni M, Denti P, Caumo A, et al. Assessment of $\beta$-cell function in humans, simultaneously with insulin sensitivity and hepatic extraction, from intravenous and oral glucose tests. Am J Physiol Endocrinol Metab. 2007;293(1), E1-E15.

53. Erion K, Corkey BE. $\beta$-Cell Failure or $\beta$-Cell Abuse?. Front Endocrinol (Lausanne). 2018;9:532.

54. van der Velde JH, Schaper NC, Stehouwer CD, van der Kallen CJ, Sep SJ, Schram MT, et al. Which is more important for cardiometabolic health: sedentary time, higher intensity physical activity or cardiorespiratory fitness? The Maastricht Study. Diabetologia. 2018;61(12):2561-2569. 
Valorisation addendum 


\section{Social and economic relevance}

Ideally, any theoretical and technological innovation in medical research can be applied to practice. However, Rome was not built in a day; it was built due to unremitting efforts of several generations. When M. Malpighi and A. van Leeuwenhoek first observed the blood flow through capillaries under the microscope, they might not have realized that a new chapter in the knowledge of circulation and its (patho)physiological functions embarked. Moreover, the finding has driven the industry which developed a variety of techniques to quantitatively assess microvascular function. This is also the case for assessments of physical behavior. As we described in the previous chapters, we have gained more knowledge by use of these assessments in the population-based cohort. Although this dissertation only investigates microvascular (dys)function and physical (in)activity as determinants of cardiometabolic diseases, further investigations may focus on their values of prevention and treatment based on our findings. If these assessments are proven to have higher values of prevention and treatment, they are expected to reduce premature death, disability, and medical expenses due to cardiometabolic diseases.

\section{Target group}

Our study population included middle- to older-aged population. Nevertheless, our findings may be generalized to a broader population, even to young adults. According to our results, better microvascular function and physical activity at baseline reduced participants' risk of cardiovascular diseases at any given time. Previous meta-analyses have shown that microvascular dysfunction is associated with a higher risk of type 2 diabetes which may occur after 10 years ${ }^{1,2}$. These results support a concept that the risk of cardiometabolic diseases may begin to increase at a younger age, and preventive awareness and measures should be taken earlier.

\section{Innovation}

The application of innovative technologies in this dissertation have enhanced the reliability of our findings and confirmed the feasibility of their use in a large population. The use of multiple microvascular measurements enabled us to assess microvascular function across vascular beds (i.e., arterioles, venules, and capillaries) and territories and their similarity and difference 
in response to various (patho)physiological conditions. No previous studies have applied such systems physiology approach. Regarding the measurement of physical behaviors, we also included multiple parameters to investigate the effect of volume and pattern of physical behaviors on the risk of cardiovascular disease. In addition, we used thigh-worn accelerometers, which is more accurate than hip-worn accelerometers and self-reported physical activity questionnaires to assess physical activity.

The extensive phenotyping in The Maastricht Study has allowed us to investigate independent associations adjusted for many potential confounders. Additionally, it allowed further exploration of underlying mechanisms. For instance, it has been proposed that diabetes-associated retinal venular dilation is related to inflammation ${ }^{3,4}$. However, additional adjustment for inflammation did not change the association between (pre)diabetes and retinal venular diameters in our study (Chapter 3 ), suggesting that inflammation may not explain the retinal venular dilation.

\section{Implementation}

\section{Microvascular measurements for screening}

If microvascular dysfunction can predict the risk of cardiometabolic diseases with high sensitivity, the measurements may be used for screening. Among the specific measurements, the fundus photography is common in hospitals and time-saving. The Atherosclerosis Risk in Communities (ARIC) Study reported that assessing retinal microvascular diameters in addition to the Pooled Cohort Equations would reclassify $21 \%$ of low-risk women as intermediate risk ${ }^{5}$. However, determining cut-off values is necessary for screening but difficult. We and others have found that (pre)diabetes is associated with wider retinal arterioles (Chapter 3), whereas narrower retinal arterioles are associated with a higher risk of cardiovascular diseases. This may suggest different pathophysiological mechanisms as well as a bidirectional change in retinal arteriolar diameters with the progression of disease. In addition, we should take into account the strong confounding effects of age, sex, blood pressure and BMI (or waist circumference).

Microvascular function as a target of treatment 
Current evidence supports that microvascular dysfunction may play a role in cardiometabolic diseases (Chapter 3 and 5) ${ }^{1,2,5}$. Therefore, interventions on microvascular function may be promising for the treatment. Some medications on the market have already shown efficacy in improving microvascular function. For instance, calcium dobesilate, a vasoprotective that reduces capillary permeability, can effectively alleviate diabetic retinopathy and nephropathy ${ }^{6,7}$. Some traditional Chinese medicine, antihypertensive and antihyperglycemia agents, and lifestyle interventions can also improve microvascular function ${ }^{8-10}$, but whether the improvement can retard the development of cardiometabolic diseases needs further investigation. Another important question is when the intervention should be implemented. As microvascular dysfunction can occur long before the diagnosis of diabetes and cardiovascular diseases, early intervention may be taken for prevention. Of note, clinicians need to assess other profiles of patients before and after applying the medication, as most of the current medications are non-specific to microvasculatures.

\section{Physical activity for prevention and treatment of cardiometabolic diseases}

Lifestyle interventions often serve as primary prevention strategies for cardiometabolic diseases, with the advantages of less expenses and side effects. A meta-analysis showed that diet and physical activity interventions for adults without known cardiometabolic risk factors benefit cardiovascular health in 6-12 months of follow-up with a dose-response relationship ${ }^{11}$. In addition, adults at high risk may benefit more from these interventions ${ }^{12}$. With regard to long-term benefits, a recent meta-analysis showed that more daily step counts are associated with a lower risk of all-cause mortality, and cardiovascular morbidity and mortality in adults ${ }^{13}$. Another meta-analysis revealed that more self-reported sedentary behavior may increase the risk of all-cause and cardiovascular mortality and incident type 2 diabetes, independently of physical activity time ${ }^{14}$. However, we found that accelerometer-measured sedentary time is not independently associated with incident non-fatal cardiovascular disease (Chapter 6). The results are similar in children and adolescents; more moderate-to-vigorous-intensity physical activity (MVPA) is associated with better cardiometabolic risk factors, whereas sedentary time is not associated with cardiometabolic risk factors independently of MVPA ${ }^{15}$. In addition, physical activity can improve physical fitness and reduce disability in patients with stroke ${ }^{16}$, and reduce all-cause hospital admissions and cardiovascular mortality in patients with coronary heart disease ${ }^{17}$. 
Taken together, physical activity can be an effective intervention for the prevention and treatment of cardiometabolic diseases, whereas the evidence showing the cardiometabolic benefits of decreased sedentary time remains insufficient. Advocacy via media and increasing public fitness equipment may facilitate physical activity of people. For individuals, the type and intensity of physical activity should be selected with consciousness of safety and long-term compliance.

\section{Conclusion}

In summary, identification of potential risk factors and treatments is expected to lower the burden of cardiometabolic diseases on the patients and society. This dissertation provides robust evidence which shows microvascular (dys)function and physical (in)activity as determinants of cardiometabolic diseases and promising targets for the prevention and treatment. However, further investigations are needed to evaluate the rationality and feasibility of their use in the clinical practice. 


\section{Reference}

1. Muris DM, Houben AJ, Schram MT, Stehouwer CD. Microvascular dysfunction is associated with a higher incidence of type 2 diabetes mellitus: a systematic review and meta-analysis. Arterioscler Thromb Vasc Biol. 2012;32(120):3082-3094.

2. Sabanayagam C, Lye WK, Klein R, Klein BE, Cotch MF, Wang JJ, et al. Retinal microvascular calibre and risk of diabetes mellitus: a systematic review and participant-level meta-analysis. Diabetologia. 2015;58:2476-2485.

3. Nguyen TT, Wang JJ, Sharrett AR, Islam FA, Klein R, Klein BE, et al. Relationship of retinal vascular caliber with diabetes and retinopathy: the Multi-Ethnic Study of Atherosclerosis (MESA). Diabetes Care. 2008;31(3):544-549.

4. Klein R, Klein BE, Knudtson MD, Wong TY, Tsai MY. Are inflammatory factors related to retinal vessel caliber? The Beaver Dam Eye Study. Arch Ophthalmol. 2006;124:87-94.

5. Seidelmann SB, Claggett B, Bravo PE, Gupta A, Farhad H, Klein BE, et al. Retinal vessel calibers in predicting long-term cardiovascular outcomes: the atherosclerosis risk in communities study. Circulation. 2016;134(18):1328-1338.

6. Zhang X, Liu W, Wu S, Jin J, Li W, Wang N. Calcium dobesilate for diabetic retinopathy: a systematic review and meta-analysis. Sci China Life Sci. 2015;58(1):101-107.

7. Haller H, Ji L, Stahl K, Bertram A, Menne J. Molecular Mechanisms and treatment strategies in diabetic nephropathy: new avenues for calcium dobesilate-free radical scavenger and growth factor inhibition. Biomed Res Int. 2017;2017:1909258.

8. Stehouwer CD. Microvascular dysfunction and hyperglycemia: a vicious cycle with widespread consequences. Diabetes. 2018;67(9):1729-1741.

9. Climie RE, van Sloten TT, Bruno RM, Taddei S, Empana JP, Stehouwer CD, et al. Macrovasculature and microvasculature at the crossroads between type 2 diabetes mellitus and hypertension. Hypertension. 2018;73(6):1138-1149.

10. Han B, Zhang X, Zhang Q, Zhao G, Wei J, Ma S, et al. Protective effects of salvianolate on microvascular flow in a porcine model of myocardial ischaemia and reperfusion. Arch Cardiovasc Dis;104(5):313-324.

11. Patnode CD, Evans CV, Senger CA, Redmond N, Lin JS. Behavioral counseling to promote a healthful diet and physical activity for cardiovascular disease prevention in adults without known cardiovascular disease risk factors: updated evidence report and systematic review for the US Preventive Services Task Force. Jama. 2017;318(2):175-193.

12. Zabaleta-del-Olmo E, Bolibar B, García-Ortíz L, Garcia-Campayo J, Llobera J, Bellón JÁ, Ramos R. Building interventions in primary health care for long-term effectiveness in health promotion and disease prevention. A focus on complex and multi-risk interventions. Prev Med. 2015;76 Suppl:S1-S4.

13. Hall KS, Hyde ET, Bassett DR, Carlson SA, Carnethon MR, Ekelund U, et al. Systematic review of the prospective association of daily step counts with risk of mortality, cardiovascular disease, and dysglycemia. Int J Behav Nutr Phys Act. 2020;17(1):78.

14. Patterson R, McNamara E, Tainio M, de Sá TH, Smith AD, Sharp SJ, et al. Sedentary behaviour and risk of all-cause, cardiovascular and cancer mortality, and incident type 2 diabetes: a systematic review and dose response meta-analysis. Eur J Epidemiol. 2018;33(9):811-829.

15. Ekelund U, Luan JA, Sherar LB, Esliger DW, Griew P, Cooper A, International Children's Accelerometry Database (ICAD) Collaborators. Moderate to vigorous physical activity and sedentary time and cardiometabolic risk factors in children and adolescents. Jama. 2012;307(7):704-712.

16. Saunders DH, Sanderson M, Hayes S, Johnson L, Kramer S, Carter DD, et al. Physical fitness training for stroke patients. Cochrane Database Syst Rev. 2020;3(3):CD003316.

17. Chair SY, Zou H, Cao X. Effects of Exercise Therapy for Adults With Coronary Heart Disease: A Systematic Review and Meta-analysis of Randomized Controlled Trials [published online ahead of print, 2020 Jul 3]. J Cardiovasc Nurs. 2020;10.1097/JCN.0000000000000713. 
Acknowledgments 
First, I would like to acknowledge the funding received from the China Scholarship Council (CSC) to cover my expense in the Netherlands. I would also like to acknowledge the Maastricht University for providing a wonderful environment for my PhD study.

I would like to thank the members of my thesis assessment committee: Prof.dr. M.C.G.J. Brouwers (Chairman), Prof.dr. H.J.G.M. Crijns, Dr. E.C. Eringa, Dr. R.G. IJzerman, and Prof.dr. M. Visser. Thank you for the assessment, as well as your precious comments.

My promotion team (Prof.dr. C.D.A. Stehouwer, Dr. A.J.H.M. Houben, and Dr. M.T. Schram) has made great efforts to help me with this dissertation and our scientific output. Thank you all for encouraging and allowing me to keep exploring the science and life in depth. From the collision of thoughts of you three, I have learned more possibilities, in the aspects of work, life, and personality. Dear Coen, I can imagine that, in the following birthdays, I will remember there is a respectful clinician-scientist who was my promoter, on the other side of the earth, celebrating his birthday some hours later. You are rational, but of impressive sincerity; you are experienced, but full of passion. I believe that even on my day of retirement, I can still hear your voice on the top journal. Dear Boy, you are the person who led me to know Maastricht, a city 'very close to both Belgian cities (Liege $30 \mathrm{~km}$; Brussels $110 \mathrm{~km}$ ) and German cities (Aachen 30 km; Frankfurt $280 \mathrm{~km}$ )'. After meeting you the first time in Maastricht, I realized that you are lively just like this city. In the past four years, we together made the projects move on, ran along the beach, went in a parade of carnival, etc. Next time my turn to show you my city. See you in China in 2022! Dear Miranda, thanks for your patient guidance from the very beginning to the end. You are always there when I am struggling. What's more, balancing multiple things is quite a challenge for me, but you show me an example of woman who has a kind and strong heart and manages family (sweet burdens), work, relationships, health, and appearance in perfect order.

To my additional 'co-promoter' Dr. A. Koster, dear Annemarie, it is a pleasant experience to work with you. Your hard work motivates me to work more efficiently and makes me believe that we can cope with all the difficulties, and our paper can be successfully published.

I would also like to thank Prof. C.G. Schalkwijk, Dr. M.M.J. van Greevenbroek, and Dr. K.A.M. Wouters in the department of internal medicine. Dear Casper, Marleen, and Kristiaan, you always provide insights with your expertise, which indeed inspires me. Also, thank you for very helpful suggestions on my presentation, and excellent organizing journal club, christmas dinner, and lab day out. 
To my dearest colleagues in the office: Vicky, thank you for care and help in daily work, as well as your precious suggestion on the life; Petra, thank you for encouragement, which motivates me to continue the work regardless of difficulties; Margee, you have such a colorful daily life! Hope in the future I can still receive your video or photos of the activity of chorus and volunteer. And don't forget our goal of keeping fit! 亲爱的笑笛，感慨并感谢这些日子的欢乐， 希望以后还有机会在酒店的小酒吧长谈。你的学习工作我不多说啦, 总是让老师们很放心, 相 信你能在马大收获满满。以后常联系, 盼望着你毕业后来上海找我哦。

It's my great honor to work with so many talented colleagues. Nynke, Amée, Kim, Evelian, Pomme, Eline, Suzan, Maria (from Sicily), Mitchell, Mathias, Armand, Tate, and Yvo. Wish all of you have a bright and happy future. Although I didn't work in the lab, colleagues there showed their kindness and caring to me all the time. Thank you, Jean, José, Maria, and Majo. I would also thank Marian Curfs and Maggy Pisana for their help with the regular meeting arrangement and reimbursement application.

I would especially thank the team of The Maastricht Study for their conduct of the study and assistance in our projects. Dear Yvette, Carla, Marion, Lisanne, Michiel, without your support, we cannot receive data in time and proceed with the projects. I also feel so honored and pleased to acquaint many interesting people in The Maastricht Study--three gentlemen (Yuri, Tanlai, and Sytze), Frank (I think you are already a great scientist and pianist), Anouk (I'm so so happy that you and your baby can be my 'angel'. Hope we still have chance to spend blissful coffee time together in the future), April (o( $\left.{ }^{*} \unrhd \exists \cdots\right)$, Ben, Marnix, Rianneke, Cindy, Laura...In addition, I would also acknowledge the participants of The Maastricht Study for their selfless contribution.

To my Chinese colleagues and friends. 亲爱的辛莹，你简直是我见过的最温柔体贴的 人。你总是能为他人着想, 而且秀外慧中, 我有好多好多东西得向你学习。几年来也见证了你 和拉方坚定不移的感情, 你有着使自己幸福的能力, 愿你们一直和和美美, 白头到老! 亲爱的 顺金金, 坚韧如你, 愿美丽的你在荷兰不忘初心, 砥砺前行! $(\mathrm{O} \cdot-\cdot) \mathrm{O}$ 亲爱的小明（张明）, 无 论你在荷兰、比利时、还是回国, 我都相信你能闯出自己的一番天地! 祝你们夫妻俩平平安 安, 财源滚滚来! 亲爱的天宇, 你是一个充满爱的女生, 你的刚柔并济赋予你独特的鬼力, 愿 将来如你所愿, 能成为一个桃李天下的园丁。感谢邻居小组李正文, 龚英, 丁世杰, 感谢你们 和那些欢乐的日子。还有张硕, 雨霏, 乔奇, 许青和宗盛华, 徐盼, 金涵, 林溪, 隋心澄, 萍 姐……感谢能与你在此相遇。还有亲爱的小杨, 感谢受到如此可爱的你的照顾。还有曾在埃因 霍温相识的黄凡和檀蹈, 很高兴能认识你们这两个有为青年。此外, 感谢国内老师同学们的鼓 励和支持。感谢高老师在职业规划上的建议以及慧琦, 佳梦, 王杨, 范怡雯等师兄弟姐妹在日 常生活及工作上对我等关照。 
亲爱的爸爸, 妈妈, 阿娘, 阿叔, 想想, 特别感谢你们对我学习生活的支持以及长久以来 的包容。虽然我有很多缺点, 但是你们教我的正直、淡泊名利、对科学的求实求是的态度我一 直铭记在心。希望将来也不负你们所托, 为家庭、国家和社会作出自己的一份贡献。 


\section{Curriculum Vitae}

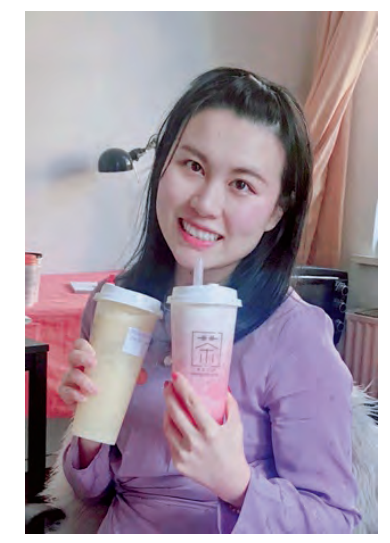

Wenjie Li was born on April 30, 1991 in Shanghai, China. In 2007 , on the ambulance carrying her grandpa to the Xinhua Hospital, she saw the words 'heal the wounded and rescue the dying' on the gate of the entrance. At that moment, she realized that she can become a medical doctor besides an engineer (she was good at mathematics and physics in the secondary school). In 2009, she entered Tongji University, and began her seven-year program in clinical medicine. In 2014, after experiencing clinical rotations in different departments at Shanghai Tenth People's Hospital and Medical University of Innsbruck, Wenjie decided to become a physician at the department of emergency medicine, who can snatch the patients from the jaws of death and alleviate the sufferings of the patients. During her master study, she joined the Tongji-Freiburg Psychotherapeutic and Psychosomatic Advanced Postgraduate Training Program to gain more knowledge on the psychosomatic medicine. In 2016, She obtained her Bachelor and Master's degree as Shanghai outstanding graduate. Nevertheless, Wenjie considered that her knowledge and skills at that time was not enough to make her a good physician. She thought scientific research may help more people to stay away from illness. Therefore, in the same year, she was awarded a national grant from the Chinese Scholar Council and started her PhD research at the department of Internal Medicine of the Maastricht University Medical Center+. During her PhD study, she investigated the role of microvascular dysfunction and physical activity in type 2 diabetes and cardiovascular diseases under the supervision of prof. dr. C.D.A. Stehouwer, dr. A.J.H.M. Houben, and dr. M.T. Schram. From 2020 onwards, Wenjie is working as a medical resident at the department of emergency medicine of the Xinhua Hospital. 


\section{Scientific Output}

List of publications

1. Li W, Schram MT, Sörensen BM, van Agtmaal MJM, Berendschot TTJM, Webers CAB, Jansen JFA, Backes WH, Gronenschild EHBM, Schalkwijk CG, Stehouwer CDA, Houben AJHM. Microvascular Phenotyping in the Maastricht Study: Design and Main Findings, 2010-2018. Am J Epidemiol. 2020;189(9):873-884.

2. Li W, Schram MT, Berendschot TTJM, Webers CAB, Kroon AA, van der Kallen CJH, Henry RMA, Schaper NC, Huang F, Dashtbozorg B, Tan T, Zhang J, Abbasi-Sureshjani S, Ter Haar Romeny BM, Stehouwer CDA, Houben AJHM. Type 2 diabetes and HbA1c are independently associated with wider retinal arterioles: the Maastricht study. Diabetologia. 2020;63(7):1408-1417.

3. Li W, Schram MT, Sep SJS, Berendschot TTJM, Webers CAB, Kroon AA, van der Kallen CJH, Henry RMA, Eussen SJPM, Schaper NC, Dagnelie PC, van Greevenbroek MMJ, Schalkwijk CG, Stehouwer CDA, Houben AJHM. Microvascular Dysfunction is Associated with Altered Beta Cell Function: The Maastricht Study. In preparation.

4. Li W, Schram MT, Henry RMA, Eussen SJPM, Kroon AA, Koster A, Berendschot TTJM, Webers CAB, van der Kallen CJH, Schaper NC, Dagnelie PC, van Greevenbroek MMJ, Schalkwijk CG, Houben AJHM, Stehouwer CDA. Microvascular Dysfunction is Associated with Higher Cardiovascular Risk: The Maastricht Study. In preparation.

5. Koster A *, Li W *, Schram MT, Houben AJHM, Dagnelie PC, Köhler S, van der Kallen CJH, Eussen SJPM, van Dongen MCJM, Wesselius A, Schaper NC, Savelberg HHCM, Stehouwer CDA. Accelerometer-Measured Sedentary Time and Physical Activity and Incident Cardiovascular Disease: The Maastricht Study. In preparation. 
Oral presentations

1. Annual Dutch Diabetes Research Meeting 2018 (Oosterbeek, the Netherlands): Type 2 diabetes and possibly prediabetes are associated with wider retinal arterioles and venules: The Maastricht Study.

2. Annual meeting of the young investigators of the Dutch Association for Diabetes Research 2019 (Soesterberg, the Netherlands): Prediabetes and type 2 diabetes are associated with wider retinal arterioles and venules.

3. ARTERY Society Annual Conference 2019 (Budapest, Hungary): Prediabetes and type 2 diabetes are associated with wider retinal arterioles and venules: The Maastricht Study.

4. Annual Dutch Diabetes Research Meeting 2019 (Wageningen, the Netherlands): Microvascular dysfunction is associated with impaired beta-cell function: The Maastricht Study.

5. Annual Dutch Diabetes Research Meeting 2019 (Wageningen, the Netherlands): Validation of self-reported incident cardiovascular disease for annual follow-up in The Maastricht Study.

\section{Poster presentations}

1. Annual Meeting of the European Association for the Study of Diabetes 2018 (Berlin, Germany): Prediabetes and diabetes are associated with wider retinal arterioles and venules: the Maastricht study.

2. 3rd Joint Meeting of the European Society for Microcirculation and the European Vascular Biology Organization 2019 (Maastricht, the Netherlands): Prediabetes and diabetes are associated with wider retinal arterioles and venules: the Maastricht study.

3. ARTERY Society Annual Conference 2019 (Budapest, Hungary): Microvascular dysfunction is associated with impaired beta-cell function: The Maastricht Study.

4. Annual Meeting of the European Association for the Study of Diabetes 2020 (Vienna, Austria): Microvascular dysfunction is associated with beta-cell function in the fasting state: The Maastricht Study. 


\section{Awards}

1. CARIM Symposium 2018 poster prize.

2. 3rd Joint Meeting of the European Society for Microcirculation (ESM) and the European Vascular Biology Organization (EVBO) 2019 poster award. 
